\title{
A Delphi Study of Challenges Perceived by West Virginia University Extension Agents
}

\author{
Caleb N. Smith
}

Follow this and additional works at: https://researchrepository.wvu.edu/etd

\section{Recommended Citation}

Smith, Caleb N., "A Delphi Study of Challenges Perceived by West Virginia University Extension Agents" (2015). Graduate Theses, Dissertations, and Problem Reports. 7131.

https://researchrepository.wvu.edu/etd/7131

This Thesis is protected by copyright and/or related rights. It has been brought to you by the The Research Repository @ WVU with permission from the rights-holder(s). You are free to use this Thesis in any way that is permitted by the copyright and related rights legislation that applies to your use. For other uses you must obtain permission from the rights-holder(s) directly, unless additional rights are indicated by a Creative Commons license in the record and/ or on the work itself. This Thesis has been accepted for inclusion in WVU Graduate Theses, Dissertations, and Problem Reports collection by an authorized administrator of The Research Repository @ WVU. For more information, please contact researchrepository@mail.wvu.edu. 
A Delphi Study of Challenges Perceived by West Virginia University Extension Agents

\author{
Caleb N. Smith
}

Thesis submitted to the Davis College of Agriculture, Natural Resources and Design at West Virginia University in partial fulfillment of the requirements for the degree of

Master of Science in Agricultural and Extension Education

\author{
Deborah A. Boone, Ph.D., Chair \\ Harry N. Boone Jr., Ph.D. \\ Jean M. Woloshuk, Ed.D. \\ School of Design and Community Development \\ Morgantown, West Virginia \\ 2015
}

Keywords: Extension Agent, West Virginia, Barrier, Challenge Copyright 2015 Caleb Smith 


\section{ABSTRACT \\ A Delphi Study of Challenges Perceived \\ by West Virginia University Extension Agents \\ Caleb N. Smith}

One of the Cooperative Extension Services main objectives is to be a non-formal education provider to the public. In order for agents to fulfill this goal, they need to be competent in many areas, some of which may be out of their area of expertise. The purpose for this study was to identify challenges perceived by West Virginia Extension Agents. A three stage Delphi technique was used to determine what Extension Agents viewed as challenges. The study found agents identified 35 challenges of being an Extension Agent in West Virginia. These challenges were separated into five constructs. The top challenges in the construct, training and support, were disconnect between needs of county and expectations of state office, prioritizing what is important, and meeting programming expectations. The top challenges in the construct funding and resources; were: lack of funding, space for storage, and limited available resources other than funding. The third construct was personal issues, which was the highest rated area and included finding time for all programs, balancing family and work obligations, and overextending on commitments. The fourth area, volunteers and community involvement, impact policies have on volunteers was the most challenging, followed closely by finding leadership in programs, community's perceptions of an agent's responsibilities, and recruiting volunteers. The challenges identified related to the last construct of organizational factors included, unclear guidelines and standards, inconsistent or nonexistent administrative policies, and employee pay and promotion. 


\section{ACKNOWLEDGEMENTS}

First and foremost I would like to thank my advisor Dr. Debby Boone for all of her assistance with this study and for advising me throughout my time at WVU. I am very appreciative of her commitment to helping me get through graduate school by keeping after me.

I would also like to thank Dr. Harry Boone and Dr. Jean Woloshuk, who not only served on my advisory committee but brought great insight into my research.

Dr. Harry, thank you for always providing me with a different way of looking at things. Anytime a wrench got thrown into the plan that I couldn't get around, all I had to do was ask for your advice and you would direct me back on track. I am very appreciative to have had you serve on my committee.

Dr. Woloshuk, working with you the past couple of years has been enlightening and allowed me to see a different side of Extension. I appreciate the knowledge and personal experiences that you have shared with me. Thank you for serving on my committee.

A sincere thank you to the Extension Agents of West Virginia for their participation in this study. Without your responses this study would not have been able to be completed.

Thank to my parents and sister for always believing in me and supporting my decision to continue my education in grad school. I know it is not the easiest being away from you all the time, but your support means the world to me.

Finally, I want to thank all of my friends that have stuck by me. This thesis has taken up a lot of my time over the past two years, but you have all been supportive and understanding. You don't know how much your support means to me. Anytime I began to doubt whether it was worth the time you all kicked me back in gear and made sure I never let it slip to the back burner and I am very thankful for that. 


\section{TABLE OF CONTENTS}

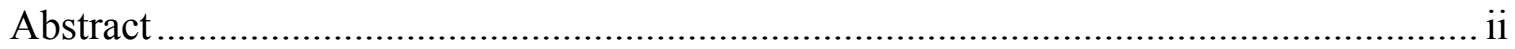

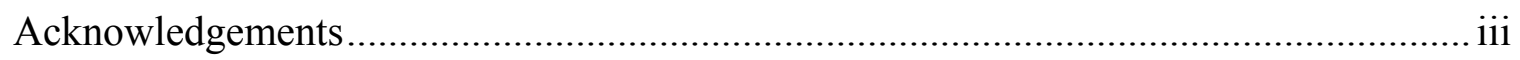

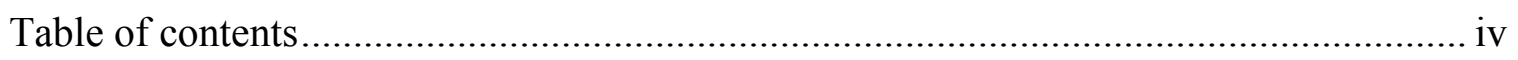

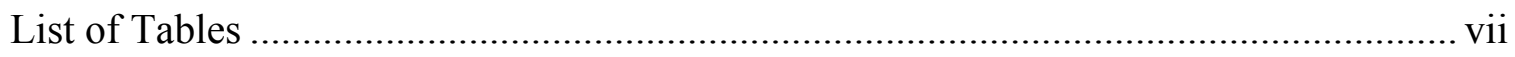

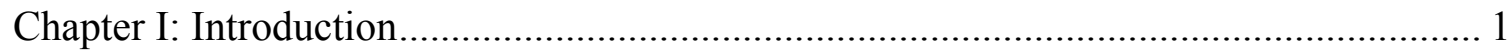

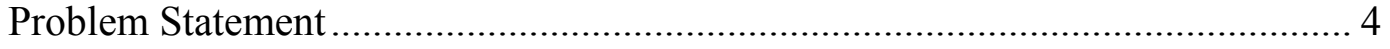

Theoretical Framework ................................................................................ 5

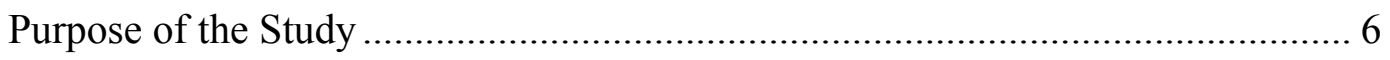

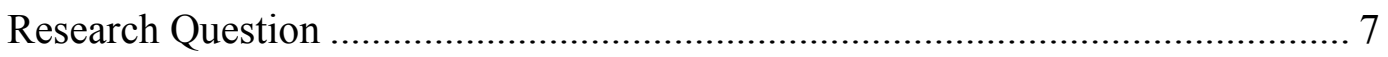

Limitations of the Study........................................................................... 7

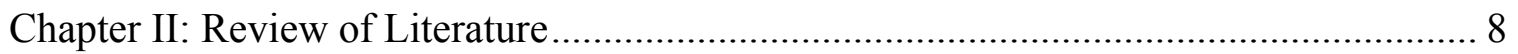

Establishment of the Cooperative Extension Service ....................................... 8

What Challenges do Extension Agents Face? ............................................ 10

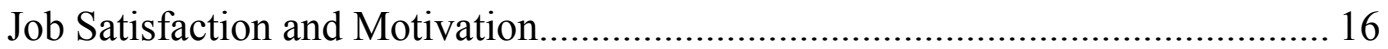

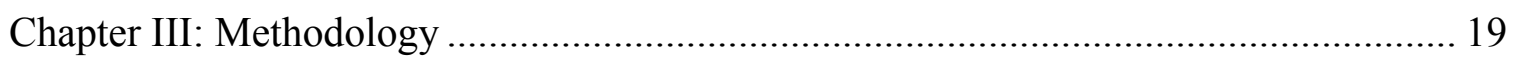

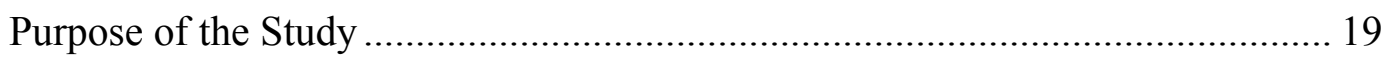

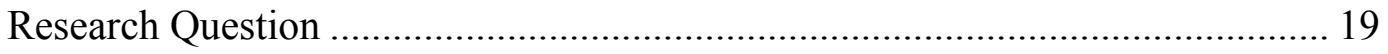

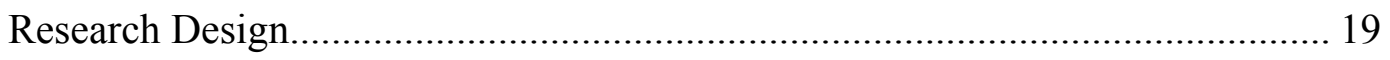

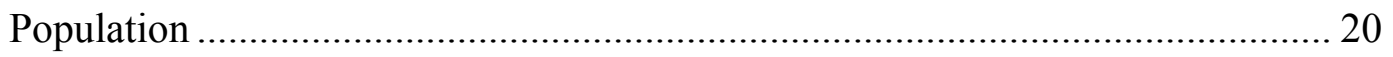

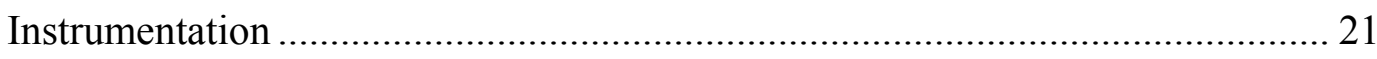

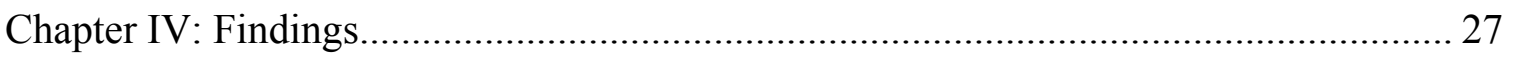

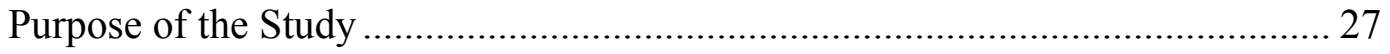

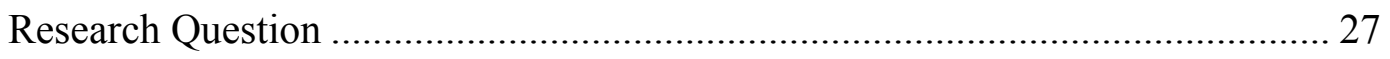

Demographic Characteristics ................................................................... 28 


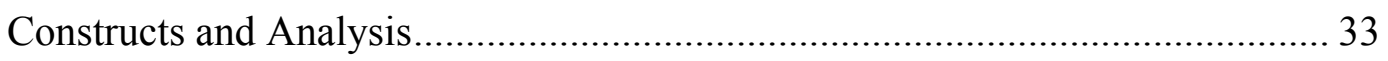

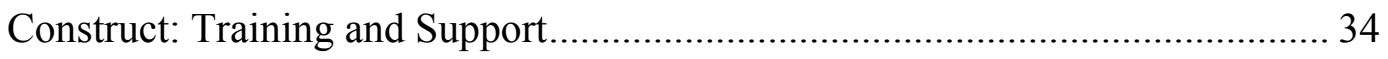

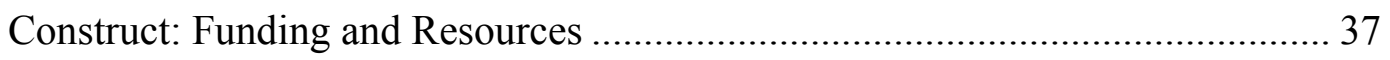

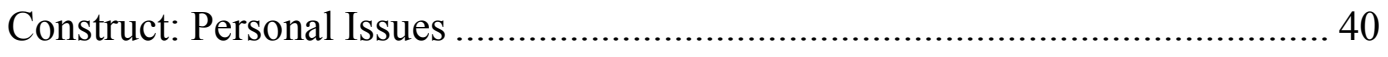

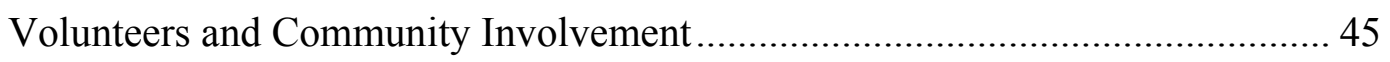

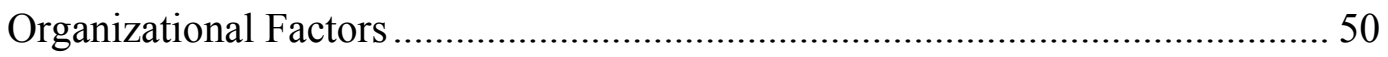

Summary of Constructs and Comparison among Program Units .......................... 55

Relationship between Gender and Perception of Challenges ............................... 58

Relationship of an Agents' Age and how they Perceive Challenges.................... 63

Relationship of Marital Status and Agents Perception of Challenges .................. 70

Relationship of Agents' with Children and Perception of Challenges ................. 75

Relationship of Challenges among Program Units .............................................. 80

Relationship of Extension Experience and Perception of Challenges ................... 87

Relationship of Agents per County and their Perception of Challenge ……........ 94

Other Relationships between Agents Perceptions of Challenges ........................ 100

Chapter V: Summary, Discussions, and Recommendations............................................ 101

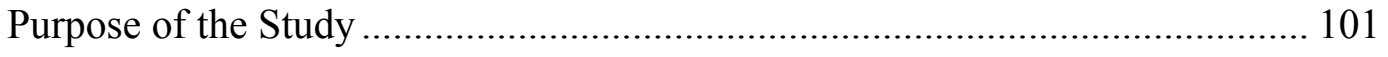

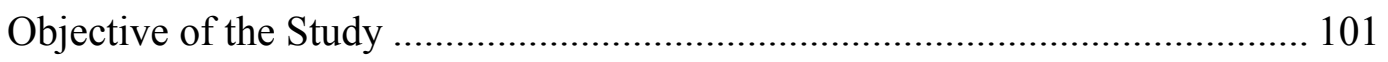

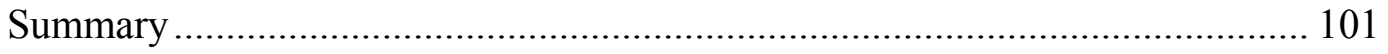

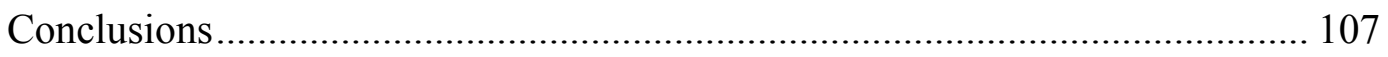

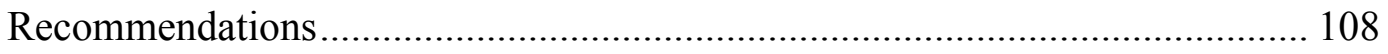

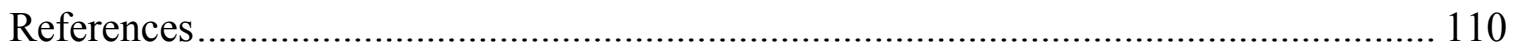

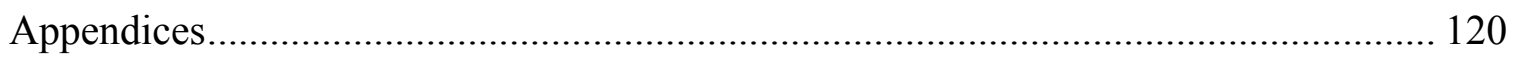

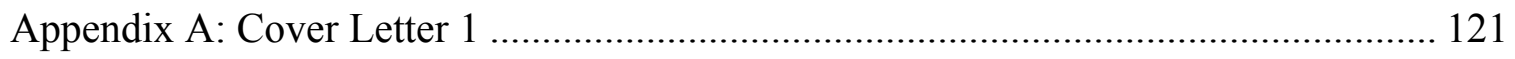




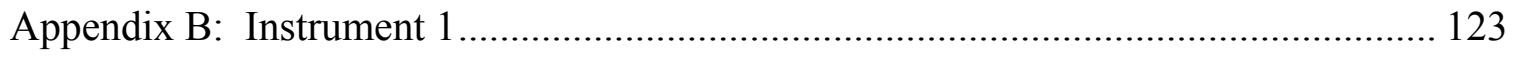

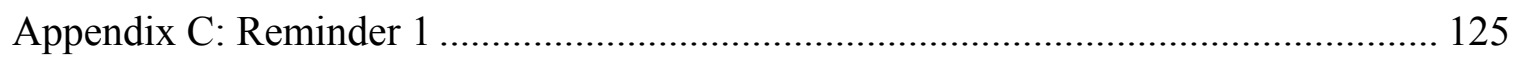

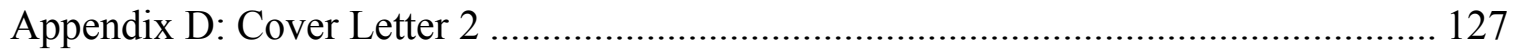

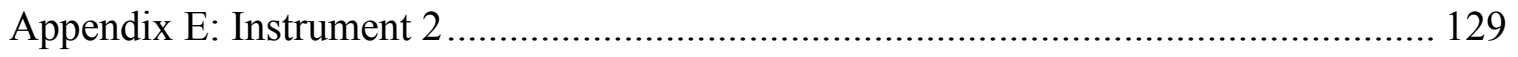

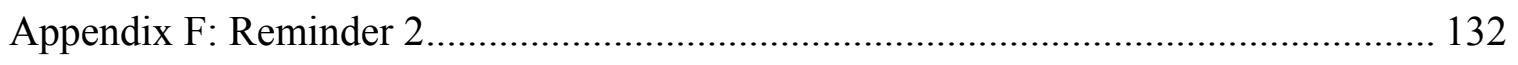

Appendix G: Cover Letter 3 ................................................................................ 134

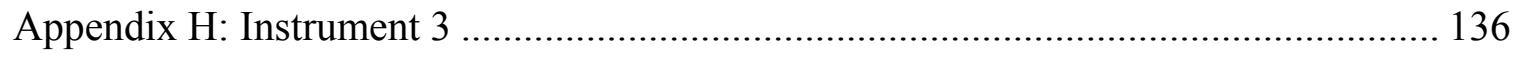

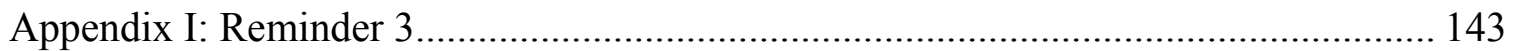

Appendix J: County Program Coordinator Data....................................................... 145

Appendix K: Effect of Number of Counties ............................................................ 148

Appendix L: Effect of a Program Assistant .......................................................... 151

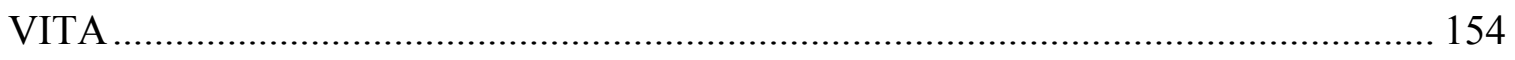


Table Title Page

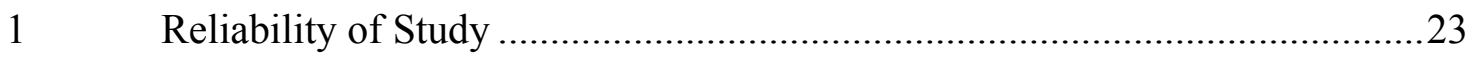

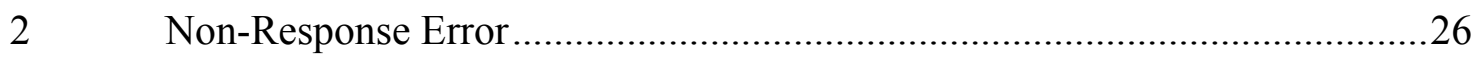

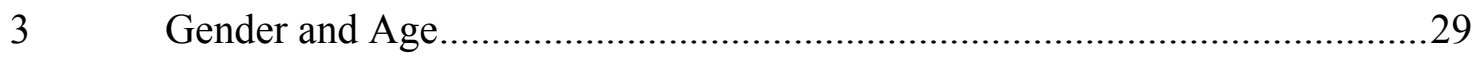

$4 \quad$ Marital Status and Children at Home ......................................................29

$5 \quad$ Program Unit and Years of Extension Experience....................................... 31

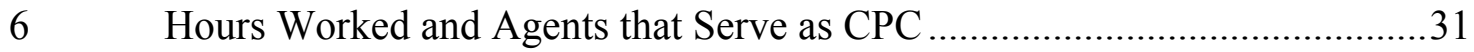

7 Number of Counties Served, Agents per County and Presence of Program

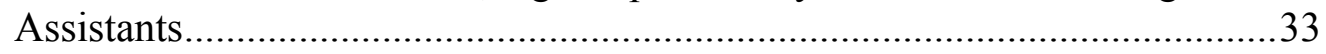

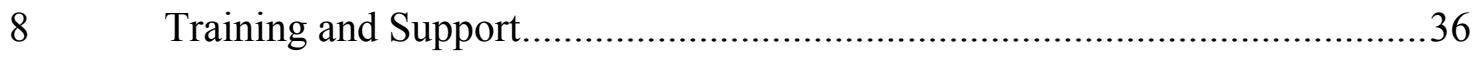

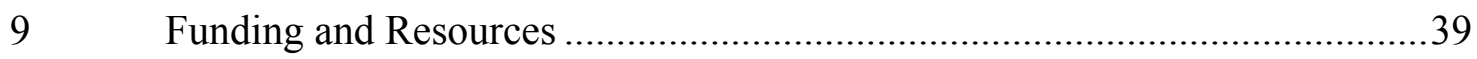

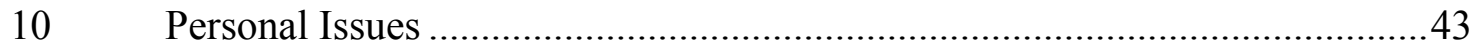

11 Volunteers and Community Involvement ................................................48

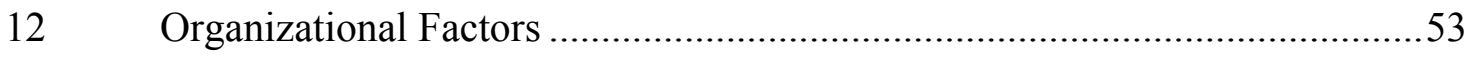

13 Construct Composite Scores Overall and by Program Unit..........................57

14 Gender and Perception of Challenges - Descriptive................................61

15 Gender and Perception of Challenges - ANOVA.....................................62

16 Age and Perception of Challenges - Descriptive ....................................68

17 Age and Perception of Challenges- ANOVA.........................................69

18 Marital Status and Perception of Challenges - Descriptive ..........................73

19 Marital Status and Perceptions of Challenges - ANOVA .............................74

20 Children at Home and Perception of Challenge - Descriptive .....................78

21 Children at Home and Perception of Challenge - ANOVA ….....................79 
22 Program Units and Perception of Challenges- Descriptive .........................85

23 Program Units and Perception of Challenges- ANOVA ..............................86

24 Extension Experience and Perception of Challenge - Descriptive ................92

25 Extension Experience and Perception of Challenge - ANOVA ....................93

26 Number of Agents per County and Perception of Challenge - Descriptive ...98

27 Number of Agents per County and Perception of Challenge - ANOVA .......99

28 CPC and Perceptions of Challenges - Descriptive ................................... 146

29 CPC and Perceptions of Challenges - ANOVA ....................................... 147

30 Number of Counties per Agent and Perception of Challenges -

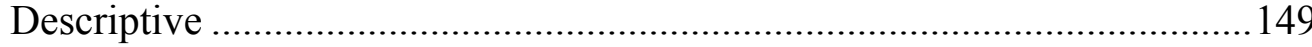

31 Number of Counties per Agent and Perception of Challenges - ANOVA ... 150

32 Program Assistant and Perceptions of Challenges - Descriptive .................152

33 Program Assistant and Perceptions of Challenges - ANOVA .....................153 


\section{CHAPTER I}

\section{Introduction}

The Cooperative Extension Services employs approximately 8,000 Extension Agents nationwide (USDA NIFA, 2010). According to NIFA (2015), Extension employees are located in or near most of the nation's 3,000 counties. Extension is the largest adult and youth, non-formal, educational organization in the world (Fiske, 1989).

Extension Agents are faced with many challenges. When Extension began, the primary objective was to serve farmers and rural educators and educate them so that they could increase agricultural productivity and enhance their rural lifestyles (West, Drake, \& Londo, 2009). Since Extension's beginning, many things have changed including traditional audiences. Extension must find ways to serve traditional partners with traditional methods while also exploring new horizons (West et al., 2009).

The most commonly found obstacles Extension Agents face are related to competency, recruitment, technology, balance of family and work, and time management. These issues all deal with the changing times and the shift of values from generation to generation. In 2005, Ensle found Extension Agents tended to be more independent thinkers and had a mindset of family comes before work. This value set can be directly related to the rapid turnover of young agents who burnout or are overworked, they generally lack skills of time management to balance work and family obligations. Manton and vas Es (1985) determined that the top three reasons for early attrition of Extension Agents were, being away from family, family moving, or change in family situation.

Borr and Young (2010) found that the turnover rates were on the rise from under $10 \%$ in 1975 to almost $40 \%$ in 2006 . Kutilek (2000) found that the turnover rate in Ohio 
for Extension Agents stayed steady through that period at 5-7\%. Borr and Young (2010) found in North Dakota Extension 75\% of the agents looked to leave their position in the next ten years with less than half of those being eligible for retirement. Staff turnover is a very expensive and inefficient use of time management (Ensle, 2005). Kutilek (2000), in an Ohio State Extension study estimated that it would cost Extension $\$ 80,000$ to replace one agent lost to employee turnover after subtracting salary savings created by the vacancy. Although losing an agent to turnover is expensive, the costly loss of program effort due to that vacancy may be just as severe (Kutilek, 2000).

Agents leave their positions for a number of reasons. Branham (2005) found employees leave their job for the following reasons: job did not meet expectations, lack of training/supervision, not recognized for work, stress of the workload, and lack of trust from leaders. In addition, Rousand and Henderson (1996), found that early attrition is also caused by: "other priorities in their lives, other job offers, insufficient pay for the amount of work performed, family obligations, too many late night meetings, too many work responsibilities, and attraction to more money elsewhere (p.1)." Fetsch and Kennington (1997) noted that Extension Agents often have non-regular work hours including nights and weekends which requires agents to balance their time at work and home. Agents with the greatest concern of balancing home and work are those in their first five years with the Extension Service (Boltes, Lippke, \& Gregory, 1995). This finding instigated the renewal of organization norms in finding balance among work, family, and personal life (Extension Committee on Organization and Policy, 1995). In 2011, Ellison recommended the addition of balancing time and work to an employee retention program after interviewing eight 4-H agents who had completed the program in 
Georgia and six of the individuals mentioned issues with balancing their time. Kroth and Peutz (2011) used a Delphi technique to identify issues in the workplace, they found that balancing work and life ranked third, only behind salaries/benefits and environment that supports work.

The most frequently noted challenge for Extension Agents is the ability to manage time efficiently. The key to avoiding burnout is being able to manage time, between family, work, and personal life (Ensle, 2005). Burnout doesn't occur all at once, it slowly builds up and is caused by overworking (Ensle, 2005). Extension is very flexible, but sometimes has abnormal hours that extend to evening and weekends (Fetsch \& Kennington, 1997). Rousan and Henderson (1996), found that former agents often cited family obligations as a major reason for leaving the organization. Kutilek, Conklin, and Gunderson (2002), found that nearly half of the Extension Agents in Ohio worked 40 to 50 hours per work and 37\% worked more than 50 hours per week. Herzberg (1968) makes the point that administration must meet the maintenance factors related to the type of work, hours worked, and pay for employees to want to remain with the organization. The work place must be appealing to the employee for them to want to stay, but the employee is also responsible for reducing the stressors of the job by planning and managing their time effectively to reduce the amount of time outside of regular hours that they are required to work (Strong \& Harder, 2009). Kutilek et al. (2002) suggests that employees can improve their work and family life balance by implementing the use of a single calendar for all of their obligations, combining family activities with work travel, setting boundaries, and establishing priorities. 
To help reduce the number of agents leaving their positions, administrators need to have first-hand knowledge of challenges faced in day to day work. This knowledge will aid with resolving challenges faced by agents, increasing the job satisfaction of that agent, and helping with retention of valuable agents.

Little research has been conducted on West Virginia Extension Agents. There are 111 current agents employed by the West Virginia University Extension Service who are assigned to one of the four program areas: Agriculture and Natural Resources; 4-H Youth Development; Community, Economic, and Workforce Development; or Families and Health (About Extension, 2014).

\section{Problem Statement}

The rate of employee turnover nationwide across all sectors is increasing at a rapid pace. From 1975 to 1995 the turnover rate was 7 to $10 \%$ (Borr \& Young, 2010), as of 2006 the estimated turnover rate was 40\% (Insala, 2005). Borr and Young (2010), found that $74 \%$ of the agents in North Dakota anticipated leaving the Extension Service in the next ten years, with $49 \%$ planning on finding a job in a different field. Recruitment and retention of employees is a significant challenge faced by Extension. The responsibilities of an Extension Agent are often very broad and require time management and prioritizing to avoid becoming overwhelmed. Igodan and Newcomb (1986) found in a study of 241 Ohio Extension Agents found that the majority of employees that showed burnout symptoms were agents under 30 and single. Kutilek et al., (2002) found in Ohio, a majority of the Extension Agents expressed concerns with life/work balance and 
identified the most critical challenges as the heavy work load, extended evening and weekend hours, and lack of control of job autonomy.

Long hours and heavy workloads are often blamed for job dissatisfaction among Extension Agents (Kutilek et al., 2002). Job satisfaction is key to keeping quality employees, Herzberg (1968) explains the use of motivators and maintenance factors together to meet the needs of employees. Harder, Gouldthorpe, and Goodwin (2014) studied the job satisfaction and motivational factors of Extension and found that agents were more likely to report both motivators and maintenance factors as important to employees rather than motivational factors alone. Riggs and Beus (1993) looked at coping strategies for agents to maintain or achieve job satisfaction, they found that the majority of agents that were satisfied used reframing to cope with challenges in the workplace. By studying the challenges of current West Virginia University Extension Agents, we will determine factors that Extension must address in order to improve job satisfaction among agents.

\section{Theoretical Framework}

The theoretical framework used for this study was Herzberg's MotivationalHygiene Theory (Herzberg, 1968). Herzberg illustrates hygiene factors to be related to the individuals work environment, including: organization, policies, supervision, working conditions, salary, status, and job security. Although these factors do not lead to motivation, without them motivation cannot be acquired. The motivators are what people are actually doing at the job and what their responsibilities are. These motivators are achievement, recognition, growth/advancement, and interest in the job. Both segments of 
the theory must be approached simultaneously. Extension Agents must be well prepared for their employment with the Extension Service, if agents are not ready for the field, the responsibilities asked of them will be overwhelming.

Strong and Harder (2009) found that Extension Agents perceived maintenance factors were lacking more often than motivators. Herzberg (1969) states that administration must make sure the employees' salary and maintenance needs are met or they will leave the organization. The employee can also make changes to reduce stress. Creating motivators within a job is known as job enrichment, these motivators make the job more appealing and stimulating for the employee. Job enrichment was implemented effectively to stimulate staff to elevated levels of accomplishments at many organizations (Daft, 1997). Strong and Harder (2009) made the point that agents can decrease the number of hours worked by emphasizing planning and managing their time instead of focusing on program delivery.

\section{Purpose of the Study}

Although over the past couple of decades Extension Offices have decreased in number, they continue to meet the needs of the public. The Cooperative Extension Service is represented by 8,000 Extension Agents nationwide (USDA NIFA, 2010). West Virginia employs 111 Extension Agents, serving all 55 counties, in the following program areas: Agriculture and Natural Resources; 4-H Youth Development; Community, Economic, and Workforce Development; or Families and Health. The purpose of this study was to determine challenges as perceived by Extension Agents in West Virginia. By determining what challenges are impeding an agent's daily work, 
administrators and directors can better understand how to resolve those issues to improve the job satisfaction for Extension Agents.

\section{Research Question}

The objective of the study is reflected in the following research question:

1. What challenges do West Virginia University Extension Agents encounter as perceived by current Extension Agents?

\section{Limitations of the Study}

The study is limited to current Extension Agents in West Virginia. All participants are affiliated with one of the four program units, including: Agriculture and Natural Resources; 4-H Youth Development; Community, Economic, and Workforce Development; or Families and Health. 


\section{CHAPTER II}

\section{Review of Literature}

\section{Establishment of the Cooperative Extension Service}

The Morrill Land Grant Act of 1862 established colleges in each state to teach agriculture and the mechanic arts. The Smith-Lever Act of 1914 established the Cooperative Extension Service, to distribute information to the public concerning agriculture and home economics (Legg, 1989). In the early years of the Extension Service, the agents' primary responsibilities were to serve as an instructor for agriculture and home economics. Their assistance ranged from educational training for farmers to providing youth development opportunities (Conglose, 2000). Extension programming was founded on delivering programs to rural communities and families (Webster \& Ingram, 2007) for the specific purpose of increasing agricultural productivity and enhancing the rural lifestyle (West, Drake \& Londo, 2009).

Extension work has been described as "A partnership between the government, the land-grant institutions, and the people, which provides service and education designed to meet the needs of the people" (Kelsey \& Hearne, 1963, p 1). Seevers and Graham (2012) describe the purpose of the Cooperative Extension System (CES) as "a publicfunded, non-formal educational system that links the education and research resources of the United State Department of Agriculture (USDA), land grant universities, and county administrative unit (p. 1)." The basic mission for the CES is that Extension should enable the public to improve themselves and the community by providing learning 
opportunities that work for those individuals (Extension Committee on Organization and Policy, 1995).

Extension is the largest adult and youth, non-formal, educational organization in the world (Fiske, 1989). Originally named Agricultural Extension Service has since been renamed to Cooperative Extension Service, Cooperative Extension, or University Extension to provide an accurate representation of the organization which provides service in four different areas: Agriculture and Natural Resources, 4-H Youth Development, Families and Consumer Sciences, and Community and Economic Development (Seevers and Graham, 2012). The differentiated divisions enables the Cooperative Extension to reach out to a more diverse audience and provide assistance to a greater population in a wider variety of areas.

The state of West Virginia employees 111 Extension Agents across all 55 counties which are assigned to four different program units. Each county is represented by at least one agent and some counties have up to five agents working out of one office. These agents are responsible for presenting information to their respective audiences regarding new technologies and improvements related to their fields. The constant change of procedures requires agents to be very competent in a variety of areas within their unit. As communities begin to change, due to expansion and shifts in populations, so does Extension programming (Borich, 2001; Schafer, Huegel, \& Mazotti, 1992). According to the Director of Extension in Texas:

"We cannot have leaders who constrain Extension to serving only production agriculture and to working only in rural areas. The vision for Extension must parallel the needs of our nation; the vision must recognize 
both the basic, traditional needs and the ever-evolving needs of our society in a rapidly changing, diverse world. (Fehlis, 2005 p. 2)

\section{What Challenges do Extension Agents Face?}

Extension Agents face different challenges every day. Possibly the most difficult challenge agents encounter is the need to be competent with a much broader range of information in their respective units as their audiences become more diverse, expand, and grow over time. "Diverse job assignments require diverse competencies. To be successful, agents must have increased technical competencies in more than one program area" (Cooper \& Graham, 2001, p. 7).

Identifying competencies needed by Extension Agents' needs and the pre-entry competencies of the new members of the organization is important to properly training Extension Agents (Benge, Harder, \& Carter, 2011). Extension faculty often lack the competencies to fully manage and utilize resources with which they are not comfortable (Boyd, 2004). Boyd (2004) identified 33 competencies required by individuals in an agents position, some of these areas included organization and system leadership, positive organizational culture, personal skills, and skills to manage volunteers. Benge et al. (2011), identified self-management, program development processes, communication skills, interpersonal skills, and technical/subject matter expertise as the most necessary pre-entry competencies for Florida Extension Agents. Reasons for the incompetence in the field is not certain, however Webster and Ingram (2007) found that as communities begin to change, due to expansion and shifts in populations, so should the focus of Extension programming. In order to be able to make this shift with the population, 
Extension Agents need a greater source of information to be successful in unfamiliar areas. Increased workloads and lack of time and funding were identified as the most constraining barriers of Extension Agents acquiring competencies (Lakai, Jayaratne, Moore, \& Kistler, 2012). In the future, the ability for the Extension Service to maintain its success will depend greatly on the ability of the system to keep highly qualified agents that have a wide range of competencies relevant to the population they serve (Cooper \& Graham, 2001). Extension must find ways to serve traditional partners with traditional methods while also exploring new horizons (West et al., 2009). If Extension does not market its ability to respond to the changing needs of their audiences, its efforts may not be needed (McDowell, 2004).

Much like beginning agriculture educators, Extension Agents also face challenges of time management, technology barriers, public funding, early resignation, and insufficient facilities (Boone \& Boone, 2007; Harder, Lamm, \& Strong, 2009). The intensive and long hours an Extension Agent is expected to work have contributed to high rates of turnover and burnout (Ensle, 2005). Harder et al. (2009) found that the combination of lingering issues and modern needs, pressures Extension to make adjustments to retain its reputation as a relevant source of non-formal education for Americans. Gregg and Irani (2004) report that "the ability of Extension to use computers, software, and associated peripheral devices for purposes of serving clientele, research, and in support of Extension's administrative infrastructure, has become an essential job related skill)" (p. 1). Beginning educators should be sufficiently prepared for teaching, if they are not well equipped the negative experience could result in early resignation (Touchstone, 2014). 
Recruitment and retention are two of the top internal issues that challenge Cooperative Extension according to Extension Committee on Organization and Policy (2002, 2005). Arnold, Place, Osborne, Israel, \& Tenbroeck (2008), found that the six categories that influenced agents' decisions to enter Extension were: agent background, career contacts, service to the agricultural community, nature of Extension work, position fit, and university supported education. In order for Cooperative Extension to continue being agile and flexible, Extension must focus on long term employment (Extension Committee on Organization and Policy, 2002).

Safrit and Owen (2010) developed a RETAINS model focusing on retaining county program professionals. RETAINS operates under seven themes, Recruit authentically, Expand on new employees' experiences, Training, Advocate for employee and position, Inspire, invest in, and empower employees, Nurture connectivity among employees, and Show appreciation through effective recognition. The usefulness of this model will decrease the turnover rate, because only the most qualified applicants will be retained.

The departure of employees causes excessive stress on an organization, each year. According to a study completed by the Ohio State Extension Service, Kutilek (2000) reports that there is a net cost of $\$ 80,000$ to replace each agent that leaves. Chandler (2005) estimates the approximate cost of replacing one employee on a $\$ 30,000$ salary to range anywhere from $\$ 7,185$ to $\$ 30,000$. Branham (2005) found seven reasons why agents leave their jobs early: the job is not what was expected, mismatch of job and person, little coaching and/or feedback, too few growth or advancement opportunities, feeling devalued or unrecognized, stress from overwork, loss of trust and/or confidence in 
senior leaders. Rousan and Henderson (1996) also found that other priorities in life, insufficient pay, family obligations, late nights, excessive work responsibilities and attraction to more pay elsewhere, were also incentives for employees to leave their jobs early.

Young, Stone, Aliaga, and Shuck (2013) studied the link of job embeddedness to agent retention across two states. The job embeddedness theory examines an individual's link to other people, teams, groups, the perception of their fit with the job, organization, and community, and the beliefs about what they would have to sacrifice if they left their job (Young et al., 2013). Although the two states had a very high retention rate over the previous 5 years, there were many of those agents that do not expect to stay with the organization (Young et al., 2013).

Extension administrators must thoroughly examine how to employ competent, long term staff, to ensure the longevity of the program (Arnold \& Place, 2010). According to Benge, Harder, and Goodwin (2015), Extension administration should focus on maintenance factors including workload, compensation and promotion, and motivational factors including recognition and organizational support to increase employee retention. Mowbray (2001) proposed that Extension administration should consider the following to reduce turnover within the organization: "explore ways to share or shift workloads, explore new delivery methods to decrease after hours activities, keep starting salaries competitive, provide recruits with realistic work expectations, develop a formal exiting interview process (p. 142)." While a lot of the challenges can be caused by the stress of the work place and administration, employees can take it upon themselves to reduce the amount of stress in their lives. Strong and Harder (2009) explain that if 
employees dedicate more hours to planning and managing their time, they can avoid the stress of not having enough time.

A common struggle for many Extension Service faculty is being able to balance family and work. Extension Agent's turnover can be related to its highly absorptive nature of work or the role that an agent is supposed to fill, also resulting in lower quality of family life (St. Pierre, 1984). Often times, an agents work demands long hours including nights or weekends (Fetsch \& Kennington, 1997). Boltes, Lippke, and Gregory (1995) found the greatest concern expressed was finding a balance between home and work, with the largest gap being represented by agents and specialists within their first five years on the job. This finding resulted in the restructuring of the organizational norms for balancing time with family, work, and personal life (Extension Committee on Organization and Policy, 1995). Extension requires a person that is organized, has high energy, and is a good communicator; these individuals are often left without any supervision or over supervised.

Burnout often happens slow and derives from being overworked, not from dislike of the job itself. Overworking directly relates to the decrease in time spent with one's family which is a big cause for early exiting of the Extension career (Ensle, 2005). In a study conducted in Illinois, the top three reasons for Extension Agents leaving were: changes in family situation, family moving, and too much time away from family (Manton \& van Es, 1985). Young agents' major issue with balancing work and family is directly related to their values. They are following a generation that had the mind set of work comes first, in order to support their family (Ensle, 2005). Agents going into the field today are independent thinkers and have a much different mindset of work. They do 
not mind sacrificing promotions or tenure to spend more time with their families; "life is too short to be a workaholic" (Ensle, 2005, p. 6).

Extension Agent attrition and resignation are due in part to being overworked and agents feeling that they are ineffective (Bennet, Iverson, Rohns, Langone, \& Edwards, 2002). Brain, Irani, Hodges, and Fuhrman (2009) found that agents showed a lack of interest, knowledge, and awareness in his study in Florida; those agents also lacked access to resources and key contacts, and showed inconsistency and ineffective message delivery methods. Much of the incompetency is caused by added stress. Bradley, Driscoll, and Bardon (2012), state that job burnout begins with day to day stress and frustrations. Three primary sources of stress for an Extension Agent are an employee's personal life, work conditions and environment, and situations occurring within the job (Kirkpatrick, Lewis, Daft, Dessler, \& Garcia, 1996). In a study conducted by Place and Jacob (2001), stress relief can be obtained by preparing "to do" lists, balancing your time with family and work, proactive professional development, and workday planning. An Ohio State University Extension study found that coping strategies that included the use of: goal setting, recognition of stress and burnout, asking for help, having a support system at home and work, maintaining an active social life, good health habits, taking time off, having professional involvement, and being positive, will reduce stress and occupational burnout (Ensle, 2005). In a study conducted by Bradley et al., (2012) they surveyed agents and directors at seven regionals meetings and were able to compile a list of tips for removing tension from Extension. The responses fell into these categories: invest in yourself, invest in your career, focus your effort, turn loose, stay organized, 
develop a network, shine as a professional, develop funding and resources, save time, inspire, and handle the tough stuff.

\section{Job Satisfaction and Motivation}

Extension Agents are more engaged to work because their jobs have motivating factor tasks that are stimulating and fulfilling, rather than because of maintenance factors that promote job security, income, or benefits (Herzberg, Mauzner, \& Snyderman, 1959). Extension workers are known for having an unselfish orientation towards their work (Morrill \& Morrill, 1967). Agents still need to be adequately compensated for their work, along with other maintenance factors to ensure their long term employment with the organization (Herzberg, 1968). Factors that proved to be influential for Extension Agents to remain in the occupation are: internal satisfaction, community leadership, external motivators, career benefits, change agents, network of support, and extension work environment (Arnold \& Place, 2010). In a study of job satisfaction in Colorado, Harder, Gouldthorpe, and Goodwin (2014) found that a majority of Extension professionals were at least somewhat satisfied with their jobs, while only $15 \%$ were dissatisfied. Harder et al. (2014) found the highest percentage of respondents strongly agreed that the following statement, "opportunity to make a difference in the lives of others" (p. 5) was a positive motivator. Being motivated to work will coincidentally increase ones satisfaction with their job. Boltes et al. (1995) in a Texas study found that in order to maintain or increase job satisfaction amongst employee's factors of: balance between professional and personal life, a clear vision of the future, attention to training and development, and employee involvement must be met. 
In a study of Cooperative Extension in Pennsylvania, Ensle (2005), found that inservice trainings were highly received to counter issues with employee retention because the employees found the information practical and useful. A series of workshops by Kansas Cooperative Extension which addressed increasing employees' pride of their jobs, and addressed both work and life responsibilities indicated that factors relating to job satisfaction were: being involved in a teamwork atmosphere, feeling of belonging to a group who cares, the variety of the job, as well as having valued administrators and supervisors (Ensle, 2005). Job satisfaction has been proven to be directly related to continued employment with an organization. Satisfied employees become lifetime employees (Arnold \& Place, 2007). According to a survey in the Western region of the United States (Arizona, Colorado, Idaho, Montana, Nevada, New Mexico, Utah, and Wyoming) conducted by Ensle (2005), as the number of responsibilities of an agent increased, their job satisfaction decreased; agents with children were less satisfied; and agent's used coping strategies to handle stressful job situations. Factors that resulted in high job satisfaction in the survey were: adequate salary and benefits, authority to manage extension programs, positive relations with supervisors, opportunity for growth within the job, supportive colleagues, and overall satisfaction with the CES organization (Ensle, 2005).

Many of the challenges that affect Extension Agents are caused from being over worked, lack of training, and stress. The constant over working of an employee will result in burnout of that individual and will eventually lead to that employee leaving the organization if the issues isn't resolved. The responsibility of improving job satisfaction is not solely on the employer, the employees can reduce their stress by taking the time to 
plan and organize. Job satisfaction is reached when an employee is content with their work environment and they are being properly recognized and rewarded for their effort. 


\section{CHAPTER III}

\section{Methodology}

\section{Purpose of the Study}

Although over the past couple of decades Extension Offices have decreased in number, they continue to meet the needs of the public. The Cooperative Extension Service is represented by 8,000 Extension Agents nationwide (USDA NIFA, 2010). West Virginia employs 111 Extension Agents, serving all 55 counties, in the following program areas: Agriculture and Natural Resources; 4-H Youth Development; Community, Economic, and Workforce Development; or Families and Health. The purpose of this study was to determine challenges as perceived by Extension Agents in West Virginia. By determining what challenges are impeding an agent's daily work, administrators and directors can better understand how to resolve those issues to improve the job satisfaction for Extension Agents.

\section{Research Question}

The objective of the study is reflected in the following research question:

1. What challenges do West Virginia University Extension Agents encounter as perceived by current Extension Agents?

\section{Research Design}

The Delphi research method was used to establish a consensus of challenges faced by West Virginia Extension Agents. The Delphi technique is a method developed as a 
group communication process that "aims to achieve convergence of opinion on a specific real world issue" (Hsu \& Sandford, 2007, p. 1). Delbecq, Van de Ven, and Gustafson (1975) outlined objectives that the Delphi technique could achieve including: to determine or develop a range of possible program alternatives, to explore or expose underlying assumptions or information leading to different judgements, to seek out information which may generate a consensus on the part of the respondent group, to correlate informed judgements on a topic spanning a wide range of disciplines, and to educate the respondent group as to the diverse and interrelated aspects of the topic (p. 11).

\section{Population}

The target population for this the study were 111 Extension Agents employed by the West Virginia University Extension Service as of October 2014. The accessible population for this study consisted of all current Extension Agents in West Virginia ( $\mathrm{N}=$ 111). A census of all 111 agents was conducted, 83 surveys were returned for a response rate of 74.8 percent.

The population of agents included in the study consisted of 43 4-H Youth Development agents, 35 Agriculture and Natural Resources agents, 24 Families and Health agents, and 9 Community, Economic, and Workforce Development agents (Extension Service Directory, 2014). 


\section{Instrumentation}

A Delphi Technique was used to collect data, therefore the instrument was created by the participants' responses to three different rounds of questions. Extension Agents were contacted to participate via Email, which contained an embedded link to each round of questions. The first round of the survey was designed to collect a list of perceived challenges Extension Agents faced, using the following open ended question: "Please list the three greatest challenges you face as a West Virginia University Extension Agent." The responses gathered from the first survey were compiled and organized into a condensed list. That list of challenges was used to develop the instrument in the second round. A total of 113 responses were gathered from the initial survey. Those items were compiled and organized to a list of 67 challenges to be used as the second survey.

The second round was used to generate the challenges that were the most problematic. Participants were sent the responses from the initial round and asked to indicate whether each response was a challenge or not a challenge. The responses that were rated by at least 50 percent of participants as being a challenge were used as part of the third survey. Of the 67 items that were sent to the Extension Agents in round two, 35 items were identified as a challenge by at least 50 percent of the population.

The third round survey of the Delphi study included the 35 items identified as challenges by at least 50 percent of the respondents. Those 35 items were organized into five construct areas: training and support, funding and resources, personal issues, volunteers and community involvement, and organizational factors. Participants were asked to rate each of the challenges in the constructs as to how challenging they perceived them. A scale was determined to ensure an accurate representation of all 
challenges based on the mean composite scores of each challenge $($ Not a Challenge $=$ $1.00-1.50$, Slightly Challenging $=1.51-2.50$, Somewhat Challenging $=2.51-3.50$, and Very Challenging $=3.51$ or greater). Demographic questions in the third instrument included: gender, age, marital status, if they had children at home, program unit affiliation, if there was a program assistant, if they served as county program coordinator, number of agents per county, and number of counties for which agent is responsible.

The instrument was presented to a panel of faculty members in Agricultural and Extension Education and an Extension Specialist at West Virginia University to establish content and face validity. Reliability was determined using SPSS to calculate Cronbach's alpha for each of the sections and Spearman-Brown was calculated for the overall reliability. The reliability of categories personal issues, organizational factors, and overall were exemplary at $.892, .843$, and .800 respectively, categories of training and support, funding and resources, and personal issues were extensive at .763, .718, and .783 respectively (see Table 1) (Robinson, Shaver, \& Wrightsman, 1991). The instrument was determined to be a reliable measure.

Frame error was avoided because the researcher used an official list of current Extension Agents in West Virginia. Selection and sample errors were avoided by surveying a census of the Extension Agent population in West Virginia. 
Table 1

Reliability of Study

\begin{tabular}{llc}
\hline & \multicolumn{1}{c}{ Statistic } & Value \\
\hline Overall Reliability & $\begin{array}{c}\text { Spearman-Brown } \\
\text { Coefficient }\end{array}$ & .800 \\
Training and Support & Cronbach's alpha & .763 \\
Funding and Resources & Cronbach's alpha & .718 \\
Personal Issues & Cronbach's alpha \\
Volunteers and Community & Cronbach's alpha & .892 \\
Organizational Factors & Cronbach's alpha & .783 \\
\hline
\end{tabular}

\section{Data Collection Procedures}

Each round of the Delphi Study was conducted using Qualtrics an online webbased survey program with a personal link to the survey embedded in personalized email messages to the target population. Email addresses for each participant $(\mathrm{N}=111)$ were obtained from the WVU Extension Service Directory (2014). Since every county Extension Office has Internet service, an online survey was determined to be the most expedient and cost effective means to collect data.

In the first round Extension Agents were asked to respond to the following prompt, "Please list what you see as the three (3) greatest challenges you currently face as a WVU Extension Agent." Two reminders were sent to Extension Agents who had not responded. The first reminder was at two weeks after the initial mailing and the second was sent four weeks after the initial mailing. Based on the responses received in the first round 67 unique challenges were identified. 
In the second round, the 67 challenges collected in round one were compiled into a list and sent back out to the population. Agents were asked to indicate whether each statement was a challenge or not. Two reminders were used in the second round, the first reminder was sent two weeks after the survey was sent out. The second reminder was sent at four weeks after the survey was sent. Round two resulted in 35 of the 67 items being reported by at least 50 percent of the population as being a challenge. Those 35 items were then organized into five constructs which consisted of training and support, funding and resources, personal issues, volunteers and community involvement, and organizational factors.

The third round consisted of the 35 challenge statements organized as constructs and demographic questions. The survey was sent to the Extension Agents asking them to rate how challenging each of the statements were for them using a Likert scale of not a challenge, slightly challenging, somewhat challenging, very challenging, or not applicable. Demographic information was also collected in the final survey. There were three reminders sent out in the third round. The first reminder was sent two weeks after the initial survey, followed by the second reminder two weeks later. The final reminder was sent out five weeks after the initial survey of the third round. The data were analyzed using SPSS.

\section{Analysis of Data}

Final round data were analyzed using descriptive statistics. Data collected using Likert-type scales, interval data, were described using means and standard deviations. Nominal data were reported using frequencies and percentages. The data were 
downloaded from Qualtrics into an Excel spreadsheet and were analyzed using the Statistical Package for the Social Sciences (SPSS). The level of significance was set $a$ priori at $\alpha \leq .05$ for all statistical tests. Frequencies, means, standard deviations, and ANOVA were run. Fifty-seven agents $(68.7 \%)$ were early respondents while twenty-six $(31.3 \%)$ were late respondents. An ANOVA test was run on early and late responses in each of the five constructs to determine if there was a nonresponse error. No significant differences were found in the areas of training and support $(\mathrm{F}=.00)$, funding and resources $(F=1.45)$, personal issues $(F=.20)$, volunteers and community involvement $(F$ $=.039)$, or organizational factors $(\mathrm{F}=1.26)$ (see Table 2$)$.

\section{Use of Findings}

The data were analyzed and reported to show the challenges of Extension Agents throughout different stages of their career and various demographic factors. The results of this study will be reported to Extension Administration so that they may work to resolve or minimize the challenges, thereby improving the retention of agents with WVU Extension Service. 
Table 2

Non-Response Error

\begin{tabular}{|c|c|c|c|c|c|c|}
\hline & & $\begin{array}{l}\text { Sum of } \\
\text { Squares }\end{array}$ & $\mathrm{df}$ & $\begin{array}{l}\text { Mean } \\
\text { Square }\end{array}$ & $\mathrm{F}$ & Sig. \\
\hline \multirow{3}{*}{$\begin{array}{l}\text { Training and } \\
\text { Support }\end{array}$} & Between Groups & 0.000 & 1 & .000 & 0.000 & .998 \\
\hline & Within Groups & 44.555 & 79 & .564 & & \\
\hline & Total & 44.555 & 80 & & & \\
\hline \multirow{3}{*}{$\begin{array}{l}\text { Funding and } \\
\text { Resources }\end{array}$} & Between Groups & .775 & 1 & .775 & 1.445 & .233 \\
\hline & Within Groups & 42.350 & 79 & .536 & & \\
\hline & Total & 43.125 & 80 & & & \\
\hline \multirow[t]{3}{*}{ Personal Issues } & Between Groups & .010 & 1 & .010 & 0.020 & .889 \\
\hline & Within Groups & 40.355 & 79 & .511 & & \\
\hline & Total & 40.365 & 80 & & & \\
\hline \multirow{3}{*}{$\begin{array}{l}\text { Volunteers and } \\
\text { Community } \\
\text { Involvement }\end{array}$} & Between Groups & .014 & 1 & .014 & .039 & .844 \\
\hline & Within Groups & 28.202 & 80 & .353 & & \\
\hline & Total & 28.216 & 81 & & & \\
\hline \multirow{3}{*}{$\begin{array}{l}\text { Organizational } \\
\text { Factors }\end{array}$} & Between Groups & .559 & 1 & .559 & 1.257 & .266 \\
\hline & Within Groups & 35.556 & 80 & .444 & & \\
\hline & Total & 36.115 & 81 & & & \\
\hline
\end{tabular}




\section{CHAPTER IV}

\section{Findings}

\section{Purpose of the Study}

Although over the past couple of decades Extension Offices have decreased in number, they continue to meet the needs of the public. The Cooperative Extension Service is represented by 8,000 Extension Agents nationwide (USDA NIFA, 2010). West Virginia employs 111 Extension Agents, serving all 55 counties, in the following program areas: Agriculture and Natural Resources; 4-H Youth Development; Community, Economic, and Workforce Development; or Families and Health. The purpose of this study was to determine the challenges as perceived by Extension Agents in West Virginia. By determining what challenges are impeding an agents daily work, administrators and directors can better understand how to resolve the those issues to improve the job satisfaction for an Extension Agent.

\section{Research Question}

The objectives of the study are reflected in the following research question:

1. What challenges do West Virginia University Extension Agents encounter as perceived by current Extension Agents? 


\section{Demographic Characteristics}

The accessible population for this study consisted of all current Extension Agents in West Virginia $(\mathrm{N}=111)$. A census of all agents was conducted, 82 surveys were returned for a response rate of 74.8 percent.

Eighty-two agents reported their gender. Forty-seven of the participants (57.3\%) were female while 35 participants (42.7\%) were male (see Table 3). Eighty-two agents reported their age. The age range of the respondents were as follows: none of the agents were under 25 years of age, 12 agents (14.63\%) were between 36-30 years old, 20 agents $(24.39 \%)$ were between $31-35$ years of age, six agents $(7.32 \%)$ were $36-40$ years old, 10 agents (12.20\%) were 41-45 years old, eight agents $(9.76 \%)$ were $46-50$ years of age, and 26 agents $(31.71 \%)$ were over 50 years of age (see Table 3$)$.

Of the 82 respondents, $11(13.3 \%)$ were single, 66 agents $(79.5 \%)$ were married, three (3.6\%) were divorced, and two (2.4\%) were widowed (see Table 4). Seventy-nine agents responded to the question related to children at home. Forty agents (48.2\%) reported they had children at home while 39 (47\%) did not (see Table 4). 
Table 3

Gender and Age

M $\%$

Gender

Male

35

42.68

Female

47

57.32

Age Range

21-25 years

0

0.00

26-30 years

12

14.63

31-35 years

20

24.39

$36-40$ years

6

7.32

41-45 years

10

12.20

46-50 years

8

9.76

$50+$ years

26

31.71

Table 4

Marital Status and Children at Home

M $\%$

Marital Status

Single

11

13.41

Married

66

80.49

Divorced

3

3.66

Widowed

2

2.44

Children at Home

Yes

40

50.63

No

39

49.37 
Seventy-eight respondents reported the program unit they were associated. Twenty-six agents (31.3\%) reported being from Agriculture and Natural Resources (ANR), which is $74 \%$ of the ANR agents. Families and Health (F\&H) were represented by 14 agents (16.9\%), which is $58 \%$ the F\&H agents. Community, Economic, and Workforce Development (CEWD) had eight respondents (9.6\%), but is $89 \%$ of the CEWD unit. Thirty agents (36.1\%) reported they were 4-H Youth Development agents (4-H), which represents $70 \%$ of the $4-\mathrm{H}$ agents (see Table 5).

Eighty agents reported their years of experience with the Extension Service as an agent. Twenty-nine agents (34.9\%) reported having less than five years of experience. Twenty agents (24.1\%) reported that they had six to ten years of experience. Nine agents (10.8\%) reported having 11-15 years of extension experience. Four agents (4.8\%) reported 16-20 years of experience and $18(21.7 \%)$ reported having more than 21 years of experience (see Table 5).

In reference to the number of hours an agent works per week, 81 agents responded. One agent (1.23\%) reported working less than 37.5 hours per week. Forty agents (49.38\%) said they worked between 37.6 and 47.5 hours per week. Twenty-nine agents $(35.80 \%)$ reported working 47.6 to 57.5 hours per week. Eleven agents (13.58\%) reported they worked more than 57.5 hours per week (see Table 6).

Seventy-eight agents responded to the question related to being a County Program Coordinator. The responses were evenly split, 39 respondents (50\%) were County Program Coordinators and 39 (50\%) were not (see Table 6). 
Table 5

Program Unit and Years of Extension Experience

\begin{tabular}{lcc}
\hline & M & $\%$ \\
\hline Program Unit & 26 & 33.33 \\
ANR & 14 & 17.95 \\
F\&H & 8 & 10.26 \\
CEWD & 30 & 38.46 \\
4-H & & \\
Years of Extension Experience & 29 & 36.25 \\
0-5 years & 20 & 25.00 \\
6-10 years & 9 & 11.25 \\
11-15 years & 4 & 5.00 \\
16-20 years & 18 & 22.50 \\
21+ years & & \\
\hline
\end{tabular}

Table 6

Hours Worked and Agents that Serve as CPC

M $\%$

Number of Hours Agents' work per week

Less than 37.5 hours

$37.6-47.5$ hours

$47.6-57.5$ hours

More than 57.5 hours

Agents that are County Program Coordinators

Yes

39

No 
Eighty respondents reported on the number of counties they were responsible for programming. Seventy-one agents $(85.5 \%)$ are responsible for a single county. Eight agents (9.6\%) report two counties. One agent (1.2\%) reports four counties (see Table 7).

Eighty agents responded to the question about the number of agents that worked in their county. Nine respondents $(10.8 \%)$ stated that they were the only agents in the county. Thirty-two agents (38.6\%) serve the county with one other agent. Thirty-seven agents $(44.6 \%)$ have three agents serving their county. Two agents $(2.4 \%)$ work in a county that employs four agents (see Table 7).

Eighty responses were received to the question about whether or not their county employed a program assistant. Thirty-one respondents (37.3\%) state that "yes" their county employs a program assistant, while $49(59.0 \%)$ said that their county did not employ a program assistant (see Table 7). 
Table 7

Number of Counties Served, Agents per County and Presence of Program Assistants

\begin{tabular}{lcc}
\hline & M & $\%$ \\
\hline Number of Counties Agent is Responsible for & 71 & \\
1 county & 8 & 10.00 \\
2 counties & 0 & 0.00 \\
3 counties & 1 & 1.25 \\
4 counties & & \\
Number of Agents in Respondents' County & 9 & 11.25 \\
1 agent & 32 & 40.00 \\
2 agents & 37 & 46.25 \\
3 agents & 2 & 2.50 \\
4 agents & 31 & 0.00 \\
5 agents & 49 & 38.75 \\
Program Assistant in Agents' County & 0 & \\
Yes & & \\
\hline
\end{tabular}

\section{Constructs and Analysis}

The 35 questions were organized and grouped into five constructs: training and support, funding and resources, personal issues, volunteers and community involvement, and organizational factors. The respondents were asked to rank the challenge using a Likert scale of not a challenge, slightly challenging, somewhat challenging or very challenging. 


\section{Construct: Training and Support}

The construct training and support included five items: lack of guidancesupervision, lack of training, prioritizing what is important, meeting program expectations, and disconnect from county needs and state office expectations.

Of the 81 respondents who ranked lack of guidance - supervision, 23 (28.40) reported that it was not a challenge. Twenty-one (25.93\%) perceived it to be slightly challenging. Nineteen respondents $(23.46 \%)$ reported it was somewhat challenging. Eighteen respondents (22.22\%) reported lack of guidance - supervision to be very challenging (see Table 8).

Of the 80 agents that ranked lack of training, $14(17.50 \%)$ reported it as not being a challenge. Twenty-six agents $(32.50 \%)$ saw lack of training as a slight challenge, while 21 agents $(26.25 \%)$ reported it to be somewhat challenging and 19 respondents $(23.75 \%)$ saw lack of training to be very challenging (see Table 8).

Eighty agents responded and ranked the statement prioritizing what is important. Sixteen agents $(20.0 \%)$ did not perceive this to be a challenge, where $15(18.75 \%)$ felt it was a slight challenge. Thirty-one respondents (38.75\%) found prioritizing what is important as somewhat challenging and $18(22.5 \%)$ found it to be very challenging (see Table 8).

In regard to the statement of meeting program expectations, 77 responses were reported. Twelve agents $(15.58 \%)$ found this to not be a challenge. Nineteen agents (24.68\%) found this to be slightly challenging. Thirty-one respondents $(40.26 \%)$ saw this to be somewhat challenging, while 15 agents (19.48\%) reported meeting program expectations to be very challenging (see Table 8). 
The last statement in this category asked agents to rank how challenging the disconnect from county needs and state office expectations were for them. Eighty-one respondents ranked the items. Nine respondents $(11.11 \%)$ reported that this was not a challenge. Twenty-two (27.16\%) participants rated this to be slightly challenging, and 26 agents (32.1\%) reported it to be somewhat challenging. Twenty-three agents (28.4\%) ranked the disconnect between the county office and state office to be very challenging and one $(1.23 \%)$ reported it was not applicable (see Table 8$)$.

The scores for the five items in training and support were averaged for each participant. The following scale was used to interpret the training and support composite. Composite scores of the items in the construct were calculated using the rankings Not a Challenge $=1.00-1.50$, Slightly Challenging $=1.51-2.50$, Somewhat Challenging $=$ $2.51-3.50$, and Very Challenging $=3.51$ or greater. Training and support as a composite construct was rated as somewhat challenging $(\mathrm{M}=2.60, \mathrm{SD}=.75)$ 
Table 8

Training and Support

\begin{tabular}{|c|c|c|c|c|c|c|c|c|c|c|}
\hline & \multicolumn{2}{|c|}{ Not a Challenge } & \multicolumn{2}{|c|}{$\begin{array}{l}\text { Slightly } \\
\text { Challenging }\end{array}$} & \multicolumn{2}{|c|}{$\begin{array}{l}\text { Somewhat } \\
\text { Challenging }\end{array}$} & \multicolumn{2}{|c|}{ Very Challenging } & \multicolumn{2}{|c|}{ NA } \\
\hline & $\mathrm{N}$ & $\%$ & $\mathrm{~N}$ & $\%$ & $\mathrm{~N}$ & $\%$ & $\mathrm{~N}$ & $\%$ & $\mathrm{~N}$ & $\%$ \\
\hline $\begin{array}{l}\text { Lack of Guidance- } \\
\text { Supervision }\end{array}$ & 23 & 28.40 & 21 & 25.93 & 19 & 23.46 & 18 & 22.22 & 0 & 0.00 \\
\hline Lack of Training & 14 & 17.50 & 26 & 32.50 & 21 & 26.25 & 19 & 23.75 & 0 & 0.00 \\
\hline $\begin{array}{l}\text { Prioritizing What is } \\
\text { Important }\end{array}$ & 16 & 20.00 & 15 & 18.75 & 31 & 38.75 & 18 & 22.50 & 0 & 0.00 \\
\hline $\begin{array}{l}\text { Meeting Programming } \\
\text { Expectations }\end{array}$ & 12 & 15.58 & 19 & 24.68 & 31 & 40.26 & 15 & 19.48 & 0 & 0.00 \\
\hline $\begin{array}{l}\text { Disconnect County Needs- } \\
\text { State Office Expectations }\end{array}$ & 9 & 11.11 & 22 & 27.16 & 26 & 32.10 & 23 & 28.40 & 1 & 1.23 \\
\hline
\end{tabular}




\section{Construct: Funding and Resources}

The funding and resources construct consisted of the following challenges: lack of funding, limited available resources, space for storage, and limited human resources. The challenge of lack of funding received a total of 81 responses. Eight respondents (9.88\%) reported that funding was not a challenge. Fourteen agents (17.28\%) indicated that a lack of funding was a slight challenge. Twenty-three responses $(28.4 \%)$ reported it to be somewhat challenging, while 36 agents (44.44\%) noted lack of funding to be very challenging (see Table 9).

Eighty-one agents ranked limited available resources (other than funding). Seven respondents $(8.64 \%)$ reported that it was not a challenge. Twenty-three agents $(28.4 \%)$ ranked this to be slightly challenging, while 34 agents $(41.98 \%)$ felt limited available resources (other than funding) was somewhat challenging. Seventeen agents $(20.99 \%)$ felt it was very challenging (see Table 9).

When asked to rank having enough space for storage as a challenge, 81 agents responded with 13 respondents $(16.05 \%)$ indicating it was not a challenge. Eighteen agents $(22.22 \%)$ ranked it as a slight challenge and 21 participants $(25.93 \%)$ reported it was somewhat challenging. Twenty-nine $(35.8 \%)$ reported that space for storage was very challenging (see Table 9).

Limited human resources had a response rate of 81 agents. Nine individuals $(11.11 \%)$ did not perceive limited human resources to be a challenge. Twenty-eight individuals (34.57\%) ranked it slightly challenging and 22 agents $(27.16 \%)$ reported it was somewhat challenging. Twenty-one agents $(25.93 \%)$ ranked limited human resources 
to be very challenging and the question was not applicable to one respondent $(1.23 \%)$ (see Table 9).Constructs - Funding and Resources

The four items were combined into a composite construct. The scale for the composite constructs is as follows: Not a Challenge $=1.00-1.50$, Slightly Challenging $=$ $1.51-2.50$, Somewhat Challenging $=2.51-3.50$, and Very Challenging $=3.51$ and above. Funding and resources as a composite construct was rated as somewhat challenging $(\mathrm{M}=2.84, \mathrm{SD}=.73)($ see Table 9$)$.

The scores for the four items in funding and resources were averaged for each participant. The following scale was used to interpret the funding and resources composite. Composite scores of the items in the construct were calculated using the rankings Not a Challenge -1.00 to 1.50 , Slightly Challenging $=1.51$ to 2.50 , Somewhat Challenging $=2.51$ to 3.50 and Very Challenging 3.51 or greater. Funding and resources as a composite construct was rated as somewhat challenging $(\mathrm{M}=2.84, \mathrm{SD}=.73)$. 
Table 9

Funding and Resources

\begin{tabular}{|c|c|c|c|c|c|c|c|c|c|c|}
\hline & \multicolumn{2}{|c|}{ Not a Challenge } & \multicolumn{2}{|c|}{ Slightly Challenging } & \multicolumn{2}{|c|}{$\begin{array}{l}\text { Somewhat } \\
\text { Challenging }\end{array}$} & \multicolumn{2}{|c|}{ Very Challenging } & \multicolumn{2}{|c|}{ NA } \\
\hline & $\mathrm{N}$ & $\%$ & $\mathrm{~N}$ & $\%$ & $\mathrm{~N}$ & $\%$ & $\mathrm{~N}$ & $\%$ & $\mathrm{~N}$ & $\%$ \\
\hline Lack of Funding & 8 & 9.88 & 14 & 17.28 & 23 & 28.40 & 36 & 44.44 & 0 & 0.00 \\
\hline \multicolumn{11}{|l|}{ Limited Available } \\
\hline Resources & 7 & 8.64 & 23 & 28.40 & 34 & 41.98 & 17 & 20.99 & 0 & 0.00 \\
\hline Space for Storage & 13 & 16.05 & 18 & 22.22 & 21 & 25.93 & 29 & 35.80 & 0 & 0.00 \\
\hline \multicolumn{11}{|l|}{ Limited Human } \\
\hline Resources & 9 & 11.11 & 28 & 34.57 & 22 & 27.16 & 21 & 25.93 & 1 & 1.23 \\
\hline
\end{tabular}




\section{Construct: Personal Issues}

In the construct personal issues agents were asked to rank how challenging they perceived eight different statements. The statements included time management, mental health, balancing family and work, identifying personal limits, time required for promotion and tenure files, working evening and weekends, time spent on reports, and finding time for all programs (see Table 10).

In regard to time management, 81 responses were received. Fifteen agents (18.52\%) reported it was not a challenge. Seventeen agents $(20.99 \%)$ responded that it was only slightly challenging and 26 ranked it to be somewhat challenging. Twenty-three reported that time management was very challenging (see Table 10).

When asked about maintenance of mental health, 79 agents reported. Sixteen respondents $(20.25 \%)$ did not see this as a challenge. Twenty-one agents $(26.58 \%)$ felt it was slightly challenging while 28 respondents (35.44\%) ranked it to be somewhat challenging. Fourteen agents $(17.72 \%)$ reported that maintaining mental health was very challenging (see Table 10).

Eighty agents ranked the statement balancing family and work. Six agents (7.5\%) did not believe that it was a challenge. Fourteen respondents $(17.50 \%)$ reported it was a slight challenge. Twenty-five agents (31.25\%) ranked balancing family and work as somewhat challenging and 35 respondents (43.75\%) reported it to be very challenging (see Table 10).

Of the 81 responses for identifying personal limits, thirteen respondents $(16.05 \%)$ did not find it challenging. Fifteen participants (18.52\%) reported it as a slight challenge 
and $31(38.27 \%)$ indicated it to be somewhat challenging. Twenty-two agents $(27.16 \%)$ ranked identifying personal limits as very challenging (see Table 10).

When asked to rank the time required for promotion and tenure files, 10 agents $(12.50 \%)$ of the 80 agents who responded did not find it challenging. Sixteen participants $(20.0 \%)$ reported it as a slight challenge and 29 agents $(36.25 \%)$ felt it was somewhat challenging. Twenty-three agents $(28.75 \%)$ found time required for promotion and tenure files very challenging, while two agents $(2.5 \%)$ replied that the question was not applicable to them (see Table 10).

Of the 81 responses to the statement working nights and weekends, nine respondents (11.11\%) reported they did not find it challenging. Seventeen agents (20.99\%) responded that it was slightly challenging and $34(41.95 \%)$ ranked it somewhat challenging. Twenty-one agents (25.93\%) reported working nights and weekends was very challenging (see Table 10).

When asked about time spent on reports, 81 agents responded and eight reported it was not a challenge. Twenty-eight agents (34.57\%) ranked time spent on reports to be slightly challenging and 31 respondents (38.27\%) reported it as somewhat challenging. Thirteen agents $(16.05 \%)$ reported time spent on reports as being very challenging and one $(1.23 \%)$ reported the question was not being applicable (see Table 10$)$.

Eighty-one respondents ranked to finding time for all programs. Three agents (3.7\%) did not find this challenging. Fourteen agents (17.28\%) reported it as being a slight challenge and 22 respondents $(27.16 \%)$ ranked it to be somewhat challenging. Forty-one agents $(50.62 \%)$ reported that finding time for all programs was very 
challenging. One respondent (1.23\%) reported the question as not applicable (see Table $10)$.

Overextending on commitments had 81 responses, 4 respondents (4.94\%) reported that it was not a challenge. Fourteen respondent (17.28\%) indicated a slight challenge with overextending on commitments. While 34 participants $(41.98 \%)$ ranked it as somewhat challenging. Twenty-nine (35.80\%) reported it to be very challenging (see Table 10).

The scores for the nine items in personal issues were averaged for each participant. The following scale was used to interpret the personal issues composite. Composite scores of the items in the construct were calculated using the rankings Not a Challenge $=1.00-1.50$, Slightly Challenging $=1.51-2.50$, Somewhat Challenging $=$ $2.51-3.50$, and Very Challenging $=3.51$ or greater. Personal issues as a composite construct was rated as somewhat challenging $(\mathrm{M}=2.86, \mathrm{SD}=.71)$. 
Table 10

\section{Personal Issues}

\begin{tabular}{|c|c|c|c|c|c|c|c|c|c|c|}
\hline & \multicolumn{2}{|c|}{ Not a Challenge } & \multicolumn{2}{|c|}{ Slightly Challenging } & \multicolumn{2}{|c|}{$\begin{array}{l}\text { Somewhat } \\
\text { Challenging }\end{array}$} & \multicolumn{2}{|c|}{ Very Challenging } & \multicolumn{2}{|c|}{ NA } \\
\hline & $\mathrm{N}$ & $\%$ & $\mathrm{~N}$ & $\%$ & $\mathrm{~N}$ & $\%$ & $\mathrm{~N}$ & $\%$ & $\mathrm{~N}$ & $\%$ \\
\hline Time Management & 15 & 18.52 & 17 & 20.99 & 26 & 32.10 & 23 & 28.40 & 0 & 0.00 \\
\hline Mental Health & 16 & 20.25 & 21 & 26.58 & 28 & 35.44 & 14 & 17.72 & 0 & 0.00 \\
\hline \multicolumn{11}{|l|}{ Balancing Family and } \\
\hline Work & 6 & 7.50 & 14 & 17.50 & 25 & 31.25 & 35 & 43.75 & 0 & 0.00 \\
\hline \multicolumn{11}{|l|}{ Identifying Personal } \\
\hline Limits & 13 & 16.05 & 15 & 18.52 & 31 & 38.27 & 22 & 27.16 & 0 & 0.00 \\
\hline \multicolumn{11}{|l|}{ Time Required For P \& } \\
\hline T File & 10 & 12.50 & 16 & 20.00 & 29 & 36.25 & 23 & 28.75 & 2 & 2.50 \\
\hline \multicolumn{11}{|l|}{ Working Evening and } \\
\hline Weekends & 9 & 11.11 & 17 & 20.99 & 34 & 41.98 & 21 & 25.93 & 0 & 0.00 \\
\hline Time Spent on Reports & 8 & 9.88 & 28 & 34.57 & 31 & 38.27 & 13 & 16.05 & 1 & 1.23 \\
\hline
\end{tabular}


Table 10 (continued)

\section{Personal Issues}

\begin{tabular}{|c|c|c|c|c|c|c|c|c|c|c|}
\hline & \multicolumn{2}{|c|}{ Not a Challenge } & \multicolumn{2}{|c|}{$\begin{array}{c}\text { Slightly } \\
\text { Challenging }\end{array}$} & \multicolumn{2}{|c|}{$\begin{array}{l}\text { Somewhat } \\
\text { Challenging }\end{array}$} & \multicolumn{2}{|c|}{ Very Challenging } & \multicolumn{2}{|c|}{ NA } \\
\hline & $\mathrm{N}$ & $\%$ & $\mathrm{~N}$ & $\%$ & $\mathrm{~N}$ & $\%$ & $\mathrm{~N}$ & $\%$ & $\mathrm{~N}$ & $\%$ \\
\hline \multicolumn{11}{|c|}{ Finding Time for all } \\
\hline Programs & 3 & 3.70 & 14 & 17.28 & 22 & 27.16 & 41 & 50.62 & 1 & 1.23 \\
\hline \multicolumn{11}{|c|}{ Overextending on } \\
\hline Commitments & 4 & 4.94 & 14 & 17.28 & 34 & 41.98 & 29 & 35.80 & 0 & 0.00 \\
\hline
\end{tabular}




\section{Volunteers and Community Involvement}

In the construct of volunteers and community involvement, agents were asked to rank each of the following: recruiting volunteers, training volunteers, retaining volunteers, impact policies have on volunteers, finding leadership in programs, managing expectations of clientele, communities' perception of agents' responsibilities, dealing with difficult personalities, and keeping at risk youth engaged.

When asked about recruiting volunteers, 82 agents responded. Five agents $(6.10 \%)$ reported that it was not a challenge, 21 agents $(25.61 \%)$ ranked it to be slightly challenging, 32 participants $(39.02 \%)$ reported recruiting volunteers to be slightly challenging, 21 agents $(25.61 \%)$ rated it very challenging and three $(3.66 \%)$ responded that the question as not applicable (see Table 11).

Of the 81 participants that rated the statement training volunteers, nine agents $(11.11 \%)$ did not find it challenging. Twenty-four agents $(29.63 \%)$ replied that they saw a slight challenge with training volunteers, while 25 respondents $(30.86 \%)$ reported it to be somewhat challenging. Nineteen agents $(23.46 \%)$ found it very challenging and four agents (4.94\%) replied it was not applicable (see Table 11).

Eighty-one responses were entered regarding retaining volunteers. Twelve agents $(14.81 \%)$ reported that retaining volunteers was not a challenge, while 27 agents $(33.33 \%)$ indicated a slight challenge with retention, 24 agents $(29.63 \%)$ reported it to be somewhat challenging, and 15 agents $(18.52 \%)$ ranked it was very challenging. Three respondents (3.70\%) replied not applicable (see Table 11$)$.

The impact policies have on volunteers received 82 responses. Six agents $(7.32 \%)$ did not see a challenge with the policies, 16 agents (19.51\%) reported a slight challenge, 
and 28 respondents $(34.15 \%)$ ranked it to be somewhat challenging. Twenty-seven participants $(32.93 \%)$ reported the impact policies had on volunteers was very challenging. Six individuals (6.10\%) responded it was not applicable (see Table 11).

Of the 82 responses received for finding leadership in programs, six agents (7.32\%) did not find it challenging. Fourteen agents (17.07\%) reported finding leadership was slightly challenging and $39(47.56 \%)$ ranked it to be somewhat challenging. Twentytwo agents $(26.83 \%)$ felt it was very challenging and one respondent $(1.22 \%)$ reported it not applicable (see Table 11).

Five participants $(6.10 \%)$ of the 82 who responded to managing expectations of clientele, found it to not be challenging. Twenty-nine agents $(35.37 \%)$ reported only a slight challenge, while 35 (42.68\%) ranked it somewhat challenging. Twelve agents $(14.63 \%)$ responded that it was very challenging and one respondent $(1.22 \%)$ indicated it was not applicable (see Table 11).

Eighty-two responses were received for the statement communities' perceptions of agents' responsibilities. Six agents (7.32\%) responded that this was not a challenge, 20 agents $(24.39 \%)$ ranked it slightly challenging, 34 agents $(41.46 \%)$ reported that it was somewhat challenging, and 22 agents $(26.83 \%)$ found it to be very challenging (see Table 11).

When dealing with difficult personalities, 81 agents participated, eight agents (9.88\%) did not find it challenging. Thirty respondents (37.04\%) reported it be slightly challenging and 28 agents (34.57\%) reported it being somewhat challenging. Fifteen agents reported (18.52\%) dealing with difficult personalities to be very challenging (see Table 11). 
The challenge of keeping at risk youth engaged received 82 responses. Of those, seven agents (8.54\%) did not find it challenging, 23 agents $(28.05 \%)$ reported it to be slightly challenging, 28 agents (34.15\%) ranked it somewhat challenging, while 11 participants (13.41\%) indicated it to be very challenging. Thirteen responses $(15.85 \%)$ reported it was not applicable (see Table 11).

The scores for the nine items in volunteers and community involvement were averaged for each participant. The following scale was used to interpret the volunteers and community involvement composite. Composite scores of the items in the construct were calculated using the rankings Not a Challenge $=1.00-1.50$, Slightly Challenging $=$ $1.51-2.50$, Somewhat Challenging $=2.51-3.50$, and Very Challenging $=3.51$ or greater. Volunteers and community involvement as a composite construct was rated as somewhat challenging $(\mathrm{M}=2.74, \mathrm{SD}=.59)$ 
Table 11

Volunteers and Community Involvement

\begin{tabular}{|c|c|c|c|c|c|c|c|c|c|c|}
\hline & \multicolumn{2}{|c|}{ Not a Challenge } & \multicolumn{2}{|c|}{ Slightly Challenging } & \multicolumn{2}{|c|}{$\begin{array}{l}\text { Somewhat } \\
\text { Challenging }\end{array}$} & \multicolumn{2}{|c|}{ Very Challenging } & \multicolumn{2}{|c|}{ NA } \\
\hline & $\mathrm{N}$ & $\%$ & $\mathrm{~N}$ & $\%$ & $\mathrm{~N}$ & $\%$ & $\mathrm{~N}$ & $\%$ & $\mathrm{~N}$ & $\%$ \\
\hline Recruiting Volunteers & 5 & 6.10 & 21 & 25.61 & 32 & 39.02 & 21 & 25.61 & 3 & 3.66 \\
\hline Training Volunteers & 9 & 11.11 & 24 & 29.63 & 25 & 30.86 & 19 & 23.46 & 4 & 4.94 \\
\hline Retaining Volunteers & 12 & 14.81 & 27 & 33.33 & 24 & 29.63 & 15 & 18.52 & 3 & 3.70 \\
\hline \multicolumn{11}{|l|}{ Impact Policies have on } \\
\hline Volunteers & 6 & 7.32 & 16 & 19.51 & 28 & 34.15 & 27 & 32.93 & 5 & 6.10 \\
\hline \multicolumn{11}{|l|}{ Finding Leadership in } \\
\hline Programs & 6 & 7.32 & 14 & 17.07 & 39 & 47.56 & 22 & 26.83 & 1 & 1.22 \\
\hline $\begin{array}{l}\text { Managing Expectations } \\
\text { of Clientele }\end{array}$ & 5 & 6.10 & 29 & 35.37 & 35 & 42.68 & 12 & 14.63 & 1 & 1.22 \\
\hline \multicolumn{11}{|c|}{$\begin{array}{l}\text { Communities' Perception } \\
\text { of Agents' }\end{array}$} \\
\hline Responsibilities & 6 & 7.32 & 20 & 24.39 & 34 & 41.46 & 22 & 26.83 & 0 & 0.00 \\
\hline
\end{tabular}


Table 11 (continued)

Volunteers and Community Involvement

\begin{tabular}{|c|c|c|c|c|c|c|c|c|c|c|}
\hline & \multicolumn{2}{|c|}{ Not a Challenge } & \multicolumn{2}{|c|}{ Slightly Challenging } & \multicolumn{2}{|c|}{$\begin{array}{l}\text { Somewhat } \\
\text { Challenging }\end{array}$} & \multicolumn{2}{|c|}{ Very Challenging } & \multicolumn{2}{|c|}{ NA } \\
\hline & $\mathrm{N}$ & $\%$ & $\mathrm{~N}$ & $\%$ & $\mathrm{~N}$ & $\%$ & $\mathrm{~N}$ & $\%$ & $\mathrm{~N}$ & $\%$ \\
\hline \multicolumn{11}{|c|}{ Dealing with Difficult } \\
\hline Personalities & 8 & 9.88 & 30 & 37.04 & 28 & 34.57 & 15 & 18.52 & 0 & 0.00 \\
\hline \multicolumn{11}{|c|}{ Keeping at-risk Youth } \\
\hline Engaged & 7 & 8.54 & 23 & 28.05 & 28 & 34.15 & 11 & 13.41 & 13 & 15.85 \\
\hline
\end{tabular}




\section{Organizational Factors}

The construct of organizational factors included: reporting requirementspaperwork, inconsistent/nonexistent administrative policies, constant system changes, unclear guidelines-standards, ineffective evaluation systems, employee pay-promotion, lack of direction throughout extension, and support staff to fulfill clientele needs.

For reporting requirements and paperwork, 82 responses were received. Six agents $(7.32 \%)$ responded that there were no challenges with reporting requirements. Thirty agents (36.59\%) indicated it to be slightly challenging and 33 agents $(40.24 \%)$ ranked it as somewhat challenging. Thirteen agents $(15.85 \%)$ reported that reporting requirements and paperwork was very challenging (see Table 12).

Twelve agents (14.81\%) of the 81 who responded to the statement inconsistent or nonexistent administrative policies did not find it challenging. Fifteen participants $(18.52 \%)$ reported it to be slightly challenging and $28(34.57 \%)$ ranked it as somewhat challenging. Twenty-six agents $(32.10 \%)$ indicated the inconsistent or nonexistent administrative policies to be very challenging.

Eighty-one agents responded to the statement about constant system changes, 10 $(12.35 \%)$ of those agents reported that it was not a challenge, 25 agents $(30.86 \%)$ ranked this as a slight challenge, while 24 agents $(29.63 \%)$ responded it was somewhat challenging. Twenty respondents $(24.69 \%)$ reported that the constant system changes were very challenging and two agents $(2.47 \%)$ replied it was not applicable (see Table 12).

Unclear guidelines and standards received 82 responses, five respondents $(6.10 \%)$ did not see this as a challenge. Twenty-four (29.27\%) participants felt that it provided a 
slight challenge while 20 agents $(24.39 \%)$ reported it to be somewhat challenging. Thirtythree agents (40.24\%) reported unclear guidelines and standards to be very challenging (see Table 12).

Of the 82 responses received for ineffective evaluation systems, $10(12.20 \%)$ reported it as not a challenge. Twenty-one (25.61\%) participants reported it as only a slight challenge, while 29 respondents (35.37\%) felt it was somewhat challenging, and 21 agents $(25.93 \%)$ reported that ineffective evaluation system as very challenging. One respondent (1.22\%) indicated it was not applicable (see Table 12).

For the challenge of employee pay and promotion, five participants $(6.17 \%)$ of the 81 who responded said that it was not a challenge. Twenty-four agents $(29.63 \%)$ ranked it as a slight challenge while 30 agents (37.04\%) reported it to be somewhat challenging. Twenty-one respondents (25.93\%) indicated employee pay and promotion to be very challenging and one agent (1.23\%) reported it was not applicable (see Table 12).

In the area of lack of direction throughout extension, 82 responses were received. Ten respondents (12.20\%) reported it was not a challenge. Twenty-five (30.49\%) agents ranked it as slightly challenging. Twenty-four agents (29.27\%) reported that lack of direction was somewhat challenging and 22 agents (26.83\%) found lack of direction throughout extension to be very challenging. One respondent (1.22\%) indicated it as not applicable (see Table 12).

Eighty-two rankings were entered for the challenge of support staff to fulfill clientele needs. Thirteen agents (15.85\%) reported that this was not a challenge, 17 agents $(20.73 \%)$ reported it as slightly challenging, 28 respondents $(34.15 \%)$ ranked it as somewhat challenging, 23 agents (28.05\%) felt support staff to fulfill clientele needs was 
very challenging, and one (1.22\%) respondent indicated the challenge was not applicable (see Table 12).

The scores for the eight items in organizational factors were averaged for each participant. The following scale was used to interpret the organizational factors composite. Composite scores of the items in the construct were calculated using the rankings: Not a Challenge $=1.00-1.50$, Slightly Challenging $=1.51-2.50$, Somewhat Challenging $=2.51-3.50$, and Very Challenging $=3.51$ and above. Organizational factors as a composite construct was rated as somewhat challenging $(\mathrm{M}=2.78, \mathrm{SD}=$ $.67)$. 
Table 12

\section{Organizational Factors}

\begin{tabular}{|c|c|c|c|c|c|c|c|c|c|c|}
\hline & \multicolumn{2}{|c|}{ Not a Challenge } & \multicolumn{2}{|c|}{$\begin{array}{c}\text { Slightly } \\
\text { Challenging }\end{array}$} & \multicolumn{2}{|c|}{$\begin{array}{l}\text { Somewhat } \\
\text { Challenging }\end{array}$} & \multicolumn{2}{|c|}{ Very Challenging } & \multicolumn{2}{|c|}{ NA } \\
\hline & $\mathrm{N}$ & $\%$ & $\mathrm{~N}$ & $\%$ & $\mathrm{~N}$ & $\%$ & $\mathrm{~N}$ & $\%$ & $\mathrm{~N}$ & $\%$ \\
\hline \multicolumn{11}{|l|}{ Reporting Requirements- } \\
\hline Paperwork & 6 & 7.32 & 30 & 36.59 & 33 & 40.24 & 13 & 15.85 & 0 & 0.00 \\
\hline \multicolumn{11}{|l|}{ Inconsistent/ Nonexistent } \\
\hline Administrative Policies & 12 & 14.81 & 15 & 18.52 & 28 & 34.57 & 26 & 32.10 & 0 & 0.00 \\
\hline Constant System Changes & 10 & 12.35 & 25 & 30.86 & 24 & 29.63 & 20 & 24.69 & 2 & 2.47 \\
\hline \multicolumn{11}{|l|}{ Unclear Guidelines- } \\
\hline Standards & 5 & 6.10 & 24 & 29.27 & 20 & 24.39 & 33 & 40.24 & 0 & 0.00 \\
\hline \multicolumn{11}{|l|}{ Ineffective Evaluation } \\
\hline Systems & 10 & 12.20 & 21 & 25.61 & 29 & 35.37 & 21 & 25.61 & 1 & 1.22 \\
\hline Employee Pay-Promotion & 5 & 6.17 & 24 & 29.63 & 30 & 37.04 & 21 & 25.93 & 1 & 1.23 \\
\hline
\end{tabular}


Table 12 (continued)

Organizational Factors

\begin{tabular}{|c|c|c|c|c|c|c|c|c|c|c|}
\hline & \multicolumn{2}{|c|}{ Not a Challenge } & \multicolumn{2}{|c|}{$\begin{array}{l}\text { Slightly } \\
\text { Challenging }\end{array}$} & \multicolumn{2}{|c|}{$\begin{array}{l}\text { Somewhat } \\
\text { Challenging }\end{array}$} & \multicolumn{2}{|c|}{ Very Challenging } & \multicolumn{2}{|c|}{ NA } \\
\hline & $\mathrm{N}$ & $\%$ & $\mathrm{~N}$ & $\%$ & $\mathrm{~N}$ & $\%$ & $\mathrm{~N}$ & $\%$ & $\mathrm{~N}$ & $\%$ \\
\hline $\begin{array}{l}\text { Lack of Direction } \\
\text { throughout Extension }\end{array}$ & 10 & 12.20 & 25 & 30.49 & 24 & 29.27 & 22 & 26.83 & 1 & 1.22 \\
\hline Support Staff to Fulfill & & & & & & & & & & \\
\hline Clientele Needs & 13 & 15.85 & 17 & 20.73 & 28 & 34.15 & 23 & 28.05 & 1 & 1.22 \\
\hline
\end{tabular}




\section{Summary of Constructs and Comparison among Program Units}

The Likert items were combined into composite constructs. The scale for the composite constructs was: Not a Challenge $=1.00-1.50$, Slightly Challenging $=1.51-$ 2.50, Somewhat Challenging $=2.51-3.50$, and Very Challenging $=3.51$ and greater.

In the area of training and support, the overall composite score was somewhat challenging $(M=2.60, S D=.75)$. Agents aligned with Families and Health reported a composite score of $\mathrm{M}=2.15(\mathrm{SD}=.67)$, which indicated the construct to be slightly challenging. Agents aligned with Agriculture and Natural Resources ranked training and support with a mean composite score of $2.52(\mathrm{SD}=.64) .4-\mathrm{H}$ Youth Development agents had a mean composite score of $3.02(\mathrm{SD}=.64)$ and Community, Economic, and Workforce Development agents had a mean composite score of $2.72(\mathrm{SD}=.79)$ indicating the construct of training and support as somewhat challenging for each unit respectively (see Table 13).

Funding and resources had an overall composite score of somewhat challenging $(\mathrm{M}=2.84, \mathrm{SD}=.73)$. Agents in Agriculture and Natural Resources unit ranked funding and resources with a mean composite score of $2.77(\mathrm{SD}=.73)$. Families and Health agents ranked funding and resources with a mean composite score of $2.67(\mathrm{SD}=.70)$. Community, Economic, and Workforce Development agents rankings of funding and resources resulted in a mean composite of $3.06(\mathrm{SD}=.74)$. While 4-H Youth Development agents rankings resulted in a mean composite score of $2.93(\mathrm{SD}=.76)$. The mean composite scores for all units rate the construct as somewhat challenging (see Table 13). 
The overall composite score of personal issues was somewhat challenging $\mathrm{M}=$ $2.86(\mathrm{SD}=.71)$. Families and Health agents rated personal issues with a composite mean score of $2.58(\mathrm{SD}=.75)$. Agriculture and Natural Resources respondents ranked personal issues with a mean composite score of $2.94(\mathrm{SD}=.63)$. Community, Economic, and Workforce Development agents rankings of personal issues resulted in a mean composite score of $2.97(\mathrm{SD}=.81)$. While the 4-H Youth Development agents recorded a composite mean score of $2.88(\mathrm{SD}=.81)$ for the construct of personal issues. The mean composite score for all units rate the construct as somewhat challenging (see Table 13).

In the construct of volunteers and community involvement, the overall composite score was somewhat challenging $(\mathrm{M}=2.74, \mathrm{SD}=.59)$. Families and Health reported a mean composite score of $2.33(\mathrm{SD}=.57)$, which indicates the construct was slightly challenging. Agriculture and Natural Resources agents rated volunteers and community involvement as somewhat challenging with a mean composite score of $2.67(\mathrm{SD}=.60)$. Agents aligned with Community, Economic, and Workforce Development recorded a mean composite score of $3.15(\mathrm{SD}=.52)$ and 4-H Youth Development agents recorded a mean composite score of $2.89(\mathrm{SD}=.52)$ for the construct of volunteers and community involvement indicated the construct was somewhat challenging (see Table 13). 
Table 13

Construct Composite Scores Overall and by Program Unit

\begin{tabular}{|c|c|c|c|c|c|c|c|c|c|c|}
\hline & \multicolumn{10}{|c|}{ Program Unit ${ }^{1}$} \\
\hline & \multicolumn{2}{|c|}{ Overall } & \multicolumn{2}{|c|}{ ANR } & \multicolumn{2}{|c|}{$\mathrm{F} \& \mathrm{H}$} & \multicolumn{2}{|c|}{ CEWD } & \multicolumn{2}{|c|}{$4-\mathrm{H}$} \\
\hline & $\mathrm{M}^{2}$ & SD & $\mathrm{M}^{2}$ & SD & $\mathrm{M}^{2}$ & SD & $\mathrm{M}^{2}$ & $\mathrm{SD}$ & $\mathrm{M}^{2}$ & SD \\
\hline \multicolumn{11}{|l|}{ Training and } \\
\hline Support & 2.60 & .75 & 2.52 & .65 & 2.15 & .67 & 3.02 & .64 & 2.72 & .79 \\
\hline \multicolumn{11}{|l|}{ Funding and } \\
\hline Resources & 2.84 & .73 & 2.77 & .73 & 2.67 & .70 & 3.06 & .74 & 2.93 & .76 \\
\hline Personal Issues & 2.86 & .71 & 2.94 & .63 & 2.58 & .75 & 2.97 & .81 & 2.88 & .75 \\
\hline \multicolumn{11}{|l|}{ Volunteers and } \\
\hline \multicolumn{11}{|l|}{ Community } \\
\hline Involvement & 2.74 & .59 & 2.67 & .60 & 2.33 & .57 & 3.15 & .52 & 2.89 & .52 \\
\hline \multicolumn{11}{|l|}{ Organizational } \\
\hline Factors & 2.78 & .67 & 2.76 & .62 & 2.40 & .63 & 2.89 & .58 & 2.89 & .72 \\
\hline
\end{tabular}


The construct of organization factors received an overall composite score of somewhat challenging $(\mathrm{M}=2.78, \mathrm{SD}=.67)$. Families and Health agents rated organizational factors with a composite mean score of $2.40(\mathrm{SD}=.63)$, which indicates a slight challenge within this construct. Agriculture and Natural Resources agents gave organizational factors a mean composite score of $2.76(\mathrm{SD}=.62)$, which indicates the construct as somewhat challenging. Community, Economic, and Workforce Development agents rated organizational factors as somewhat challenge with a mean composite score of $2.89(\mathrm{SD}=.58)$. The 4-H Youth Development agents also ranked organizational factors as somewhat challenging $(\mathrm{M}=2.89, \mathrm{SD}=.72)$ (see Table 13).

\section{Relationship between Gender and Perception of Challenges}

Training and Support. A total of 81 agents reported their gender. Thirty-five males and 46 females responded to the category of training and support. Based on mean composite scores both groups ranked training and support as somewhat challenging. Male respondents had a composite score of $2.56(\mathrm{SD}=.72)$; while the female respondents averaged $2.63(\mathrm{SD}=.77)($ see Table 14$)$.

A one-way ANOVA was performed on the means of each genders perception of challenges to test the null hypothesis that there were no significant difference between gender and an agent's perception of the training and support challenge construct. The research hypothesis was there was a significant difference between gender and an agent's perception of the training and support challenge construct. The ANOVA produced an F value of $.233(\mathrm{df}=1,79)$ and was not significant (see Table 15). The null hypothesis 
failed to be rejected. There was no difference between gender and an agent's perception of the training and support challenge construct.

Funding and Resources. Eighty-one respondents reported their gender in the funding and resources category. Thirty-five men and 46 women both rated the level of challenge at somewhat challenging. The men rated the construct with a composite score of 2.85 with a standard deviation of .73 while the women rated the construct with an average of 2.83 with a standard deviation of .75 (see Table 14).

A one-way ANOVA was performed on the means of each genders perception of challenges to test the null hypothesis that there was no significant difference between gender and an agent's perception of the funding and resource challenge construct. The research hypothesis was there was a significant difference between gender and an agent's perception of the funding and resources challenge construct. The ANOVA produced an F value of $.017(\mathrm{df}=1,79)$ and was not significant (see Table 15). The researcher failed to reject the null hypothesis. There was no difference between gender and an agent's perception of the funding and resource challenge construct.

Personal Issues. A total of 81 respondents reported their gender in the personal issues area. Thirty-five men and 46 women both rated the level of challenge at somewhat challenging. The men rated the construct with a composite score of 2.70 with a standard deviation of .77 while the women averaged 2.97 with a standard deviation of .64 (see Table 14).

A one-way ANOVA was performed to test the null hypothesis that there were no significant difference between gender and an agent's perception of the personal issues construct. The research hypothesis was there was a significant difference between gender 
and an agent's perception of the personal issues construct. The ANOVA produced an F value of $.2 .93(\mathrm{df}=1,79)$ and was not significant (see Table 15). The researcher failed to reject the null hypothesis. There was no difference between gender and an agent's perception of the personal issues construct.

Volunteers and Community Involvement. Eighty-two respondents reported their gender in the volunteers and community involvement category. Thirty-five men and 47 women both rated the level of challenge at somewhat challenging. The men had a composite score of 2.70 with a standard deviation of .65 while the women averaged 2.77 with a standard deviation of .54 (see Table 14).

A one-way ANOVA was performed to test the null hypothesis that there were no significant difference between gender and an agent's perception of the volunteers and community involvement construct. The research hypothesis was there was a significant difference between gender and an agent's perception of the volunteers and community involvement construct. The ANOVA produced an F value of $.234(\mathrm{df}=1,80)$ and was not significant (see Table 15). The researcher failed to reject the null hypothesis. There was no difference between gender and an agent's perception of volunteers and community involvement construct.

Organizational Factors. Eighty-two respondents reported their gender in the funding and resources category. Thirty-five men and 47 women both rated the level of challenge at somewhat challenging. The men rated the construct with a composite score of 2.77 and a standard deviation of .68 while the women averaged 2.78 with a standard deviation of .67 (see Table 14). 
A one-way ANOVA was performed to test the null hypothesis that there were no significant difference between gender and an agent's perception of the organizational factors construct. The research hypothesis was there was a significant difference between gender and an agent's perception of organizational factors construct.

The ANOVA produced an $\mathrm{F}$ value of $.003(\mathrm{df}=1,80)$ and was not significant (see Table 15). The researcher failed to reject the null hypothesis. There was no difference between gender and an agent's perception of responses to the organizational factors construct.

Table 14

Gender and Perception of Challenges - Descriptive

\begin{tabular}{lcccc}
\hline & \multicolumn{3}{c}{ Gender } \\
\cline { 2 - 5 } & $\mathrm{M}$ & Male & $\mathrm{M}$ & Female \\
\cline { 2 - 5 } & 2.55 & .72 & 2.63 & SD \\
\hline Training & 2.85 & .73 & 2.83 & .77 \\
Resources & 2.70 & .77 & 2.97 & .75 \\
Personal & 2.70 & .65 & 2.77 & .64 \\
Community & 2.77 & .68 & 2.78 & .67 \\
Reporting & & & & .54 \\
\hline
\end{tabular}


Table 15

Gender and Perception of Challenges - ANOVA

\begin{tabular}{|c|c|c|c|c|c|c|}
\hline & & Sum of Squares & $\mathrm{df}$ & Mean Square & $\mathrm{F}$ & Sig. \\
\hline \multirow{3}{*}{$\begin{array}{l}\text { Training and } \\
\text { Support }\end{array}$} & Between Groups & .131 & 1 & .131 & .233 & .631 \\
\hline & Within Groups & 44.424 & 79 & .562 & & \\
\hline & Total & 44.555 & 80 & & & \\
\hline \multirow{3}{*}{$\begin{array}{l}\text { Funding and } \\
\text { Resources }\end{array}$} & Between Groups & .009 & 1 & .009 & .017 & .897 \\
\hline & Within Groups & 43.115 & 79 & .546 & & \\
\hline & Total & 43.125 & 80 & & & \\
\hline \multirow[t]{3}{*}{ Personal Issues } & Between Groups & 1.445 & 1 & 1.445 & 2.932 & .091 \\
\hline & Within Groups & 38.921 & 79 & .493 & & \\
\hline & Total & 40.365 & 80 & & & \\
\hline \multirow{3}{*}{$\begin{array}{l}\text { Volunteers and } \\
\text { Community } \\
\text { Involvement }\end{array}$} & Between Groups & .082 & 1 & .082 & .234 & .630 \\
\hline & Within Groups & 28.134 & 80 & .352 & & \\
\hline & Total & 28.216 & 81 & & & \\
\hline \multirow{3}{*}{$\begin{array}{l}\text { Organizational } \\
\text { Factors }\end{array}$} & Between Groups & .001 & 1 & .001 & .003 & .958 \\
\hline & Within Groups & 36.113 & 80 & .451 & & \\
\hline & Total & 36.115 & 81 & & & \\
\hline
\end{tabular}




\section{Relationship of an Agents’ Age and how they Perceive Challenges}

For research purposes age ranges were compiled to compare against the constructs to determine if there were any differences. The age ranges used were as follows: less than 30 years of age, 31 to 39 years of age, 41 to 50 years of age, and 51 years of age and older.

Training and Support. Out of the 81 respondents for the construct of training and support, 12 agents reported that they were less than 30 years of age and rated training and support as somewhat challenging $(\mathrm{M}=2.72, \mathrm{SD}=.71)$. Twenty-six agents reported their age being between 31 and 40 and ranked the training and support construct as somewhat challenging $(\mathrm{M}=2.71, \mathrm{SD}=.78)$. Eighteen agents reported that their age was between 41 and 50 years old and indicated that the construct of training and support was somewhat challenging $(\mathrm{M}=2.61, \mathrm{SD}=.80)$. Twenty-five agents reported that they were 51 years of age or older and found the construct of training and support to have a mean composite score of $2.41(\mathrm{SD}=.69)$ indicating it was a slight challenge (see Table 16).

A one-way ANOVA was performed on the means of each age ranges perception of challenges to test the null hypothesis that there were no significant differences between an agent's age and an agent's perception of the training and support challenge construct. The research hypothesis was there was a significant difference between an agent's age and an agent's perception of the training and support challenge construct.

The ANOVA produced an F value of $.828(\mathrm{df}=3,77)$ and was not significant (see Table 17). The researcher failed to reject the null hypothesis. There was no difference between the agents range and an agent's perception of the training and support challenge construct. 
Funding and Resources. Of the 81 respondents of funding and resources, 12 reported that they were under 30 years of age and found the area to be somewhat challenging $(\mathrm{M}=3.18, \mathrm{SD}=.63)$. Twenty-six responded to being between the ages of 31 and 40 , they also found funding and resources to be somewhat challenging $(\mathrm{M}=2.88, \mathrm{SD}$ $=.72)$. Eighteen agents reported their age falling between 41 and $50(\mathrm{M}=2.60, \mathrm{SD}=$ .88 ), while 25 agents said that they were 51 or older, both groups found the area to be somewhat challenging $(\mathrm{M}=2.79, \mathrm{SD}=.66$; see Table 16$)$.

A one-way ANOVA was performed to test the null hypothesis that there were no significant differences between an agent's age and an agent's perception of the funding and resource challenge construct. The research hypothesis was there was a significant difference between an agent's age and an agent's perception of the funding and resources challenge construct.

The ANOVA produced an F value of $1.623(\mathrm{df}=3,77)$ and was not significant (see Table 17). The researcher failed to reject the null hypothesis. There was no difference between an agent's age and an agent's perception of the funding and resource challenge construct.

Personal Issues. Eighty-one agents responded to the construct of personal issues, 12 agents reported that they were under 30 years of age and indicated that personal issues were somewhat challenging with a mean composite score of $2.94(\mathrm{SD}=.62)$. Twenty-six agents reported being between the ages of 31 and 40 and they indicated that the construct of personal issues were somewhat challenging $(\mathrm{M}=3.12, \mathrm{SD}=.60)$. Eighteen agents reported their age falling between 41 and 50 with a mean composite score of $2.78(\mathrm{SD}=$ .72). Twenty-five agents reported that they were 51 years old or older; and rated the 
construct of personal issues as somewhat challenging with a mean composite score of $2.61(\mathrm{SD}=.79)($ see Table 16$)$.

A one-way ANOVA was performed to test the null hypothesis that there were no significant differences between an agent's age and an agent's perception of the personal issues challenge construct. The research hypothesis was there was a significant difference between an agent's age and an agent's perception of the personal issues challenge construct.

The ANOVA produced an $\mathrm{F}$ value of $2.274(\mathrm{df}=3,77)$ and was not significant (see Table 17). The researcher failed to reject the null hypothesis. There was no difference between an agent's age and an agent's perception of the personal issues challenge construct.

Volunteer and Community Involvement. A total of 82 agents reported their age. Twelve agents reported that they were under 30 years of age and reported that the construct of volunteers and community involvement was somewhat challenging $(\mathrm{M}=$ $2.72, \mathrm{SD}=.67)$.Twenty-six agents reported that their age was between 31 and 40 years and indicated that the construct of personal issues was somewhat challenging with a mean composite score of $2.91(\mathrm{SD}=.49)$. Eighteen agents reported their age was between 41 and 50 years and rate the construct of volunteer and community involvement with a mean composite score of $2.68(\mathrm{SD}=.59)$, and 26 agents reported that they were 51 years of age or older and rated this construct with a mean composite score of $2.62(\mathrm{SD}=$ .64); both age groups indicated that volunteers and community involvement was somewhat challenging (see Table 16). 
A one-way ANOVA was performed to test the null hypothesis that there were no significant differences between an agent's age and an agent's perception of the volunteer and community involvement challenge construct. The research hypothesis was there was a significant difference between an agent's age and an agent's perception of the volunteer and community involvement challenge construct.

The ANOVA produced an F value of $1.207(\mathrm{df}=3,78)$ and was not significant (see Table 17). The researcher failed to reject the null hypothesis. There were no differences between an agent's age and an agent's perception of the volunteer and community involvement challenge construct.

Organizational Factors. Eighty-two agents responded to the construct of organizational factors, 12 agents reported that they were less 30 years of age and that organizational factors were somewhat challenging $(\mathrm{M}=2.73, \mathrm{SD}=.57)$. Twenty-six agents reported being between the ages of 31 and 40 years and indicated that organizational factors were somewhat challenging with a mean composite score of 2.80 $(\mathrm{SD}=.72)$. Eighteen agents reported their age being between 41 and 50 years old and indicated the construct of organizational factors to be somewhat challenging with a mean composite score of $2.79(\mathrm{SD}=.73)$, Twenty-five agents reported being at least 51 years of age and that the construct of organizational factors was somewhat challenging $(\mathrm{M}=$ $2.77, \mathrm{SD}=.64)($ see Table 16$)$.

A one-way ANOVA was performed on the means of each age ranges perception of challenges to test the null hypothesis that there were no significant differences between an agent's age and an agent's perception of the organizational challenge construct. The 
research hypothesis was there was a significant difference between an agent's age and an agent's perception of the organizational challenge construct.

The ANOVA produced an $\mathrm{F}$ value of $.028(\mathrm{df}=3,78)$ and was not significant with an alpha greater than .05 (see Table 17). The researcher failed to reject the null hypothesis. There was no difference between an agent's age and an agent's perception of the organizational challenge construct. 
Table 16

Age and Perception of Challenges - Descriptive

\begin{tabular}{|c|c|c|c|c|c|c|c|c|}
\hline & \multicolumn{8}{|c|}{ Age } \\
\hline & \multicolumn{2}{|c|}{ Under 30 years } & \multicolumn{2}{|c|}{$31-40$ years } & \multicolumn{2}{|c|}{ 41-50 years } & \multicolumn{2}{|c|}{50 plus years } \\
\hline & M & SD & $\mathrm{M}$ & SD & M & SD & $\mathrm{M}$ & SD \\
\hline \multicolumn{9}{|l|}{ Training and } \\
\hline Support & 2.72 & .71 & 2.71 & .78 & 2.61 & .80 & 2.41 & .69 \\
\hline \multicolumn{9}{|l|}{ Funding and } \\
\hline Resources & 3.18 & .63 & 2.88 & .72 & 2.60 & .88 & 2.79 & .66 \\
\hline Personal Issues & 2.94 & .62 & 3.11 & .60 & 2.78 & .72 & 2.61 & .79 \\
\hline \multicolumn{9}{|l|}{ Volunteer and } \\
\hline Involvement & 2.72 & .67 & 2.91 & .49 & 2.68 & .59 & 2.62 & .64 \\
\hline \multicolumn{9}{|l|}{ Organizational } \\
\hline Factors & 2.73 & .57 & 2.80 & .72 & 2.79 & .73 & 2.77 & .64 \\
\hline
\end{tabular}


Table 17

Age and Perception of Challenges-ANOVA

\begin{tabular}{|c|c|c|c|c|c|c|}
\hline & & Sum of Squares & $\mathrm{df}$ & Mean Square & $\mathrm{F}$ & Sig. \\
\hline \multirow{3}{*}{$\begin{array}{l}\text { Training and } \\
\text { Support }\end{array}$} & Between Groups & 1.392 & 3 & .464 & .828 & .483 \\
\hline & Within Groups & 43.162 & 77 & .561 & & \\
\hline & Total & 44.555 & 80 & & & \\
\hline \multirow{3}{*}{$\begin{array}{l}\text { Funding and } \\
\text { Resources }\end{array}$} & Between Groups & 2.565 & 3 & .855 & 1.623 & .191 \\
\hline & Within Groups & 40.559 & 77 & .527 & & \\
\hline & Total & 43.125 & 80 & & & \\
\hline \multirow[t]{3}{*}{ Personal Issues } & Between Groups & 3.285 & 3 & 1.095 & 2.274 & .087 \\
\hline & Within Groups & 37.080 & 77 & .482 & & \\
\hline & Total & 40.365 & 80 & & & \\
\hline \multirow{3}{*}{$\begin{array}{l}\text { Volunteers and } \\
\text { Community } \\
\text { Involvement }\end{array}$} & Between Groups & 1.252 & 3 & .417 & 1.207 & .313 \\
\hline & Within Groups & 26.965 & 78 & .346 & & \\
\hline & Total & 28.216 & 81 & & & \\
\hline \multirow{3}{*}{$\begin{array}{l}\text { Organizational } \\
\text { Factors }\end{array}$} & Between Groups & .039 & 3 & .013 & .028 & .994 \\
\hline & Within Groups & 36.076 & 78 & .463 & & \\
\hline & Total & 36.115 & 81 & & & \\
\hline
\end{tabular}




\section{Relationship of Marital Status and Agents Perception of Challenges}

For research purposes, marital status has been combined into two groups, single and married. Respondents were also given the options of divorced and widowed which were merged with the single category.

Training and Support. Eighty-one agents reported their marital status. Sixteen respondents reported their current marital status was single and indicated the construct of training and support to be somewhat challenging $(\mathrm{M}=2.60, \mathrm{SD}=.72)$. Sixty-five agents reported their current marital status as married and reported the construct of training and support to be somewhat challenging $(\mathrm{M}=2.60, \mathrm{SD}=.76)$ (see Table 18).

A one-way ANOVA was performed to test the null hypothesis that there were no significant differences between an agent's marital status and an agent's perception of the training and support challenge construct. The research hypothesis was there was a significant difference between marital status and an agent's perception of the training and support challenge construct.

The ANOVA produced an $\mathrm{F}$ value of $.001(\mathrm{df}=1,79)$ and was not significant (see Table 19). The researcher failed to reject the null hypothesis. There was not a significant difference between marital status and an agent's perception of the training and support challenge construct.

Funding and Resources. Of the 81 respondents who reported their marital status, 16 agents reported being single and indicated that the construct of funding and resources was somewhat challenging $(M=3.23, \mathrm{SD}=.71)$. Sixty-five agents reported that their marital status was married and rated the construct of funding and resources at a mean 
composite score of $2.73(\mathrm{SD}=.71)$ indicating it was somewhat challenging (see Table 18).

A one-way ANOVA was performed to test the null hypothesis that there were no significant differences between an agent's marital status and an agent's perception of the funding and resources challenge construct. The research hypothesis was there was a significant difference between marital status and an agent's perception of the funding and resources challenge construct.

The ANOVA produced an F value of $6.276(\mathrm{df}=1,79)$ and was significant at an alpha level of $\leq .05$ (see Table 19). The null hypothesis was rejected and the research hypothesis was accepted. There was a significant difference between marital status and an agent's perception of the funding and resources challenge construct. The single agents rated funding and resources more challenging. The difference between the group means exhibited a medium effect (Cohen, 1988).

Personal Issues. Sixteen of the 81 respondents to the construct of personal issues reported being single and rated this construct with a composite score of $2.83(\mathrm{SD}=.73)$, indicating personal issues were somewhat challenging. Sixty-five agents reported they were married and rated personal issues to be somewhat challenging $(\mathrm{M}=2.86, \mathrm{SD}=.71)$ (see Table 18).

A one-way ANOVA was performed to test the null hypothesis that there were no significant differences between an agent's marital status and an agent's perception of the personal issues challenge construct. The research hypothesis was there was a significant difference between marital status and an agent's perception of the personal issues challenge construct. 
The ANOVA produced an F value of $.036(\mathrm{df}=1,79)$ and was not significant at an alpha level of .05 (see Table 19). The researcher failed to reject the null hypothesis. There was not a significant difference between marital status and an agent's perception of personal issues challenge construct.

Volunteers and Community Involvement. Eighty-two respondents reported their marital status for volunteers and community involvement. Sixteen respondents reported being single and ranked the construct of volunteers and community involvement as somewhat challenging $(\mathrm{M}=2.65, \mathrm{SD}=.65)$. Sixty-five agents responded that they were married and reported the construct of volunteers and community involvement to have a mean composite score of $2.76(\mathrm{SD}=.58)$ indicating it was somewhat challenging (see Table 18).

A one-way ANOVA was performed to test the null hypothesis that there were no significant differences between an agent's marital status and an agent's perception of the volunteers and community involvement challenge construct. The research hypothesis was there was a significant difference between marital status and an agent's perception of volunteers and community challenge construct.

The ANOVA produced an F value of $.496(\mathrm{df}=1,80)$ and was not significant (see Table 19). The researcher failed to reject the null hypothesis. There was not a significant difference between marital status and an agent's perception of volunteers and community involvement challenge construct.

Organizational Factors. Of the 82 agents that reported in the construct area of organizational factors, 16 agents were single and ranked the construct of organizational factors to be somewhat challenging $(\mathrm{M}=2.77, \mathrm{SD}=.57)$. Sixty-six agents reported being 
married and rated the mean composite score of the organizational factor construct at 2.78 $(\mathrm{SD}=.69)$ indicating the construct to be somewhat challenging (see Table 19).

A one-way ANOVA was performed to test the null hypothesis that there were no significant differences between an agent's marital status and an agent's perception of the organizational factors challenge construct. The research hypothesis was there was a significant difference between marital status and an agent's perception of the organizational factors challenge construct.

The ANOVA produced an $\mathrm{F}$ value of $.002(\mathrm{df}=1,80)$ and was not significant at an alpha level of .05 (see Table 19). The researcher failed to reject the null hypothesis. There was not a significant difference between marital status and an agent's perception of organizational factors construct.

Table 18

Marital Status and Perception of Challenges - Descriptive

\begin{tabular}{lcccc}
\hline & \multicolumn{3}{c}{ Marital Status } \\
\cline { 2 - 5 } & \multicolumn{2}{c}{ Single } & M & SD \\
\cline { 2 - 5 } & $\mathrm{M}$ & $\mathrm{SD}$ & 2.60 & .76 \\
\hline Training and Support & 2.60 & .72 & 2.74 & .71 \\
Funding and Resources & 3.23 & .70 & 2.86 & .71 \\
Personal Issues & 2.83 & .73 & & .58 \\
Volunteers and & & & 2.76 & .69 \\
Community Involvement & 2.65 & .65 & 2.78 \\
Organizational Factors & 2.77 & .57 & & \\
\hline
\end{tabular}


Table 19

Marital Status and Perceptions of Challenges - ANOVA

\begin{tabular}{|c|c|c|c|c|c|c|}
\hline & & Sum of Squares & df & Mean Square & $\mathrm{F}$ & Sig. \\
\hline \multirow{3}{*}{$\begin{array}{l}\text { Training and } \\
\text { Support }\end{array}$} & Between Groups & .001 & 1 & .001 & .001 & .974 \\
\hline & Within Groups & 44.554 & 79 & .564 & & \\
\hline & Total & 44.555 & 80 & & & \\
\hline \multirow{3}{*}{$\begin{array}{l}\text { Funding and } \\
\text { Resources }\end{array}$} & Between Groups & 3.174 & 1 & 3.174 & 6.276 & .014 \\
\hline & Within Groups & 39.951 & 79 & .506 & & \\
\hline & Total & 43.125 & 80 & & & \\
\hline \multirow[t]{3}{*}{ Personal Issues } & Between Groups & .018 & 1 & .018 & .036 & .851 \\
\hline & Within Groups & 40.347 & 79 & .511 & & \\
\hline & Total & 40.365 & 80 & & & \\
\hline \multirow{3}{*}{$\begin{array}{l}\text { Volunteers and } \\
\text { Community } \\
\text { Involvement }\end{array}$} & Between Groups & .174 & 1 & .174 & .496 & .484 \\
\hline & Within Groups & 28.043 & 80 & .351 & & \\
\hline & Total & 28.216 & 81 & & & \\
\hline \multirow{3}{*}{$\begin{array}{l}\text { Organizational } \\
\text { Factors }\end{array}$} & Between Groups & .001 & 1 & .001 & .002 & .962 \\
\hline & Within Groups & 36.114 & 80 & .451 & & \\
\hline & Total & 36.115 & 81 & & & \\
\hline
\end{tabular}




\section{Relationship of Agents’ with Children and Perception of Challenges}

Training and Support. Of the 78 respondents to the construct of training and support, 40 agents replied that there were children living in their household. Agents who had children living at home reported the construct of training and support to have a mean composite score of $2.56(\mathrm{SD}=.75)$ which indicated the construct was somewhat challenging (see Table 20). Thirty-eight respondents reported not having children living at home and ranked the construct of training and support to have a mean composite score of $2.64(\mathrm{SD}=.77)$ indicating that training and support was somewhat challenging.

A one-way ANOVA was performed to test the null hypothesis that there were no significant differences between an agent having children at home and an agent's perception of the training and support challenge construct. The research hypothesis was there was a significant difference between an agent having children at home and an agent's perception of the training and support challenge construct.

The ANOVA produced an $\mathrm{F}$ value of $.187(\mathrm{df}=1,77)$ and was not significant (see Table 21). The researcher failed to reject the null hypothesis. There was not a significant difference between having children at home and an agent's perception of the training and support challenge construct.

Funding and Resources. Seventy-eight agents responded to the construct of funding and resources. Forty respondents reported having children at home and ranked funding and resources as somewhat challenging with a mean composite score of 2.89 (SD $=.80)$. Thirty-eight agents reported not having children at home and rated the construct of funding and resources to have a mean composite score of $2.78(\mathrm{SD}=.69)$ indicating the construct was somewhat challenging (see Table 20). 
A one-way ANOVA was performed to test the null hypothesis that there were no significant differences between an agent having children at home and an agent's perception of the funding and resources challenge construct. The research hypothesis was there was a significant difference between an agent having children at home and an agent's perception of the funding and resources challenge construct.

The ANOVA produced an $\mathrm{F}$ value of $.378(\mathrm{df}=1,77)$ and was not significant (see Table 21). The researcher failed to reject the null hypothesis. There was not a significant difference between having children at home and an agent's perception of the funding and resources construct.

Personal Issues. Out of the 78 agents who reported in the construct area of personal issues, 40 respondents had children at home and rated personal issues as somewhat challenging with a mean composite score of $2.92(\mathrm{SD}=.70)$. The remaining 38 agents who reported, did not have children living at home and ranked personal issues with a mean composite score of $2.81(\mathrm{SD}=.69)$ giving the construct area a rating of somewhat challenging (see Table 20).

A one-way ANOVA was performed to test the null hypothesis that there were no significant differences between an agent having children at home and an agent's perception of the personal issues challenge construct. The research hypothesis was there was a significant difference between an agent having children at home and an agent's perception of the personal issues challenge construct.

The ANOVA produced an $\mathrm{F}$ value of $.456(\mathrm{df}=1,77)$ and was not significant (see Table 21). The researcher failed to reject the null hypothesis. There was not a 
significant difference between having children at home and an agent's perception of the personal issues challenge construct.

Volunteers and Community Involvement. Seventy-nine agents responded to the construct area of volunteers and community involvement. Forty agents reported having children at home and rated the construct area to be somewhat challenging (see Table 20) based on a composite mean score of $2.77(\mathrm{SD}=.57)$. Thirty-nine agents reported not have children living at home and ranked the construct area of volunteers and community involvement as somewhat challenging $(\mathrm{M}=2.72, \mathrm{SD}=.62)$.

A one-way ANOVA was performed to test the null hypothesis that there were no significant differences between an agent having children at home and an agent's perception of the volunteers and community involvement challenge construct. The research hypothesis was there was a significant difference between an agent having children at home and an agent's perception of the volunteers and community involvement challenge construct.

The ANOVA produced an F value of $.123(\mathrm{df}=1,78)$ and was not significant (see Table 21). The researcher failed to reject the null hypothesis. There was not a significant difference between having children at home and an agent's perception of the volunteers and community involvement challenge construct.

Organizational Factors. Of the 79 agents who responded to the construct of organizational factors, 40 agents reported that they had children at home and rated organizational factors as somewhat challenging with a mean composite score of 2.78 (SD $=.75)$. Thirty-nine agents responded they did not have children at home and rated with a 
mean composite score of $2.79(\mathrm{SD}=.57)$ indicating the construct to be somewhat challenging (see Table 20).

A one-way ANOVA was performed to test the null hypothesis that there were no significant differences between an agent having children at home and an agent's perception of the organizational factors challenge construct. The research hypothesis was there was a significant difference between an agent having children at home and an agent's perception of the organizational factors challenge construct.

The ANOVA produced an $\mathrm{F}$ value of $.002(\mathrm{df}=1,78)$ and was not significant (see Table 21). The researcher failed to reject the null hypothesis. There was not a significant difference between having children at home and an agent's perception of the organizational factors challenge construct.

Table 20

Children at Home and Perception of Challenge - Descriptive

\begin{tabular}{lcccc}
\hline & \multicolumn{5}{c}{ Children at Home } \\
\cline { 2 - 5 } & M & Yes & M & SD \\
\cline { 2 - 5 } & 2.56 & .75 & 2.64 & .77 \\
Training & 2.89 & .80 & 2.78 & .66 \\
Resources & 2.92 & .70 & 2.81 & .69 \\
Personal & 2.77 & .57 & 2.72 & .61 \\
Community & 2.78 & .75 & 2.79 & .57 \\
Reporting & & & & .69 \\
\hline
\end{tabular}


Table 21

Children at Home and Perception of Challenge - ANOVA

\begin{tabular}{|c|c|c|c|c|c|c|}
\hline & & Sum of Squares & df & Mean Square & $\mathrm{F}$ & Sig. \\
\hline \multirow{3}{*}{$\begin{array}{l}\text { Training and } \\
\text { Support }\end{array}$} & Between Groups & .108 & 1 & .108 & .187 & .667 \\
\hline & Within Groups & 43.927 & 76 & .578 & & \\
\hline & Total & 44.035 & 77 & & & \\
\hline \multirow{3}{*}{$\begin{array}{l}\text { Funding and } \\
\text { Resources }\end{array}$} & Between Groups & .205 & 1 & .205 & .378 & .540 \\
\hline & Within Groups & 41.128 & 76 & .541 & & \\
\hline & Total & 41.333 & 77 & & & \\
\hline \multirow[t]{3}{*}{ Personal Issues } & Between Groups & .222 & 1 & .222 & .456 & .501 \\
\hline & Within Groups & 36.913 & 76 & .486 & & \\
\hline & Total & 37.135 & 77 & & & \\
\hline \multirow{3}{*}{$\begin{array}{l}\text { Volunteers and } \\
\text { Community } \\
\text { Involvement }\end{array}$} & Between Groups & .043 & 1 & .043 & .123 & .726 \\
\hline & Within Groups & 27.148 & 77 & .353 & & \\
\hline & Total & 27.191 & 78 & & & \\
\hline \multirow{3}{*}{$\begin{array}{l}\text { Organizational } \\
\text { Factors }\end{array}$} & Between Groups & .001 & 1 & .001 & .002 & .961 \\
\hline & Within Groups & 34.173 & 77 & .444 & & \\
\hline & Total & 34.175 & 78 & & & \\
\hline
\end{tabular}




\section{Relationship of Challenges among Program Units}

Training and Support. Seventy-seven agents reported the program unit that they served. Twenty-six agents worked with Agriculture and Natural Resources and reported training and support to be somewhat challenging with mean composite score of 2.52 (SD $=.65)$. Thirteen respondents served the Families and Health unit, those agents rated training and support to have mean composite score of $2.15(\mathrm{SD}=.67)$ which indicated a slight challenge (see Table 22). Community, Economic, and Workforce Development were represented by eight agents who reported the construct area of training and support was somewhat challenging $(M=3.02, S D=.79)$. Thirty respondents reported serving the 4-H Youth Development unit and indicated that the construct area of training and support was somewhat challenging $(\mathrm{M}=2.72, \mathrm{SD}=.79)$.

A one-way ANOVA was performed to test the null hypothesis that there were no significant differences between the program units and an agent's perception of the training and support construct. The research hypothesis was there was a significant difference between program units and an agent's perception of the training and support construct.

The ANOVA produced an F value of $3.028(\mathrm{df}=3,76)$ and was significant at an alpha level of .05 (see Table 23). The null hypothesis was rejected and the research hypothesis was accepted. There was a significant difference between the program units and an agent's perception of training and support construct. The difference between the group means exhibited a medium effect (Cohen, 1988).

A LSD post hoc analysis was conducted and significant difference was found between the Families and Health unit $(\mathrm{M}=2.15)$ and the Community, Economic, and 
Workforce Development unit $(\mathrm{M}=3.02)$ as well as between the Families and Health unit $(M=2.15)$ and 4-H Youth Development $(M=2.72)$. Families and Health rated Training and Support less challenging than both 4-H Youth Development and Community, Economic, and Workforce Development (see Table 23).

Funding and Resources. Of the 77 agents that responded to the construct of funding and resources, 26 agents were aligned Agriculture and Natural Resources and reported a mean composite score of $2.77(\mathrm{SD}=.73)$ indicating the construct was somewhat challenging (see Table 22). Thirteen respondents reported from the Families and Health unit and ranked funding and resources to be somewhat challenging $(\mathrm{M}=$ $2.067, \mathrm{SD}=.70$ ). The eight agents which responded from the Community, Economic, and Workforce Development unit rated the funding and resources construct at a mean composite score of $3.06(\mathrm{SD}=.74)$ and the 30 agents the reported from 4-H Youth Development rated funding and resources at a mean composite score of $2.93(\mathrm{SD}=.76)$, both units indicated that the funding and resources construct was somewhat challenging. A one-way ANOVA was performed to test the null hypothesis that there were no significant differences between an agent's program unit and an agent's perception of the funding and resources challenge construct. The research hypothesis was there was a significant difference between an agent's program unit and an agent's perception of the funding and resources challenge construct.

The ANOVA produced an $\mathrm{F}$ value of $.710(\mathrm{df}=3,76)$ and was not significant (see Table 23). The researcher failed to reject the null hypothesis. There is not a significant difference between an agent's program unit and an agent's perception of the funding and resources challenge construct. 
Personal Issues. A total of 77 agents reported their perception of challenges within the personal issues construct. Twenty-six agents reported from the Agriculture and Natural Resources unit and rated the construct of personal issues at a composite mean score of $2.94(\mathrm{SD}=.63)$ indicating the construct was somewhat challenging (see Table 22). The Families and Health unit was represented by 13 agents, who responded that personal issues were somewhat challenging $(\mathrm{M}=2.58, \mathrm{SD}=.75)$. Eight agents reported from the Community, Economic, and Workforce Development unit and perceived personal issues to be somewhat challenging $(\mathrm{M}=2.97, \mathrm{SD}=.81)$. The $304-\mathrm{H}$ Youth Development agents reported the construct of personal issues, at a composite mean score of $2.88(\mathrm{SD}=.75)$, as somewhat challenging.

A one-way ANOVA was performed to test the null hypothesis that there were no significant differences between an agent's program unit and an agent's perception of personal issues challenge construct. The research hypothesis was there was a significant difference between an agent's program unit and an agent's perception of personal issues challenge construct.

The ANOVA produced an $\mathrm{F}$ value of $.858(\mathrm{df}=3,76)$ and was not significant (see Table 23). The researcher failed to reject the null hypothesis. There is not a significant difference between an agent's program unit and an agent's perception of personal issues challenge construct.

Volunteers and Community Involvement. Seventy-eight agents reported their perceptions of challenges within the volunteers and community involvement construct. Twenty-six agents aligned with Agriculture and Natural Resources and ranked the construct of volunteers and community involvement to be somewhat challenging with 
mean composite score of $2.67(\mathrm{SD}=.60)($ see Table 22$)$. The Families and Health unit was represented by 14 agents that rated the construct of volunteers and community involvement at a composite mean score of $2.33(\mathrm{SD}=.57)$ indicating a slight challenge (see Table 22). Eight respondents reported serving the Community, Economic, and Workforce Development unit and rated the volunteers and community involvement construct with a mean score of $3.15(\mathrm{SD}=.52)$ and 30 4-H Youth Development agents reported volunteers and community involvement to have a mean score of $2.89(\mathrm{SD}=.52)$ both units indicated the construct of volunteers and community involvement was somewhat challenging.

A one-way ANOVA was performed to test the null hypothesis that there were no significant differences between an agent's program unit and an agent's perception of volunteers and community involvement challenge construct. The research hypothesis was there was a significant difference between an agent's program unit and an agent's perception of volunteers and community involvement challenge construct.

The ANOVA produced an F value of $4.775(\mathrm{df}=3,77)$ and was significant at an alpha level of $\leq .05$ (see Table 23). The null hypothesis was rejected and the research hypothesis was accepted. There was a significant difference between an agent's program unit and an agent's perception of volunteers and community involvement challenge construct. The differences between the group means exhibited a large effect (Cohen, 1988).

A LSD post hoc analysis was conducted and significant difference was found between the Agriculture and Natural Resources unit $(\mathrm{M}=2.67)$ and Community, Economic, and Workforce Development unit $(\mathrm{M}=3.15)$. The Families and Health unit 
$(\mathrm{M}=2.33)$ significantly differed from both the Community, Economic, and Workforce Development unit $(\mathrm{M}=3.15)$ and 4-H Youth Development unit $(\mathrm{M}=2.89)$. Agriculture and Natural Resources $(\mathrm{M}=2.67)$ reported volunteers and community involvement significantly lower than Community, Economic, and Workforce Development $(\mathrm{M}=$ 3.15). Families and Health $(M=2.33)$ also registered significantly lower challenge levels than both 4-H Youth Development $(\mathrm{M}=2.89)$ and Community, Economic, and Workforce Development $(\mathrm{M}=3.15)$ (see Table 23).

Organizational Factors. Of the 78 respondents that reported for the construct of organizational factors, 26 agents reported from Agriculture and Natural Resources rating organizational factors with a mean composite score of $2.76(\mathrm{SD}=.62)$ indicating it was somewhat challenging (see Table 22). Fourteen agents responded from the Families and Health unit and ranked the construct of organizational facts as slightly challenging with a composite mean of $2.40(\mathrm{SD}=.63)$. Eight respondents from Community, Economic, and Workforce Development reported this construct to be somewhat challenging $(\mathrm{M}=2.89$, $\mathrm{SD}=.58)$. The 30 agents reporting from the 4-H Youth Development unit rated organizational factors with a mean score of $2.89(\mathrm{SD}=.72)$ indicating the construct was somewhat challenging.

A one-way ANOVA was performed to test the null hypothesis that there were no significant differences between an agent's program unit and an agent's perception of organizational factors challenge construct. The research hypothesis was there was a significant difference between an agent's program unit and an agent's perception of organizational factors challenge construct. 
The ANOVA produced an $\mathrm{F}$ value of $1.935(\mathrm{df}=3,77)$ and was not significant (see Table 23). The researcher failed to reject the null hypothesis. There was not a significant difference between an agent's program unit and an agent's perception of organizational factors challenge construct.

Table 22

Program Units and Perception of Challenges-Descriptive

\begin{tabular}{|c|c|c|c|c|c|c|c|c|}
\hline & \multicolumn{8}{|c|}{ Program Unit } \\
\hline & \multicolumn{2}{|c|}{ ANR } & \multicolumn{2}{|c|}{$\mathrm{F} \& \mathrm{H}$} & \multicolumn{2}{|c|}{ CEWD } & \multicolumn{2}{|c|}{$4-\mathrm{H}$} \\
\hline & $\mathrm{M}$ & $\mathrm{SD}$ & $\mathrm{M}$ & $\mathrm{SD}$ & $\mathrm{M}$ & $\mathrm{SD}$ & $\mathrm{M}$ & $\mathrm{SD}$ \\
\hline \multicolumn{9}{|l|}{ Training and } \\
\hline Support & 2.52 & .65 & 2.15 & .67 & 3.02 & .64 & 2.72 & .79 \\
\hline \multicolumn{9}{|l|}{ Funding and } \\
\hline Resources & 2.77 & .73 & 2.67 & .70 & 3.06 & .74 & 2.93 & .76 \\
\hline Personal Issues & 2.94 & .63 & 2.58 & .75 & 2.97 & .81 & 2.88 & .75 \\
\hline \multicolumn{9}{|l|}{ Volunteers and } \\
\hline Involvement & 2.67 & .60 & 2.33 & .57 & 3.15 & .52 & 2.89 & .52 \\
\hline \multicolumn{9}{|l|}{ Organizational } \\
\hline Factors & 2.76 & .62 & 2.40 & .63 & 2.89 & .58 & 2.89 & .72 \\
\hline
\end{tabular}


Table 23

Program Units and Perception of Challenges- ANOVA

\begin{tabular}{|c|c|c|c|c|c|c|}
\hline & & Sum of Squares & df & Mean Square & $\mathrm{F}$ & Sig. \\
\hline \multirow{3}{*}{$\begin{array}{l}\text { Training and } \\
\text { Support }\end{array}$} & Between Groups & 4.585 & 3 & 1.528 & 3.028 & .035 \\
\hline & Within Groups & 36.838 & 73 & .505 & & \\
\hline & Total & 41.422 & 76 & & & \\
\hline \multirow{3}{*}{$\begin{array}{l}\text { Funding and } \\
\text { Resources }\end{array}$} & Between Groups & 1.159 & 3 & .386 & .710 & .549 \\
\hline & Within Groups & 39.717 & 73 & .544 & & \\
\hline & Total & 40.876 & 76 & & & \\
\hline \multirow[t]{3}{*}{ Personal Issues } & Between Groups & 1.323 & 3 & .441 & .858 & .467 \\
\hline & Within Groups & 37.516 & 73 & .514 & & \\
\hline & Total & 38.839 & 76 & & & \\
\hline \multirow{3}{*}{$\begin{array}{l}\text { Volunteers and } \\
\text { Community } \\
\text { Involvement }\end{array}$} & Between Groups & 4.474 & 3 & 1.491 & 4.775 & .004 \\
\hline & Within Groups & 23.115 & 74 & .312 & & \\
\hline & Total & 27.589 & 77 & & & \\
\hline \multirow{3}{*}{$\begin{array}{l}\text { Organizational } \\
\text { Factors }\end{array}$} & Between Groups & 2.513 & 3 & .838 & 1.935 & .131 \\
\hline & Within Groups & 32.032 & 74 & .433 & & \\
\hline & Total & 34.544 & 77 & & & \\
\hline
\end{tabular}




\section{Relationship of Extension Experience and Perception of Challenges}

Respondents were asked to report the number of years they had worked as an Extension Agent. Agents were given the options of the following ranges: less than five years, six to ten years, 11 to 20 years, or more than 20 years.

Training and Support. Of the 79 agents who responded to the construct of training and support, 29 agents reported working with Extension as an agent for less than five years and rated training and support at a mean composite score of $2.79(\mathrm{SD}=.69)$ and indicated the construct was somewhat challenging (see Table 24). Twenty agents reported being with the organization for six to ten years and rated training and support to be slightly challenging $(\mathrm{M}=2.35, \mathrm{SD}=.76)$. Thirteen agents reported working for 11 to 20 years with the Extension Service and rated training and support were somewhat challenging $(\mathrm{M}=2.66, \mathrm{SD}=.78)$. Seventeen agents reported working with the Extension Service for more than 20 years and indicated that training and support were slightly challenging $(\mathrm{M}=2.41, \mathrm{SD}=.74)$.

A one-way ANOVA was performed to test the null hypothesis that there were no significant differences between years of Extension experience and an agent's perception of the training and support challenge construct. The research hypothesis was there was a significant difference between years of Extension experience and an agent's perception of the training and support challenge construct.

The ANOVA produced an $\mathrm{F}$ value of $1.814(\mathrm{df}=3,78)$ and was not significant (see Table 25). The researcher failed to reject the null hypothesis. There was not a significant difference between Extension experience and an agents' perceptions of the training and support challenge construct. 
Funding and Resources. A total of 79 agents responded to the challenge construct of funding and resources. Twenty-nine agents reported being in their first five years of service with Extension and rated funding and resources at mean composite score of 2.89 $(\mathrm{SD}=.70)$ which indicates the construct being somewhat challenging (see Table 24). Twenty agents reported being between their sixth and tenth year of work with the Extension Service and ranked funding and resources at a composite mean score of 2.81 $(\mathrm{SD}=.73)$ indicating the construct was somewhat challenging. Thirteen agents reported their service working with Extension has spanned 11 to 20 years and indicated the construct area of funding and resources was somewhat challenging $(\mathrm{M}=3.04, \mathrm{SD}=.64)$. Seventeen agents reported being veteran agents, working more than 20 years with Extension, and reported the construct area of funding and resources as somewhat challenging with a mean composite score of $2.56(\mathrm{SD}=.87)$.

A one-way ANOVA was performed to test the null hypothesis that there were no significant differences between years of Extension experience and an agent's perception of the funding and resources challenge construct. The research hypothesis was there was a significant difference between years of Extension experience and an agent's perception of the funding and resources challenge construct.

The ANOVA produced an $\mathrm{F}$ value of $1.186(\mathrm{df}=3,78)$ and was not significant (see Table 25). The researcher failed to reject the null hypothesis. There was not a significant difference between years of Extension experience and an agent's perception of the funding and resources challenge construct.

Personal Issues. Seventy-nine respondents completed the survey for the construct of personal issues, 29 agents reported having worked with Extension for less than five 
years and rated personal issues at a mean composite score of $2.93(\mathrm{SD}=.71)$ as somewhat challenging (see Table 24). Twenty agents reported having worked for six to ten years with Extension and ranked this construct as somewhat challenging $(M=2.90$, $\mathrm{SD}=.67)$. A total of 13 agents reported working between 11 and 20 years with Extension, rated personal issues as somewhat challenge with a composite mean score of $3.10(\mathrm{SD}=.59)$. Seventeen veteran agents who had worked with Extension for an excess of 20 years indicated the construct of personal issues to be slightly challenging $(\mathrm{M}=$ $2.46, \mathrm{SD}=.76)$

A one-way ANOVA was performed to test the null hypothesis that there were no significant differences between years of Extension experience and an agent's perception of the personal issues challenge construct. The research hypothesis was there was a significant difference between years of Extension experience and an agent's perception of the personal issues challenge construct.

The ANOVA produced an F value of $2.471(\mathrm{df}=3,78)$ and was not significant (see Table 25). The researcher failed to reject the null hypothesis. There was not a significant difference between years of Extension experience and an agent's perception of the personal issues challenge construct.

Volunteers and Community Involvement. Of the 80 agents who responded to the construct of volunteers and community involvement, 29 agents reported being in their first five years of work with Extension and they rated volunteers and community involvement at a mean score of $2.76(\mathrm{SD}=.52)$ which indicated the construct was somewhat challenging (see Table 24). Twenty agents reported working with Extension for six to ten years and ranked the volunteers and community involvement with a mean 
composite score of $2.74(\mathrm{SD}=.65)$. Thirteen respondents had worked for Extension between 11 and 20 years and rated it with a composite mean score of $3.01(\mathrm{SD}=.50)$ indicating the construct was somewhat challenging. Eighteen veteran agents reported to the construct of volunteers and community involvement and indicating that it was slightly challenging $(\mathrm{M}=2.48, \mathrm{SD}=.65)$.

A one-way ANOVA was performed to test the null hypothesis that there were no significant differences between years of Extension experience and an agent's perception of the volunteers and community involvement challenge construct. The research hypothesis was there was a significant difference between years of Extension experience and an agent's perception of the volunteers and community involvement challenge construct.

The ANOVA produced an $\mathrm{F}$ value of $2.145(\mathrm{df}=3,79)$ and was not significant (see Table 25). The researcher failed to reject the null hypothesis. There was not a significant difference between Extension experience and an agents' perceptions of the volunteers and community involvement challenge construct.

Organizational Factors. Eighty agents responded to the construct of organizational factors, 29 agents reported being their first five years of work with Extension and gave the organizational factors construct a mean composite score of 2.81 $(\mathrm{SD}=.72)$ rating the construct as somewhat challenging (see Table 24$).$ Twenty agents reported having worked with Extension for six to ten years ranked organizational factors as somewhat challenging $(\mathrm{M}=2.68, \mathrm{SD}=.62)$. The 13 agents that reported work between 11 and 20 years with extension ranked organizational factors with a mean score of $2.93(\mathrm{SD}=.70)$, as somewhat challenging. Eight veteran agents, that had worked with 
Extension more than 20 years, perceived organizational factors as somewhat challenging $(\mathrm{M}=2.63, \mathrm{SD}=.66)$.

A one-way ANOVA was performed on the means of how challenges are perceived by agents based on their Extension experience to test the null hypothesis that there were no significant differences between years of Extension experience and an agent's perception of the organizational factors challenge construct. The research hypothesis was there was a significant difference between years of Extension experience and an agent's perception of the organizational factors challenge construct.

The ANOVA produced an $\mathrm{F}$ value of $.686(\mathrm{df}=3,79)$ and was not significant (see Table 25). The researcher failed to reject the null hypothesis. There was not a significant difference between years of Extension experience and an agent's perception of the organizational factors challenge construct. 
Table 24

Extension Experience and Perception of Challenge - Descriptive

\begin{tabular}{|c|c|c|c|c|c|c|c|c|}
\hline & \multicolumn{8}{|c|}{ Extension Agent Experience } \\
\hline & \multicolumn{2}{|c|}{$0-5$ years } & \multicolumn{2}{|c|}{$6-10$ years } & \multicolumn{2}{|c|}{$11-20$ years } & \multicolumn{2}{|c|}{21 plus years } \\
\hline & M & SD & M & SD & M & SD & M & SD \\
\hline \multicolumn{9}{|l|}{ Training and } \\
\hline Support & 2.79 & .69 & 2.35 & .76 & 2.66 & .78 & 2.41 & .73 \\
\hline \multicolumn{9}{|l|}{ Funding and } \\
\hline Resources & 2.89 & .70 & 2.81 & .73 & 3.04 & .64 & 2.56 & .87 \\
\hline Personal Issues & 2.93 & .71 & 2.90 & .67 & 3.10 & .59 & 2.46 & .76 \\
\hline \multicolumn{9}{|l|}{ Volunteers and } \\
\hline \multicolumn{9}{|l|}{ Community } \\
\hline Involvement & 2.76 & .52 & 2.74 & .65 & 3.01 & .50 & 2.48 & .65 \\
\hline \multicolumn{9}{|l|}{ Organizational } \\
\hline Factors & 2.81 & .72 & 2.68 & .62 & 2.93 & .70 & 2.63 & .59 \\
\hline
\end{tabular}


Table 25

Extension Experience and Perception of Challenge - ANOVA

\begin{tabular}{|c|c|c|c|c|c|c|}
\hline & & Sum of Squares & df & Mean Square & $\mathrm{F}$ & Sig. \\
\hline \multirow{3}{*}{$\begin{array}{l}\text { Training and } \\
\text { Support }\end{array}$} & Between Groups & 2.900 & 3 & .967 & 1.814 & .152 \\
\hline & Within Groups & 39.964 & 75 & .533 & & \\
\hline & Total & 42.864 & 78 & & & \\
\hline \multirow{3}{*}{$\begin{array}{l}\text { Funding and } \\
\text { Resources }\end{array}$} & Between Groups & 1.937 & 3 & .646 & 1.186 & .321 \\
\hline & Within Groups & 40.835 & 75 & .544 & & \\
\hline & Total & 42.772 & 78 & & & \\
\hline \multirow[t]{3}{*}{ Personal Issues } & Between Groups & 3.584 & 3 & 1.195 & 2.471 & .068 \\
\hline & Within Groups & 36.254 & 75 & .483 & & \\
\hline & Total & 39.837 & 78 & & & \\
\hline \multirow{3}{*}{$\begin{array}{l}\text { Volunteers and } \\
\text { Community } \\
\text { Involvement }\end{array}$} & Between Groups & 2.179 & 3 & .726 & 2.145 & .101 \\
\hline & Within Groups & 25.732 & 76 & .339 & & \\
\hline & Total & 27.911 & 79 & & & \\
\hline \multirow{3}{*}{$\begin{array}{l}\text { Organizational } \\
\text { Factors }\end{array}$} & Between Groups & .913 & 3 & .304 & .686 & .563 \\
\hline & Within Groups & 33.698 & 76 & .443 & & \\
\hline & Total & 34.611 & 79 & & & \\
\hline
\end{tabular}




\section{Relationship of Agents per County and their Perception of Challenge}

Agents were asked to select the number of agents that were working out of their county, they were given the option of one through four. For statistical purposes to protect individual confidentiality, options have been narrowed to three (one, two, or more than two).

Training and Support. Of the 79 agents that reported the number of agents in their county in the construct of training and support, nine agents said that they were the only agents in their county and responded that the construct of training and support was somewhat challenging with a mean composite score of $2.91(\mathrm{SD}=.70)$. Thirty agents reported that they served in a county with one other agent and rated training and support at a mean composite score of $2.68(\mathrm{SD}=.64)$ indicating it was somewhat challenging (see Table 26). Thirty-eighty agents reported serving alongside two or more agents in their county and ranked the construct of training and support as slightly challenging $(\mathrm{M}=$ $2.41, \mathrm{SD}=.80)$

A one-way ANOVA was performed to test the null hypothesis that there were no significant differences between the number of agents in a county and an agent's perception of the training and support challenge construct. The research hypothesis was there was a significant difference between the number of agents in a county and an agent's perception of the training and support challenge construct.

The ANOVA produced an $\mathrm{F}$ value of $2.299(\mathrm{df}=2,78)$ and was not significant (see Table 27). The researcher failed to reject the null hypothesis. There was not a significant difference between the number of agents per county and an agents' perceptions of the training and support challenge construct. 
Funding and Resources. Seventy-nine agents reported their perception of challenges in the construct of funding and resources. Nine agents reported that they were the only agent in their county and gave funding and resources a mean composite score of $3.19(\mathrm{SD}=.69)$ indicating the construct was somewhat challenging (see Table 26). Thirty-two agents reported serving in a county that employed two agents and ranked funding and resources as somewhat challenging $(\mathrm{M}=2.82, \mathrm{SD}=.75)$. Thirty-eight agents reported working alongside at least two other agents in their county and rated funding and resources with a mean composite score of $2.74(\mathrm{SD}=.74)$ and somewhat challenging.

A one-way ANOVA was performed to test the null hypothesis that there were no significant differences between the number of agents in a county and an agents' perceptions of the funding and resources challenge construct. The research hypothesis was there was a significant difference between the number of agents in a county and an agents' perceptions of the funding and resources construct.

The ANOVA produced an $\mathrm{F}$ value of $1.365(\mathrm{df}=2,78)$ and was not significant (see Table 27). The researcher failed to reject the null hypothesis. There was not a significant difference between the number of agents per county and an agents' perceptions of the funding and resources challenge construct.

Personal Issues. A total of 79 respondents participated in the personal issues construct, nine agents who reported being the only agent in their county rated the personal issues construct with mean composite score of $3.28(\mathrm{SD}=.5)$ to be somewhat challenging (see Table 26). The 32 agents who reported working in a county with one other agent perceived personal issues to be somewhat challenging $(\mathrm{M}=2.85, \mathrm{SD}=.66)$. Thirty-eight agents indicated they worked with at least two additional agents in their 
count and rated the personal issues construct as somewhat challenging $(\mathrm{M}=2.75, \mathrm{SD}=$ $.71)$.

A one-way ANOVA was performed to test the null hypothesis that there were no significant differences between the number of agents in a county and an agent's perception of the personal issues challenge construct. The research hypothesis was there was a significant difference between the number of agents in a county and an agent's perception of the personal issues construct.

The ANOVA produced an F value of $2.299(\mathrm{df}=2,78)$ and was not significant (see Table 27). The researcher failed to reject the null hypothesis. There was not a significant difference between the number of agents per county and an agents' perceptions of the personal issues construct.

Volunteers and Community Involvement. Eighty agents reported how challenging they perceived the construct of volunteers and community involvement. Nine agents that were the only agent in their county reported the construct of volunteers and community involvement to be somewhat challenging, with a mean composite score of $3.23(\mathrm{SD}=$ .34). Thirty-two agents reported being from a county that had two agents and they rated volunteers and community involvement with a mean score of $2.75(\mathrm{SD}=.48)$ indicating the construct was somewhat challenging (see Table 26). The 39 agents the reported being from a county with more than two agents employed indicated the construct of volunteers and community involvement was somewhat challenging $(\mathrm{M}=2.60, \mathrm{SD}=.67)$.

A one-way ANOVA was performed to test the null hypothesis that there were no significant differences between the number of agents in a county and an agent's perception of the volunteers and community challenge construct. The research hypothesis 
was there was a significant difference between the number of agents in a county and an agents' perceptions of the volunteers and community construct.

The ANOVA produced an F value of $4.566(\mathrm{df}=2,79)$ and was significant (see Table 27). The null hypothesis was rejected and the research hypothesis was accepted. There was a significant difference between the number of agents in a county and the agents' perceptions of challenges within the volunteers and community involvement construct. The differences between the group means exhibited a medium effect (Cohen, 1988).

A LSD post hoc analysis was conducted and a significant difference was found between the number of agents per county and an agents' perception of the volunteers and community involvement construct. Agents that were the only agent in a county $(\mathrm{M}=$ 3.23) found working with volunteers and community involvement to be significantly more challenging than agents that worked in a county with two agents $(M=2.75)$ or a county with three or four agents $(M=2.60)$ (see Table 27).

Organizational Factors. Of the 80 agents who reported their perceptions of the construct organizational factors, nine agents reported being the only agent in their county and rated organizational factors at a mean composite score of $3.18(\mathrm{SD}=.58)$ indicating the construct was somewhat challenging (see Table 26). Thirty-two agents reported being employed in a county with two agents and ranked organizational factors as somewhat challenging $(\mathrm{M}=2.67, \mathrm{SD}=.69)$. Thirty-eight agents reported their employment being in a county with three or four agents and rated the construct of organizational factors as somewhat challenging $(\mathrm{M}=2.73, \mathrm{SD}=.64)$. 
A one-way ANOVA was performed to test the null hypothesis that there were no significant differences between the number of agents in a county and an agents' perceptions of the organizational factors construct. The research hypothesis was there was a significant difference between the number of agents in a county and an agent's perception of the challenges in the organizational factors construct.

The ANOVA produced an F value of $2.208(\mathrm{df}=2,78)$ and was not significant (see Table 27). The researcher failed to reject the null hypothesis. There was not a significant difference between the number of agents per county and an agents' perceptions of challenges with the organizational factors construct.

Table 26

Number of Agents per County and Perception of Challenge - Descriptive

\begin{tabular}{|c|c|c|c|c|c|c|}
\hline & \multicolumn{6}{|c|}{ Number of Agents } \\
\hline & \multicolumn{2}{|c|}{ One Agent } & \multicolumn{2}{|c|}{ Two Agents } & \multicolumn{2}{|c|}{ Three or more agents } \\
\hline & M & SD & M & SD & M & SD \\
\hline \multicolumn{7}{|l|}{ Training and } \\
\hline Support & 2.91 & .70 & 2.68 & .64 & 2.41 & .80 \\
\hline \multicolumn{7}{|l|}{ Funding and } \\
\hline Resources & 3.19 & .69 & 2.82 & .75 & 2.74 & .74 \\
\hline Personal Issues & 3.28 & .54 & 2.85 & .66 & 2.75 & .77 \\
\hline \multicolumn{7}{|l|}{ Volunteers and } \\
\hline \multicolumn{7}{|l|}{ Community } \\
\hline Involvement & 3.23 & .34 & 2.75 & .48 & 2.60 & .67 \\
\hline \multicolumn{7}{|l|}{ Organizational } \\
\hline Factors & 3.18 & .58 & 2.67 & .69 & 2.73 & .64 \\
\hline
\end{tabular}


Table 27

Number of Agents per County and Perception of Challenge - ANOVA

\begin{tabular}{|c|c|c|c|c|c|c|}
\hline & & Sum of Squares & $\mathrm{df}$ & Mean Square & $\mathrm{F}$ & Sig. \\
\hline \multirow{3}{*}{$\begin{array}{l}\text { Training and } \\
\text { Support }\end{array}$} & Between Groups & 2.445 & 2 & 1.223 & 2.299 & .107 \\
\hline & Within Groups & 40.419 & 76 & .532 & & \\
\hline & Total & 42.864 & 78 & & & \\
\hline \multirow{3}{*}{$\begin{array}{l}\text { Funding and } \\
\text { Resources }\end{array}$} & Between Groups & 1.483 & 2 & .741 & 1.365 & .262 \\
\hline & Within Groups & 41.289 & 76 & .543 & & \\
\hline & Total & 42.772 & 78 & & & \\
\hline \multirow[t]{3}{*}{ Personal Issues } & Between Groups & 2.062 & 2 & 1.031 & 2.074 & .133 \\
\hline & Within Groups & 37.776 & 76 & .497 & & \\
\hline & Total & 39.837 & 78 & & & \\
\hline \multirow{3}{*}{$\begin{array}{l}\text { Volunteers and } \\
\text { Community } \\
\text { Involvement }\end{array}$} & Between Groups & 2.959 & 2 & 1.480 & 4.566 & .013 \\
\hline & Within Groups & 24.952 & 77 & .324 & & \\
\hline & Total & 27.911 & 79 & & & \\
\hline \multirow{3}{*}{$\begin{array}{l}\text { Organizational } \\
\text { Factors }\end{array}$} & Between Groups & 1.878 & 2 & .939 & 2.208 & .117 \\
\hline & Within Groups & 32.733 & 77 & .425 & & \\
\hline & Total & 34.611 & 79 & & & \\
\hline
\end{tabular}




\section{Other Relationships between Agents Perceptions of Challenges}

Statistical analysis were run to determine if there were any significant differences between an agent's perception of challenges and an agent's role as the county program coordinator. No significant differences were found (see Appendix J).

Analysis were run to determine if there were a difference in an agent's perception of challenges, if they were responsible for more than one county. No significant differences were found (see Appendix K).

Analysis were run to determine whether there was a difference in the agent's perceptions if they worked in a county with a program assistant or not. There were no significant differences (see Appendix L). 


\section{CHAPTER V}

\section{Summary, Discussions, and Recommendations}

\section{Purpose of the Study}

Although over the past couple of decades Extension Offices have decreased in number, they continue to meet the needs of the public. The Cooperative Extension Service is represented by 8,000 Extension Agents nationwide (USDA NIFA, 2010). West Virginia employs 111 Extension Agents, serving all 55 counties, in the following program areas: Agriculture and Natural Resources; 4-H Youth Development; Community, Economic, and Workforce Development; or Families and Health. The purpose of this study was to determine challenges as perceived by Extension Agents in West Virginia. By determining what challenges are impeding an agent's daily work, administrators and directors can better understand how to resolve those issues to improve the job satisfaction for Extension Agents.

\section{Objective of the Study}

The objective of the study is reflected in the following research question:

1. What challenges do West Virginia University Extension Agents encounter as perceived by current Extension Agents?

\section{Summary}

The study consisted of a census of 111 West Virginia Extension Agents. The response rate was $74.77 \%$. 
A majority of the respondents were female (56.6\%), and $31.3 \%$ of respondents were over 50 years of age while $24.1 \%$ were between the ages of 31 and 35. More than three quarters (79.5\%) of the population were married, and slightly less than half (48.2\%) have children at home. Just over a third (36.1\%) of the respondents served the 4-H Youth Development unit while nearly one third $31.3 \%$ were with the Agriculture and Natural Resources unit. Nearly $35 \%$ of agents were serving their first five years when they completed this survey while $24.1 \%$ were in their six to tenth year of service and $21.7 \%$ had passed the 20 year mark of service with Extension. Exactly $50 \%$ of the respondents were County Program Coordinators. A majority of the agents worked between 37.6 and 47.5 hours per week while $48.2 \%$ worked more than 47.6 hours per week. Eighty-six percent of responses reported they work in only one county and $83.2 \%$ of agents indicated they worked in a county with two or three agents. A slight majority (59\%) of agents did not work in a county where a program assistant was employed.

The Likert items were compiled into five separate categories of training and support, funding and resources, personal issues, volunteers and community involvement, and organizational factors. The most challenging items were identified in each construct and demographic area.

In the construct of training and support, agents rated the area as somewhat challenging $(M=2.60)$. Families and Health agents $(M=2.15)$ rated this construct below the average, as slightly challenging, and significantly lower than both the 4-H $(M=2.72)$ and Community, Economic, and Work Force Development units $(\mathrm{M}=3.02)$. As a whole, all agents reported the disconnect between needs of county and expectations of state office to be the most challenging aspect of training and support, followed by prioritizing 
what is important and meeting programming expectations. This finding does support the research of Lakai, Jayaratne, Moore, and Kistner (2012), Harder, Lamm, and Stronger (2009), Harder and Dooley (2007), Safrit and Owen (2010), Branham (2005), and Benge, Harder, and Carter (2011). Their studies report the importance of the state staff/specialists providing the agents with material and service that will be beneficial to them and their clientele, and the importance of continued training and support to ensure agents are competent in what is asked of them. The need for state staff to take active interest in county programs and a need for clear leadership was also found by Benge, Harder, and Goodwin (2015).

Funding and resources received a composite rating of somewhat challenging $(\mathrm{M}=$ 2.84). The construct of funding and resources recorded the highest composite ratings for Families and Health and 4-H Youth Development, and registered the second highest scores in Agriculture and Natural Resources and Community, Economic, and Workforce Development. The leading concern for funding and resources was lack of funding followed by space for storage and limited available resources other than funding. The findings in this challenge construct support the findings of Harder et al. (2009) and Harder, Moore, Mazurkewicz, and Benge (2013). Their studies identified the impact of funding on Extension employees and Extension programming, lack of effective facilities, and the need for community and administrative support to make Extension programs effective. Bradley, Driscoll, and Bardon (2012), propose this solution to lack of funding and resources, simply identify and use available resources and charge cost recovery for programs and products. 
The most challenging category for agents was personal issues $(\mathrm{M}=2.86)$ which was rated somewhat challenging. Agriculture and Natural Resources rated personal issues as the most challenging category $(\mathrm{M}=2.94)$. Families and Health rated it as there second most challenging construct $(\mathrm{M}=2.58)$. The most challenging concern of personal issues according to agents were finding time for all programs, balancing family and work obligations, and overextending on commitments. The major challenges that were identified in the construct of personal issues were all related to time management. Managing ones' time can be a great challenge for agents and very stressful at times. Bradley et al. (2012) created a plan the supports the findings in this survey, the key to removing tension from Extension is for agents to focus their time, stay organized, and save time, don't waste it. Bailey, Hill, and Arnold (2014), Rousan and Henderson (1996), Mowbray (2001), Ensle (2005), Boltes, Lippke, and Gregory (1995), Kutilek, Conklin, and Gunderson (2002), and Kroth and Peutz (2011) reported the importance of balance of family and work and managing time to reduce rapid employee burnout.

In the construct of volunteers and community involvement, agents rated it as somewhat challenging $(M=2.74)$. Agriculture and Natural Resources agents $(M=2.67)$ reported volunteers and community involvement to be significantly less challenging than Community, Economic, and Workforce Development agents $(\mathrm{M}=3.15)$. Families and Health agents $(\mathrm{M}=2.33)$ found the construct to be significantly less challenging than both Community, Economic, and Workforce Development $(\mathrm{M}=3.15)$ and 4-H agents ( $\mathrm{M}$ $=2.89$ ). This finding is consistent with the number of volunteers each agent and unit is asked to interact with on the job. All units work with volunteers at one point or another, but 4-H and Community, Economic, and Workforce Development agents are asked to 
work more with the community and volunteers than Families and Health and Agriculture and Natural Resources. Community, Economic, and Workforce Development found the construct of volunteers and community involvement to be the most challenging. As a whole, agents found impact policies have on volunteers as the most challenging aspect, followed closely by finding leadership in programs, community's perceptions of an agent's responsibilities, and recruiting volunteers. McNeely, Schmiesing, King, and Kleon (2002) reported the use of the screening programs that are in place for agents to recruit adequate volunteers for their programs. This process can be a timely process but is a very valuable tool for volunteer management. The use of trained, experience volunteers to assist with implementation will take some of the burden off the agents. Those trained volunteers could also end up being leaders in Extension programs. Warner, Christtenson, Dillman, and Salant (1996) and Harder et al. (2013) reported the necessity of public knowledge of Extension and what an agents' responsibilities are.

Organizational factors were found to be somewhat challenging $(\mathrm{M}=2.78)$ by Extension Agents. The Families and Health unit found organization factors to be less challenging $(M=2.40)$ than the average mean and significantly less challenging than the 4-H Youth Development unit $(M=2.89)$. Unclear guidelines and standards was the most challenging factor, while inconsistent/ nonexistent administrative policies and employee pay and promotion followed. Much like training and support, organizational factors found a disconnect between the agents and what was being asked of them through guidelines and policies. A closer relationship with the state administration would help reduce the confusion for agents. Benge et al. (2015) reported the need for state staff to provide clear leadership and take an interest. According to Herzberg (1968), 
administrators must solve an employee's maintenance factors to increase job satisfaction, satisfying maintenance factors such as pay would increase the employee's motivation for their job. Increased salary can create a financial burden to the organization, but less of a burden than replacing that individual (Benge et al., 2015).

Analysis of variance (ANOVA) were run on program units and constructs, significant differences were found in the constructs of training and support, volunteers and community involvement, and organizational factors. Families and Health found training and support to be significantly less challenging than Community, Economic, and Workforce Development and 4-H Youth Development. Agriculture and Natural Resources found volunteers and community involvement to be significantly less challenging than Community, Economic, and Workforce Development. Families and Health also found volunteers and community involvement to be significantly less challenging than Community, Economic, and Workforce Development and 4-H. The only significant difference within the area of organizational factors was between 4- $\mathrm{H}$ and Families and Health, in which Families \& Health found organizational factors to be significantly less challenging than $4-\mathrm{H}$ saw them to be.

In the area of funding and resources, agents reported a significant differences between agents that were single (single, widowed, divorced) and married. Agents that were single reported funding and resources to be a greater challenge.

The number of agents per county showed significant differences in the areas of personal issues, volunteers and community involvement, and organizational factors. Agents that worked along two or more agents in their county reported personal issues to be significantly less challenging than agents who were the only agent in their county. 
Both agents with one additional agent and agents with two or more agents in their county ranked volunteers and community involvement to be significantly less challenging than agents that were the only agent in their county. Organization factors were reported to be significantly more challenging for single agents than agents that had additional agents in their county.

Areas of gender, children at home, county program coordinators, number of counties an agent serves, and having a program assistant did not find a significant relationship to the agents' perceptions of challenges.

\section{Conclusions}

Based on the results of this study, the following conclusions were made:

1. Agents that were married found funding and resources to be less challenging than agents that were single.

2. 4-H and CEWD both reported funding and resources and volunteers and community involvement to be more difficult than any other unit.

3. Veteran agents reported each construct to be less challenging than other groups.

4. Counties with multiple agents reported less difficulty with challenges related to working with the community and volunteers than counties with only one agent.

5. A disconnect exists between county needs and the expectations of the state office.

6. Time management, planning, and programming are major concerns among agents. 
7. Funding and facilities are continuing challenges for Extension

8. Community involvement and working with volunteers is a necessity for Extension, but is very challenging at the same time.

9. There are no relationships between construct challenges and gender, age, children at home, being a county coordinators, number of counties agent is responsible for, years of Extension experience, or whether the county has a program assistant or not.

\section{Recommendations}

Administrators that are looking to increase their employee's satisfaction of their job should first take note of what trainings and in-service learning programs are currently in place. Bridging the gap between the county office and the university would eliminate one of the highest rated construct found in this study. Are agents being properly trained when they are hired? Are continued education programs provided for current agents? Agents reported having difficulty getting funding and resources, training those agents in finding available resources and being able to create their own funding, such as grant writing, would minimize this challenge

Burnout is one of the big issues in Extension, the author recommends providing time management programs to help agents reduce the amount of time they are working in the evenings and weekends, and to learn to set their limits and how to say "no." The key to being a successful agent is knowing what the audience wants to learn and being able to provide programs that are going to benefit them. Agents must meet the needs of their population but must also set boundaries for themselves to not exceed their limitations. 
Burnout does not happen all at once, it is the constant overworking that leads to dissatisfaction of their work not the work itself.

Since veteran agents found many of the challenges to be less difficult than other agents, it is recommended that studies be conducted with agents that have worked more than 20 years to determine why those challenges are not as problematic for them.

Mentoring of new agents by veteran agents should be used as a means to assist in training agents that are in their first five years with Extension.

The Extension Service is one of the best tools, and unfortunately one of the best kept secrets, that a land grant university has to offer. It facilitates agents that are trained in many different areas to provide learning opportunities for the public. Identifying the challenges that hinder an agent's success will allow for solutions to be created so Extension can continue to grow and provide an invaluable service to the public. This study should be replicated in other state Extension Services to see if findings would be similar. 


\section{REFERENCES}

About Extension. (n.d.). Retrieved October 3, 2014, from http://www.ext.wvu.edu/about_extension/

Arnold, S. \& Place, N. (2007). Career decisions of Florida Agricultural Extension Agents. (Unpublished doctoral dissertation). University of Florida, Gainsville.

Arnold, S. \& Place, N. (2010). Influences on Agricultural Agents' decisions to remain in an Extension career. Journal of Agricultural Education, 51(2). Available at: http://www.jae-online.org/attachments/article/13/Arnold.pdf

Arnold, S., Place, N., Osborne, E., Israel, G., \& Tenbroeck, S. (2008). Influences on Florida Agricultural Extension Agents' decisions to enter into the Extension Organization. Proceedings of the $24^{\text {th }}$ Annual Meeting. EARTH University, Costa Rica.

Bailey, H., Hill, A., \& Arnold, S. (2014). Information-seeking practices of Extension Agents. Journal of Extension, 52(3). Available at: http://www.joe.org/joe/2014june/rb1.php

Benge, M., Harder, A., \& Carter, H. (2011). Necessary pre-entry competencies as perceived by Florida Extension Agents. Journal of Extension, 49(5). Available at: http://www.joe.org/joe/2011october/a2.php

Benge, M., Harder, A., \& Goodwin, J. (2015). Solutions to burnout and retention as perceived by Extension Agents of the Colorado State University Extension System. Journal of Human Sciences and Extension, 3(1). Retrieved from: http://media.wix.com/ugd/c8fe6e_349080f2854b41da902d89c15130d859.pdf 
Bennett, P.N., Iverson, M.J., Rohns,F. R., Langone, C. A., \& Edwards, M. C. (2002, February). Job Satisfaction of agriculture teachers in Georgia and selected variables indicating their risk of leaving the teaching profession. Paper presented at the Southern Agricultural Education Research Conference, Orlando, FL.

Boltes, B. V., Lippke, L. A., \& Gregory, E. (1995). Employee satisfaction in Extension: A Texas study. Journal of Extension, 33(5). Available at: http://www.joe.org/joe/1995october/rb1.html

Boone, H. N., \& Boone, D. A. (2007). Problems faced by high school agricultural education teachers. Journal of Agricultural Education, 48(2), 36-45. Available at: http://www.jae-online.org/attachments/article/174/Boone_Boone_48_2_36-45.pdf Borich, T. (2001). The Department of Housing and Urban Development and Cooperative Extension: A Case for urban collaboration. Journal of Extension, 39(6). Available at: http://www.joe.org/joe/2001december/a2.php

Borr, M. L., \& Young, R. B. (2010). Retirement and attrition trends of Extension professionals in North Dakota. Journal of Extension, 48(1). Available at: http://www.joe.org/joe/2010february/rb4.php

Boyd, B. L. (2004). Extension Agents as administrators of volunteers: competencies needed for the future. Journal of Extension, 42(2). Available at: http://www.joe.org/joe/2004april/a4.php

Bradley, L., Driscoll, E., \& Bardon, R. (2012). Removing the tension from Extension. Journal of Extension, 50(2). Available at: www.joe.org/joe/2012april/tt1.php

Brain, R., Irani, T., Hodges, A., \& Fuhrman, N. (2009). Agricultural and Natural Resources awareness programming: Barriers and benefits as perceived by County 
Extension Agents. Journal of Extension, 47(2). Available at: http://www.joe.org/joe/2009april/a3.php

Branham, L. (2005). The 7 hidden reasons employees leave. New York: AMACOM. Chandler, G. D. (2005). Organizational and individual factors related to retention of Extension Agents employed by Texas Cooperative Extension. (Dissertation) Abstracts International, 65(12), 4432A. (UMI No. 3157047)

Cohen, J. 1988. Statistical Power Analysis for the Behavioral Sciences (2nd ed.) Hillsdale, New Jersey: Erlbaum Associates.

Conglose, J. B. (2000) The Cooperative Extension Service's role in running a successful economic development program. Journal of Extension 38(3)

Cooper, A.W., \& Graham, D.L. (2001). Competencies needed to be successful Extension Agents and county supervisors. Journal of Extension. 39(1). Available at: http://www.joe.org/joe/2000june/a3.php

Daft, R. L. (1997). Management, $4^{\text {th }}$ edition. New York: Dryden Press, Harcourt Brace College Publishers.

Dalkey, N. C. (1969). An experimental study of group opinion. Futures, 1 (5), 408-426.

Dalkey, N. C. (1972). The Delphi method: An experimental study of group opinion. In N. C. Dalkey, D. L. Rourke, R. Lewis, \& D. Snyder (Eds.). Studies in the quality of life: Delphi and decision-making (pp. 13-54). Lexington, MA: Lexington Books.

Delbecq, A. L., Van de Ven, A. H., \& Gustafson, D. H. (1975). Group techniques for program planning: A guide to nominal group and Delphi processes. Glenview, IL: Scott, Foresman (as cited by Hsu and Sandford, 2007). 
Ellison, S. (2011). Effects of the University Of Georgia Cooperative Extension New Agent Training Program on the Retention of 4-H Youth Development Extension Agents (Doctoral dissertation, University of Georgia).

Ensle, K. M. (2005). Burnout: How does Extension balance job and family? Journal of Extension 43(3). Available at: http://www.joe.org/joe/2005june/a5.shtml

Extension Committee on Organizational Policy - Cooperative State Research, Education and Extension Service. (1995). Framing the future: Strategic framework for a system of partnerships (p. 25). Urbana: University of Illinois Cooperative Extension Service.

Extension Committee on Organization and Policy. (2002). The Extension system: A vision for the 21st century. Washington, D.C., National Association of State Universities and Land-Grant Colleges. Available at http://www.nasulgc.org/publications/Agriculture/ECOP2002_Vison_Resources.p df

Extension Committee on Organization and Policy Leadership Council. (2005). 2005 report. Available at http://www.nasulgc.org/CFERR/board_on_agric/

Fehlis, C. (2005). A call for visionary leadership. Journal of Extension, 43(1). Available at http://www.joe.org/joe/2005february/comm1.php

Fetsch, R. \& Kennington, M. (1997). Balancing work and family in Cooperative Extension: history, effective programs, and future directions. Journal of Extension, 35(1). Available at: http://www.joe.org/joe/1997february/a2.php 
Fiske, E.P. (1989). From rolling stones to cornerstones: anchoring land-grant education in the counties through the Smith-Lever Act of 1914. Rural Sociologist, 7-14. Available at: http://eric.ed.gov/?id=EJ405915

Gregg, J. A. \& Irani, T. A. (2004). Use of information technology by County Extension Agents of the Florida Cooperative Extension Service. Journal of Extension, 42(3). Available at: http://www.joe.org/joe/2004june/rb2.php

Harder, A. \& Dooley, K. (2007). Perceptions of important competencies for early-career and established 4-H agents. Journal of Southern Agricultural Education Research, 57(1), 43-52.

Harder, A., Gouldthorpe, J., \& Goodwin, J. (2014). Why work for Extension? An examination of job satisfaction and motivation in a statewide employee retention study. Journal of Extension, 52(3). Available at: http://www.joe.org/joe/2014june/pdf/JOE_v52_3a5.pdf

Harder, A., Lamm, A., \& Strong, R. (2009). An analysis of the priority needs of Cooperative Extension at the county level. Journal of Agricultural Education, 50(3). Available at: http://www.jaeonline.org/attachments/article/56/Harder_etal_50_3_11-21.pdf

Harder, A., Moore, A., Mazurkewicz, M., \& Benge, M. (2013). Problems impacting Extension program quality at the county level: Results from an analysis of county program reviews conducted in Florida. Journal of Extension, 51(1). Available at http://www.joe.org/joe/2013february/rb2.php

Herzberg, F. (1968). Work and the nature of man. London: Crosby 
Herzberg, F. (1969). Work and the nature of man (3 $3^{\text {rd }}$ ed.). Cleveland, Ohio: The World Publishing Company.

Herzberg, F., Mausner, B., \& Snyderman, B. B. (1959). The motivation to work. New York:

Hsu, C. \& Sandford, B. A. (2007). The Delphi Technique: Making sense of consensus. Practical Assessment, Research \& Evaluation, 12(10). Available at: http://pareonline.net/pdf/v12n10.pdf

Igodan, C.O. \& Newcomb L.H. (1986). Are you experiencing burnout? Journal of Extension. 24(1). Available at: http://www.joe.org/joe/1986spring/a1.html Insala. (2005). Employee retention and turnover. Retrieved October 3, 2014, from: http://www.insala.com/infolink/apr2005/industryresearch_2005employeeretention .asp (as cited in Borr \& Young, 2010).

Kelsey, L. D. \& Hearne, C. (1963). Cooperative Extension Work ( ${ }^{\text {rd }}$ ed.). Ithaca, New York: Comstock Publishing CO., Inc.

Kirkpatrick, T. O., Lewis, C. T., Daft, R. L., Dessler, G., \& Garcia, J. E. (1996). Management and supervision: Overview and organizational behavior applications. Orlando, FL: Harcourt Brace and Co.

Kroth, M. \& Peutz, J. (2011). Workplace issues in Extension - A Delphi study of Extension educators. Journal of Extension, 49(1). Available at: http://www.joe.org/joe/2011 february/rb1.php

Kutilek, L. M. (2000). Learning from those who leave. Journal of Extension, 38(3). Available at: http://joe.org/joe/2000june/iw2.html 
Kutilek, L. M., Conklin. N. L., \& Gunderson, G. (2002). Investing in the future: addressing work/life issues of employees. Journal of Extension (online), 40(1). Available at: http://www.joe.org/joe/2002april/a1.html

Lakai, D., Jayaratne, K.S.U., Moore, G.E., \& Kistler, M.J. (2012) Barriers and effective educational strategies to develop Extension Agents' professional competencies. Journal of Extension, 50(4). Available at: http://www.joe.org/joe/2012august/rb1.php

Legg, R. J. (1989) Factors influencing cooperation between Extension Agents and secondary agriculture teachers in West Virginia. (Unpublished thesis). West Virginia University.

Manton, L. \& van Es, J.C. (1985). Why do Extension Agents resign? Journal of Extension, 23(3). Available at: http://www.joe.org/joe/1985fall/a4.php

McDowell, G. (2004). Is Extension an idea whose time has come-and gone? Journal of Extension, 42(6). Available at: http://www.joe.org/joe/2004december/comm1.php

McNeely, N. N., Schmiesing, R. J., King, J., \& Kleon, S. (2002). Ohio 4-H Youth Development Extension Agents' use of volunteer screening tools. Journal of Extension, 40(4). Available at: http://www.joe.org/joe/2002august/a7.php

Morrill, J. G. \& Morrill, O. L. (1967). Personnel plateauing and motivation. Journal of Cooperative Extension, 5(1). Available at: http://www.joe.org/joe/1967spring/1967-1-a2.pdf Mowbray, J. (2001). Factors affecting turnover of Extension Agents in the University of Kentucky, Cooperative Extension Service (Unpublished doctoral dissertation). University of Kentucky, Lexington, Kentucky. 
Myers, B.E., Dyer, J. E., \& Washburn, S. G. (2005). Problems facing beginning agriculture teachers. Journal of Agriculture Education, 46(3). Available at: http://www.jaeonline.org/attachments/article/261/Myers\%20et\%20al_Vol46_3_47-55.pdf

National Institute of Food and Agriculture. (n.d.). Retrieved May 23, 2015, from http://nifa.usda.gov/cooperative-extension-history

Place, N. \& Jacob, S. (2001). Stress: Professional development needs of extension faculty. Journal of Agricultural Education, 42(1). Available at: http://pubs.aged.tamu.edu/jae/toc42.html\#one

Riggs, K. \& Beus, K. M. (1993). Job satisfaction in Extension. Journal of Extension, 31(2). Available at: http://www.joe.org/joe/1993summer/a5.php

Robinson, J.P., Shaver, P.R., \& Wrightsman, L.S. (1991). Criteria for scale selection and evaluation. In J.P. Robinson, P. R. Shaver, \& L.S. Wrightsman (Eds.). Measures of personality and social psychological attitudes (pp. 1-16). New York: Academic Press.

Rousan, L. M., \& Henderson, J. L. (1996). Agent turnover in Ohio State University Extension. Journal of Agricultural Education, 37(2). Available at: http://www.jae-online.org/attachments/article/568/37-02-56.pdf

Safrit, R. D. \& Owen, M. B. (2010). A conceptual model for retaining county Extension program professionals. Journal of Extension 48(2). Available at: http://www.joe.org/joe/2010april/a2.php

Schafer, J., Huegel, C., \& Mazzotti, F. (1992). Expanding into the urban area. Journal of Extension, 30(2). Available at: http://www.joe.org/joe/1992summer/a2.php 
Seevers, B \& Graham, D (2012) Education through Cooperative Extension. ( $3^{\text {rd }}$ ed.). Fayetteville, AR: University of Arkansas.

Smith-Lever Act of 1914. (1914) Ch. 79, 38 Stat. 372, 7 U.S. C. 341 et seq.

St. Pierre, T. (1984). Addressing work and family issues among Extension personnel. Journal of Home Economics, 76(4), 42-47. Available at: http://hearth.library.cornell.edu/cgi/t/text/pagevieweridx?c=hearth;cc=hearth;q1=addressing\%20work\%20and\%20family\%20issues;rg n=full\%20text;idno=4732504_5349_001;didno=4732504_5349_001;view=image ;seq $=0043$

Strong, R., \& Harder, A. (2009). Implications of maintenance and motivation factors on Extension Agent turnover. Journal of Extension, 47 (1). Available at: http://www.joe.org/joe/2009february/a2.php

Touchstone, A. (2014). Challenge facing beginning agricultural education teachers in Idaho as perceived by beginning teachers, veteran teachers, and building administrators: A Delphi Study. Western AAAE Research Conference Proceedings, 33, 30-44.

United States Department of Agriculture -National Institute of Food and Agriculture. (2010). Extension: About us.

Warner, P. D., Christenson, J. A., Dillman, D. A., \& Salant, P. (1996). Public perception of Extension. Journal of Extension, 34(4). Available at: http://www.joe.org/joe/1996august/a1.php 
Webster, N. \& Ingram, P. (2007). Exploring the challenges for Extension Educators working in urban communities. Journal of Extension, 45 (3). Available at: http://www.joe.org/joe/2007june/iw3.php

West, B. C., Drake, D., \& Londo, A. (2009). Extension: A modern-day pony express. Journal of Extension, 47(2). Available at: http://www.joe.org/joe/2009april/comm1.php

WVU Extension Employee Directory. (n.d.). Retrieved, from http://employees.ext.wvu.edu/directory

Young, J., Stone, J., Aliaga, O., \& Shuck, B. (2013). Job Embeddedness Theory: Can it help explain employee retention among Extension Agents? Journal of Extension, 51(4). Available at http://www.joe.org/joe/2013august/a7.php 
APPENDICES 
APPENDIX A:

COVER LETTER 1 
Dear (First) (Last):

As a WVU Extension Agent you are a valuable educational resource to both your community and the state. Every job has challenges, which vary from person to person. In order to identify the greatest challenges faced by current Extension agents your input is greatly needed.

My name is Caleb Smith, a graduate student at West Virginia University. I am working with my advisor Dr. Deborah Boone to conduct a study to identify work related challenges perceived by West Virginia Extension agents. Participation in this study may benefit you by identifying issues that administration may be unaware of, so that potential solution can be generated. The results of this study will be used to prepare a thesis to partially fulfill the requirements for a Master of Science degree in Agricultural and Extension Education.

Participation in this study is completely voluntary and all information you provide will be held as confidential as possible. The responses to the survey will be gathered using Qualtrics online survey and individual responses will not be identifiable. Please answer the one question honestly and to the best of your ability. There is no penalty if you choose not to participate. At any point during this study you may discontinue your participation in the survey by submitting the survey.

\section{Follow this link to the Survey:}

Take the Survey

Or copy and paste the URL below into your internet browser: http://wvu.qualtrics.com/WRQualtricsSurveyEngine/?Q_SS=8f9zfQEovdz8Pid_56noTtlI feZ1LIp\&_=1

We would like to thank you in advance for taking the time to participate in this survey. Please submit the completed survey by December 11, 2014. If you have any questions please contact Caleb Smith at csmith26@mix.wvu.edu or Dr. Deborah Boone at 304-293-5450 or debby.boone@mail.wvu.edu. We realize this is a busy time for everyone, we hope you will take time to list your top three challenges and share with us. Your response is very important to the success of this study.

Sincerely,

Caleb Smith

Graduate Student
Deborah A. Boone, Ph.D. Associate Professor

Follow the link to opt out of future emails:

Click here to unsubscribe 
APPENDIX B:

INSTRUMENT 1 
November 19, 2014

Dear West Virginia Extension Agents:

As a WVU Extension Agent you are a valuable educational resource to both your community and the state. Every job has challenges, which vary from person to person. In order to identify the greatest challenges faced by current Extension agents your input is greatly needed.

We realize this is a busy time for everyone, we hope you will take time to list your top three challenges and share with us. Your response is very important to the success of this study.

We would like to thank you in advance for taking the time to participate in this survey. Please submit the completed survey by December 11, 2014. If you have any questions please contact Caleb Smith at csmith26@mix.wvu.edu or Dr. Deborah Boone at 304-293-5450 or debby.boone@mail.wvu.edu.

Sincerely,

Caleb Smith

Graduate Student

Deborah A. Boone, Ph.D.

Associate Professor

Please list what you see as the three (3) greatest challenges you currently face as a WVU Extension Agent.

\section{Challenge 1}

Challenge 2

Challenge 3

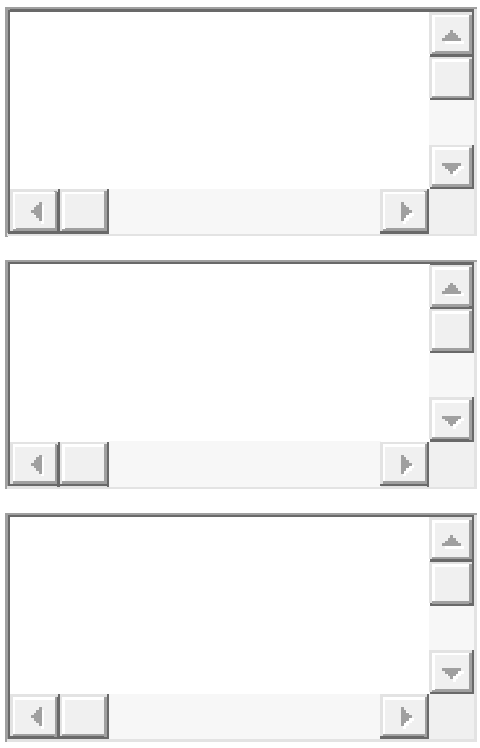


APPENDIX C:

REMINDER 1 


\section{Dear (First) (Last):}

Looks like you have not yet completed your survey on "Challenges Faced by WVU Extension Agents." There is still time to have your voice heard, please click on the link below to answer one question. We appreciate your time. We will remind you that no Extension Administrator will see individual responses.

\section{Follow this link to the Survey:}

Take the Survey

Or copy and paste the URL below into your internet browser:

http://wvu.qualtrics.com/WRQualtricsSurveyEngine/?Q_SS=8f9zfQEovdz8Pid_56noTtlI feZ1LIp\&_=1

Thanks for your assistance with my graduate research study.

Caleb Smith

Graduate Student

Deborah A. Boone, Ph.D.

Associate Professor

Agricultural and Extension Education

Follow the link to opt out of future emails:

Click here to unsubscribe 
APPENDIX D:

COVER LETTER 2 


\section{Dear First Last:}

As an Extension Agent with West Virginia University, you are a valuable educational resource to both your community and the state. With that responsibility comes many challenges, which you have to face on a regular basis. In order to identify the issues that create these challenges, your input is needed.

I am Caleb Smith, a graduate student in Agricultural and Extension Education at West Virginia University and under direction of my advisor Dr. Deborah Boone, we are conducting a study to identify challenges perceived by West Virginia Extension. The results of this study will be used to prepare a thesis to partially fulfill the requirements for a Master of Science in Agriculture and Extension Education. The results of this study will provide insight into the challenges faced by agents. The findings will be used to identify changes which need to be made within the organization. Please take a few minutes and share your opinion with us.

We have compiled a list of challenges agents report they face. We ask that you take a few minutes to simply indicate which of those items you personally view as a challenge and which do not represent a personal challenge.

\section{Follow this link to the Survey:}

Copy and paste the URL below into your internet browser:

http://wvu.qualtrics.com/WRQualtricsSurveyEngine/?Q_SS=cZ0VXjnH32wd6eN_etvyd $\mathrm{IqGcNMb} 1 \mathrm{~A} 1 \& \_=1$

Participation in this research study is completely voluntary and all information you provide will be held as confidential as possible. The questionnaire should take approximately ten minutes of your time to complete. Please answer the questions honestly and to the best of your ability. There is no penalty if you choose not to participate. You may skip any question you do not feel comfortable answering and may stop at any point and submit a partially completed survey. The results of this survey will be reported in a summary format and individual responses will be not be identifiable.

The Institutional Review Board (IRB) at West Virginia University has approved this study. Please submit the completed survey by February 27, 2015. If you have any questions please contact Caleb Smith at csmith26@mix.wvu.edu or Dr. Deborah Boone at 304-293-5450 or debby.boone@mail.wvu.edu. We would like to thank you in advance for taking the time to participate in this survey.

Sincerely,

Caleb Smith

Graduate Student

Deborah A. Boone, Ph.D. Associate Professor

Follow the link to opt out of future emails: Click here to unsubscribe 
APPENDIX E:

INSTRUMENT 2 
February 16, 2015

\section{Dear West Virginia University County Extension Agent:}

As a County Extension Agent in West Virginia University, you are a valuable educational resource to both your community and the state. With that responsibility comes many challenges, which you have to face on a regular basis.

In order to identify the issues that create these challenges, your input is needed.

With input from agents we have compiled a list of challenges agents report they face. We ask that you take a few minutes to indicate which of those items you

personally view as a challenge. Participation in this research study is completely voluntary and all information you provide will be held as

confidential as possible. The questionnaire should take approximately fifteen minutes of your time to complete.

Please answer the questions honestly and to the best of your ability. There is no penalty if you choose not to participate. You may skip any question you do not feel comfortable answering and may stop at any point and submit a partially completed survey. The results of this survey will be reported in a summary format and individual responses will be not be identifiable.

We would like to thank you in advance for taking the time to participate in this survey. Please submit the completed survey by February 27, 2015. If you have any questions please contact Caleb Smith at csmith26@mix.wvu.edu or Dr. Deborah Boone at 304-293-5450 or debby.boone@mail.wvu.edu.

Sincerely,

Caleb Smith

Graduate Student

Deborah A. Boone, Ph.D. Associate Professor

To participate in this study please click on the arrow in the bottom right corner of this page. 
At least one agent indicated the following items as potential challenges faced by West Virginia University Extension Agents. Please review the items and indicate if you believe them to represent a challenge.

Lack of guidance/supervision

Is a Challenge

Is NOT a Challenge

Lack of training

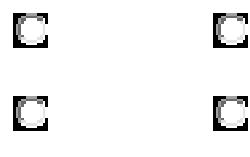

Prioritizing what is important

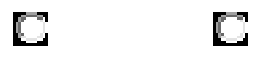

Understanding technology

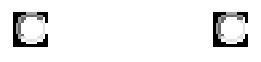

Awareness of educational trends

Lack of support from state Extension specialists

Lack of support from Extension program unit director

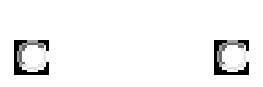

Lack of support from state Extension director

Knowing who to contact about issues

Lack of communication from state Extension office

Lack of communication from Extension program units

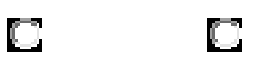

Meeting programming expectations

Disconnect between needs of county and expectations of state office

Lack of funding

Limited available resources other than funding

Funding for travel

Donations inconsistent and unreliable

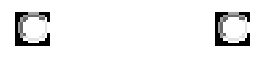

Space for storage

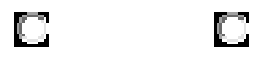

Space for programming

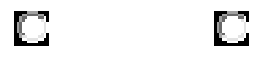

Limited human resources

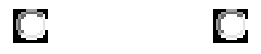

Budget preparation

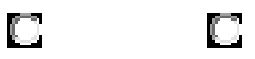

Time management

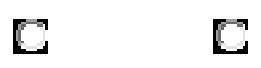

Maintaining positive mental health

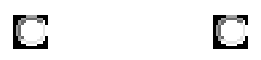


APPENDIX F:

REMINDER 2 


\section{Dear (First) (Last):}

This is a friendly reminder asking for your participation in our study of challenges that West Virginia University Extension Agents face. The survey is different from the first survey that was sent out in November. We have taken your responses from that initial survey and compiled a list of challenges. We ask that you simply indicate whether each statement is a challenge for you or if it not a challenge. Please note that this survey will be closing on Friday, February $27^{\text {th }}$ and your opinion is needed.

Follow this link to the Survey

$\$\{1: / /$ SurveyLink?d $=$ Take the Survey $\}$

Or Copy and paste the URL below into your internet browser:

$\{1: / /$ Survey URL $\}$

Follow the link to opt out of future emails:

$\$\{1: / /$ OptOutLink? $\mathrm{d}=$ Click here to unsubscribe $\}$ 
APPENDIX G:

COVER LETTER 3 


\section{Dear (First) (Last):}

Thank you for your continued participation in this study. This is the final step of our Delphi study. From your previous responses, we have compiled a list of the top challenges identified by West Virginia Extension agents.

We ask that you take a few minutes to rate each challenge and answer a few demographic questions. Please go to the following link to participate:

\section{Follow this link to the Survey:}

Take the Survey

Or copy and paste the URL below into your internet browser:

http://wvu.qualtrics.com/WRQualtricsSurveyEngine/?Q_SS=55fu1vMSpv5BqGV_8dHV $6 \mathrm{hksaRt7Uc5 \& \_}=1$

Participation in this research study is completely voluntary and all information you provide will be held as confidential as possible. The questionnaire should take approximately fifteen minutes of your time to complete. Please answer the questions honestly and to the best of your ability. There is no penalty if you choose not to participate. You may skip any question you do not feel comfortable answering and may stop at any point and submit a partially completed survey. The results of this survey will be reported in a summary format and individual responses will be not be identifiable (no Extension Administrators will see individual responses).

The Institutional Review Board (IRB) at West Virginia University has approved this study. Please submit the completed survey by March 27, 2015.

If you have any questions please contact Caleb Smith at csmith26@mix.wvu.edu or Dr. Deborah Boone at 304-293-5450 or debby.boone@mail.wvu.edu.

We would like to thank you in advance for taking the time to participate in this survey.

Sincerely,

Caleb Smith

Deborah A. Boone,

Ph.D.

Graduate Student

Associate Professor

Follow the link to opt out of future emails:

Click here to unsubscribe 
APPENDIX H:

INSTRUMENT 3 
Please rate each of the following statements according to how challenging you perceive them to be as related to your work as a County Extension Agent.

Training and Support

\begin{tabular}{l|ccccc} 
& $\begin{array}{c}\text { Not a } \\
\text { Challenge }\end{array}$ & $\begin{array}{c}\text { Slightly } \\
\text { Challenging }\end{array}$ & $\begin{array}{c}\text { Somewhat } \\
\text { Challenging }\end{array}$ & $\begin{array}{c}\text { Very } \\
\text { Challenging }\end{array}$ & $\times$ N/A \\
\hline $\begin{array}{l}\text { Lack of } \\
\text { guidance/supervision }\end{array}$ & $\mathbf{C}$ & $\mathbf{C}$ & $\mathbf{C}$ & $\mathbf{C}$ & $\mathbf{C}$ \\
$\begin{array}{l}\text { Lack of training } \\
\begin{array}{l}\text { Prioritizing what is } \\
\text { important }\end{array}\end{array}$ & $\mathbf{C}$ & $\mathbf{C}$ & $\mathbf{C}$ & $\mathbf{C}$ & $\mathbf{C}$ \\
$\begin{array}{l}\text { Meeting programming } \\
\text { expectations }\end{array}$ & $\mathbf{C}$ & $\mathbf{C}$ & $\mathbf{C}$ & $\mathbf{C}$ & $\mathbf{C}$ \\
$\begin{array}{l}\text { Disconnect between } \\
\text { needs of county and } \\
\text { expectations of state } \\
\text { office }\end{array}$ & $\mathbf{C}$ & $\mathbf{C}$ & $\mathbf{C}$ & $\mathbf{C}$ & $\mathbf{C}$ \\
\hline
\end{tabular}

Funding and Resources

\begin{tabular}{|c|c|c|c|c|c|}
\hline & $\begin{array}{c}\text { Not a } \\
\text { Challenge }\end{array}$ & $\begin{array}{c}\text { Slightly } \\
\text { Challenging }\end{array}$ & $\begin{array}{l}\text { Somewhat } \\
\text { Challenging }\end{array}$ & $\begin{array}{c}\text { Very } \\
\text { Challenging }\end{array}$ & $\times \mathrm{N} / \mathrm{A}$ \\
\hline Lack of funding & $\mathbb{C}$ & $\mathbb{C}$ & C & $\mathbb{E}$ & C \\
\hline $\begin{array}{l}\text { Limited available } \\
\text { resources other than } \\
\text { funding }\end{array}$ & $\mathbf{C}$ & $\mathbb{C}$ & $\mathbb{E}$ & C & C \\
\hline Space for storage & C & C & $\mathbf{E}$ & $\mathbf{C}$ & $\mathrm{C}$ \\
\hline $\begin{array}{l}\text { Limited human } \\
\text { resources }\end{array}$ & C & C & C & $\mathbf{C}$ & $\mathrm{C}$ \\
\hline
\end{tabular}




\begin{tabular}{|c|c|c|c|c|c|}
\hline \multicolumn{6}{|l|}{ Personal Issues } \\
\hline & $\begin{array}{c}\text { Not a } \\
\text { Challenge }\end{array}$ & $\begin{array}{c}\text { Slightly } \\
\text { Challenging }\end{array}$ & $\begin{array}{l}\text { Somewhat } \\
\text { Challenging }\end{array}$ & $\begin{array}{c}\text { Very } \\
\text { Challenging }\end{array}$ & $\times \mathrm{N} / \mathrm{A}$ \\
\hline Time management & C & $\mathbf{C}$ & $\mathbf{C}$ & $\mathbb{C}$ & $\mathbb{E}$ \\
\hline $\begin{array}{l}\text { Maintaining positive } \\
\text { mental health }\end{array}$ & C & $\mathbf{E}$ & $\mathbf{E}$ & $\mathbf{E}$ & E \\
\hline $\begin{array}{l}\text { Balancing family and } \\
\text { work obligations }\end{array}$ & C & $\mathbf{C}$ & $\mathbf{C}$ & $\mathbb{E}$ & $\mathbb{E}$ \\
\hline $\begin{array}{l}\text { Identifying personal } \\
\text { limits }\end{array}$ & $\mathbb{C}$ & C & C & $\mathbb{C}$ & $\mathbb{E}$ \\
\hline $\begin{array}{l}\text { Time required for } \\
\text { Promotion and Tenure } \\
\text { file }\end{array}$ & C & C & C & $\mathbb{E}$ & $\mathbb{E}$ \\
\hline $\begin{array}{l}\text { Working evening and } \\
\text { weekends }\end{array}$ & C & C & $\mathbb{E}$ & C & E \\
\hline Time spent on reports & $\mathbb{C}$ & $\mathbb{C}$ & $\mathbb{C}$ & C & $\mathbb{E}$ \\
\hline $\begin{array}{l}\text { Finding time for all } \\
\text { programs }\end{array}$ & C & $\mathbf{C}$ & $\mathbf{C}$ & $\mathbf{C}$ & E \\
\hline $\begin{array}{l}\text { Overextending on } \\
\text { commitments }\end{array}$ & E & $\mathbb{C}$ & $\mathbb{E}$ & C & $\mathbf{C}$ \\
\hline
\end{tabular}

Volunteers and Community Involvement

\begin{tabular}{|c|c|c|c|c|c|}
\hline & $\begin{array}{l}\text { Not a } \\
\text { Challenge }\end{array}$ & $\begin{array}{c}\text { Slightly } \\
\text { Challenging }\end{array}$ & $\begin{array}{l}\text { Somewhat } \\
\text { Challenging }\end{array}$ & $\begin{array}{c}\text { Very } \\
\text { Challenging }\end{array}$ & $\times \mathrm{N} / \mathrm{A}$ \\
\hline Recruiting volunteers & $\mathbf{E}$ & $\mathbf{E}$ & $\mathbf{E}$ & E & $\mathbf{E}$ \\
\hline Training volunteers & C & $\mathbb{C}$ & $\mathbf{E}$ & C & $\mathbb{C}$ \\
\hline Retaining volunteers & $\mathbf{E}$ & $\mathbf{E}$ & $\mathbf{E}$ & $\mathbf{E}$ & $\mathbf{E}$ \\
\hline $\begin{array}{l}\text { Impact policies have } \\
\text { on volunteers }\end{array}$ & $\mathbb{C}$ & $\mathbb{C}$ & C & $\boldsymbol{C}$ & $\mathbb{C}$ \\
\hline $\begin{array}{l}\text { Finding leadership in } \\
\text { programs }\end{array}$ & $\mathbb{E}$ & $\mathrm{C}$ & C & $\mathbf{E}$ & C \\
\hline $\begin{array}{l}\text { Managing } \\
\text { expectations of } \\
\text { clientele }\end{array}$ & C & C & $\mathbb{C}$ & $\mathbf{C}$ & $\mathbf{C}$ \\
\hline $\begin{array}{l}\text { Communities' } \\
\text { perception of an }\end{array}$ & $\mathbb{C}$ & C & C & $\mathbf{C}$ & $\mathbb{E}$ \\
\hline
\end{tabular}


Not a Slightly Somewhat Very

Challenge Challenging Challenging Challenging $\times$ N/A

\begin{tabular}{l|ccccc}
$\begin{array}{l}\text { agent's } \\
\text { responsibilities }\end{array}$ & & & & & \\
$\begin{array}{l}\text { Dealing with difficult } \\
\text { personalities }\end{array}$ & $\mathbf{C}$ & $\mathbf{C}$ & $\mathbf{C}$ & $\mathbf{C}$ & $\mathbf{C}$ \\
$\begin{array}{l}\text { Keeping at risk youth } \\
\text { engaged }\end{array}$ & $\mathbf{C}$ & $\mathbf{C}$ & $\mathbf{C}$ & $\mathbf{C}$ & $\mathbf{C}$
\end{tabular}

Organizational Factors

\begin{tabular}{|c|c|c|c|c|c|}
\hline & $\begin{array}{c}\text { Not a } \\
\text { Challenge }\end{array}$ & $\begin{array}{c}\text { Slightly } \\
\text { Challenging }\end{array}$ & $\begin{array}{l}\text { Somewhat } \\
\text { Challenging }\end{array}$ & $\begin{array}{c}\text { Very } \\
\text { Challenging }\end{array}$ & $\times \mathrm{N} / \mathrm{A}$ \\
\hline $\begin{array}{l}\text { Reporting } \\
\text { requirements/paperwork }\end{array}$ & $\mathbf{C}$ & $\mathbf{E}$ & $\mathbf{E}$ & $\mathbb{C}$ & C \\
\hline $\begin{array}{l}\text { Inconsistent/nonexistent } \\
\text { administrative policies }\end{array}$ & $\mathbf{E}$ & $\mathbf{C}$ & $\mathbf{E}$ & $\boldsymbol{C}$ & $\mathbb{E}$ \\
\hline $\begin{array}{l}\text { Constant system } \\
\text { changes }\end{array}$ & $\mathbf{C}$ & $\mathbf{C}$ & $\mathbf{C}$ & $\mathbb{C}$ & $\mathbb{E}$ \\
\hline $\begin{array}{l}\text { Unclear } \\
\text { guidelines/standards }\end{array}$ & $\mathbb{E}$ & $\mathbf{C}$ & $\mathbb{E}$ & $\mathbb{C}$ & $\mathbb{C}$ \\
\hline $\begin{array}{l}\text { Ineffective evaluation } \\
\text { systems (Promotion } \\
\& \text { Tenure file) }\end{array}$ & $\mathbf{C}$ & $\boldsymbol{C}$ & $\mathbf{C}$ & $\mathbf{C}$ & $\mathbf{C}$ \\
\hline $\begin{array}{l}\text { Employee } \\
\text { pay/promotion }\end{array}$ & $\mathbf{C}$ & $\mathbf{C}$ & $\mathbf{C}$ & $\boldsymbol{C}$ & C \\
\hline $\begin{array}{l}\text { Lack of direction } \\
\text { throughout Extension }\end{array}$ & $\mathbf{C}$ & $\mathbf{C}$ & E & $\mathbf{C}$ & C \\
\hline $\begin{array}{l}\text { Adequate support staff } \\
\text { to fulfill needs of } \\
\text { clientele }\end{array}$ & $\mathbf{E}$ & $\mathbf{C}$ & $\mathbf{E}$ & C & $\mathbb{C}$ \\
\hline
\end{tabular}

Please answer the following demographic questions.

What is your gender?

C Male

C Female 
Which category best represents your age?
[ $21-25$
[ $26-30$
C $31-35$
[ $36-40$
[ $41-45$
C $46-50$
C $50+$

What is your marital status?

C Single

C Married

C Divorced

C Widowed

Do you have children living at home?

C Yes

C No

To which program unit do you report?
C Agriculture and Natural Resources (AGNR)
C Families and Health (F\&H)
C Community, Economic, and Workforce Development (CEWD)
C 4-H Youth Development (4-H)

How many years of experience do you have as an Extension Agent?
C 0 - 5 years
C 6-10 years
C $11-15$ years
C 16 - 20 years
C 21+years 
Are you a County Program Coordinator (CPC)?

$\begin{array}{ll}\mathbb{C} & \text { Yes } \\ \mathbb{C} & \text { No }\end{array}$

On average, how many hours do you spend working for Extension per week?

C Less than 37.5 hours

C $37.6-47.5$ hours

C $47.6-57.5$ hours

C More than 57.5 hours

How many counties are you responsible for?

C 1

C 2

C 3

C 4 
How many agents are in your county?

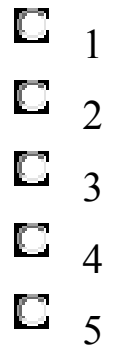

Do you have a program assistant in your county?

C Yes

E No 
APPENDIX I:

REMINDER 3 


\section{Dear (First) (Last),}

Last chance to have your voice heard in our study on Challenges of West Virginia

Extension Agents. Your response is critical to our research. Thank you for your input in the initial rounds of our study, we were able to identify 35 shared challenges that Extension Agents in West Virginia face. Your opinion is important. We ask that you please rate each of the 35 challenges as to how challenging you perceive them to be in your current position. This study is anonymous and completely voluntary. If at any point, you want to discontinue the survey, you will not be penalized. Results will be presented in aggregated form only, no individual responses will be identifiable.

Please click on the link below to complete this last survey, the deadline has been extended to April 21. Thank you for your participation in this study. We appreciate your time.

\section{Follow this link to the Survey:}

$\$\{1: / /$ SurveyLink?d=Take the Survey $\}$

Or copy and paste the URL below into your internet browser:

$\$\{1: / /$ SurveyURL $\}$

Thanks for your assistance with my graduate research study.

Caleb Smith

Graduate Student

Deborah A. Boone, Ph.D.

Associate Professor

Agricultural and Extension Education

Follow the link to opt out of future emails:

$\$\{1: / / O p t O u t L i n k ? d=$ Click here to unsubscribe $\}$ 
APPENDIX J:

COUNTY PROGRAM COORDINATOR DATA 
Table 28

CPC and Perceptions of Challenges - Descriptive

\begin{tabular}{|c|c|c|c|c|}
\hline & \multicolumn{4}{|c|}{ County Program Coordinator } \\
\hline & \multicolumn{2}{|c|}{ Yes } & \multicolumn{2}{|c|}{ No } \\
\hline & M & SD & M & SD \\
\hline $\begin{array}{l}\text { Training and } \\
\text { Support }\end{array}$ & 2.64 & .75 & 2.54 & .74 \\
\hline $\begin{array}{l}\text { Funding and } \\
\text { Resources }\end{array}$ & 2.91 & .76 & 2.78 & .71 \\
\hline Personal Issues & 2.94 & .58 & 2.78 & .82 \\
\hline $\begin{array}{l}\text { Volunteers and } \\
\text { Community } \\
\text { Involvement }\end{array}$ & 2.84 & .59 & 2.65 & .60 \\
\hline $\begin{array}{l}\text { Organizational } \\
\text { Factors }\end{array}$ & 2.81 & .70 & 2.71 & .65 \\
\hline
\end{tabular}


Table 29

CPC and Perceptions of Challenges - ANOVA

\begin{tabular}{|c|c|c|c|c|c|c|}
\hline & & Sum of Squares & df & Mean Square & $\mathrm{F}$ & Sig. \\
\hline \multirow{3}{*}{$\begin{array}{l}\text { Training and } \\
\text { Support }\end{array}$} & Between Groups & .206 & 1 & .206 & .376 & .542 \\
\hline & Within Groups & 41.216 & 75 & .550 & & \\
\hline & Total & 41.422 & 76 & & & \\
\hline \multirow{3}{*}{$\begin{array}{l}\text { Funding and } \\
\text { Resources }\end{array}$} & Between Groups & .348 & 1 & .348 & .645 & .424 \\
\hline & Within Groups & 40.527 & 75 & .540 & & \\
\hline & Total & 40.876 & 76 & & & \\
\hline \multirow[t]{3}{*}{ Personal Issues } & Between Groups & .539 & 1 & .539 & 1.055 & .308 \\
\hline & Within Groups & 38.300 & 75 & .511 & & \\
\hline & Total & 38.839 & 76 & & & \\
\hline \multirow{3}{*}{$\begin{array}{l}\text { Volunteers and } \\
\text { Community } \\
\text { Involvement }\end{array}$} & Between Groups & .692 & 1 & .692 & 1.957 & .166 \\
\hline & Within Groups & 26.896 & 76 & .354 & & \\
\hline & Total & 27.589 & 77 & & & \\
\hline \multirow{3}{*}{$\begin{array}{l}\text { Organizational } \\
\text { Factors }\end{array}$} & Between Groups & .190 & 1 & .190 & .421 & .518 \\
\hline & Within Groups & 34.354 & 76 & .452 & & \\
\hline & Total & 34.544 & 77 & & & \\
\hline
\end{tabular}


APPENDIX K:

EFFECT OF NUMBER OF COUNTIES 
Table 30

Number of Counties per Agent and Perception of Challenges - Descriptive

\begin{tabular}{|c|c|c|c|c|}
\hline & \multicolumn{4}{|c|}{ Number of Counties } \\
\hline & \multicolumn{2}{|c|}{ One County } & \multicolumn{2}{|c|}{ Multiple Counties } \\
\hline & M & SD & M & SD \\
\hline \multicolumn{5}{|l|}{ Training and } \\
\hline Support & 2.56 & .75 & 2.69 & .67 \\
\hline \multicolumn{5}{|l|}{ Funding and } \\
\hline Resources & 2.80 & .76 & 3.00 & .61 \\
\hline Personal Issues & 2.82 & .74 & 3.05 & .43 \\
\hline \multicolumn{5}{|l|}{ Volunteers and } \\
\hline \multicolumn{5}{|l|}{ Community } \\
\hline Involvement & 2.71 & .60 & 2.88 & .60 \\
\hline \multicolumn{5}{|l|}{ Organizational } \\
\hline Factors & 2.76 & .69 & 2.73 & .43 \\
\hline
\end{tabular}


Table 31

Number of Counties per Agent and Perception of Challenges - ANOVA

\begin{tabular}{|c|c|c|c|c|c|c|}
\hline & & Sum of Squares & df & Mean Square & $\mathrm{F}$ & Sig. \\
\hline \multirow{3}{*}{$\begin{array}{l}\text { Training and } \\
\text { Support }\end{array}$} & Between Groups & .132 & 1 & .132 & .239 & .627 \\
\hline & Within Groups & 42.732 & 77 & .555 & & \\
\hline & Total & 42.864 & 78 & & & \\
\hline \multirow{3}{*}{$\begin{array}{l}\text { Funding and } \\
\text { Resources }\end{array}$} & Between Groups & .311 & 1 & .311 & .565 & .455 \\
\hline & Within Groups & 42.461 & 77 & .551 & & \\
\hline & Total & 42.772 & 78 & & & \\
\hline \multirow[t]{3}{*}{ Personal Issues } & Between Groups & .397 & 1 & .397 & .776 & .381 \\
\hline & Within Groups & 39.440 & 77 & .512 & & \\
\hline & Total & 39.837 & 78 & & & \\
\hline \multirow{3}{*}{$\begin{array}{l}\text { Volunteers and } \\
\text { Community } \\
\text { Involvement }\end{array}$} & Between Groups & .217 & 1 & .217 & .611 & .437 \\
\hline & Within Groups & 27.694 & 78 & .355 & & \\
\hline & Total & 27.911 & 79 & & & \\
\hline \multirow{3}{*}{$\begin{array}{l}\text { Organizational } \\
\text { Factors }\end{array}$} & Between Groups & .007 & 1 & .007 & .015 & .902 \\
\hline & Within Groups & 34.604 & 78 & .444 & & \\
\hline & Total & 34.611 & 79 & & & \\
\hline
\end{tabular}


APPENDIX L:

EFFECT OF A PROGRAM ASSISTANT 
Table 32

Program Assistant and Perceptions of Challenges - Descriptive

\begin{tabular}{lcccc}
\hline & \multicolumn{5}{c}{ Program Assistant. } \\
\cline { 2 - 5 } & M & SD & M & SD \\
\cline { 2 - 5 } & & & & \\
\hline $\begin{array}{l}\text { Training and } \\
\text { Support }\end{array}$ & 2.64 & .70 & 2.58 & .76 \\
$\begin{array}{l}\text { Funding and } \\
\text { Resources }\end{array}$ & 2.80 & .71 & 2.88 & .74 \\
Personal Issues & 2.90 & .74 & 2.83 & .70 \\
Volunteers and & & & & .61 \\
Community & & & & \\
Involvement & 2.70 & .55 & 2.74 & \\
Organizational & & & & \\
Factors & 2.70 & .68 & 2.84 & \\
\hline
\end{tabular}


Table 33

Program Assistant and Perceptions of Challenges - ANOVA

\begin{tabular}{|c|c|c|c|c|c|c|}
\hline & & Sum of Squares & $\mathrm{df}$ & Mean Square & $\mathrm{F}$ & Sig. \\
\hline \multirow{3}{*}{$\begin{array}{l}\text { Training and } \\
\text { Support }\end{array}$} & Between Groups & .079 & 1 & .079 & .147 & .703 \\
\hline & Within Groups & 41.515 & 77 & .539 & & \\
\hline & Total & 41.594 & 78 & & & \\
\hline \multirow{3}{*}{$\begin{array}{l}\text { Funding and } \\
\text { Resources }\end{array}$} & Between Groups & .135 & 1 & .135 & .252 & .617 \\
\hline & Within Groups & 41.024 & 77 & .533 & & \\
\hline & Total & 41.159 & 78 & & & \\
\hline \multirow[t]{3}{*}{ Personal Issues } & Between Groups & .112 & 1 & .112 & .220 & .640 \\
\hline & Within Groups & 39.209 & 77 & .509 & & \\
\hline & Total & 39.321 & 78 & & & \\
\hline \multirow{3}{*}{$\begin{array}{l}\text { Volunteers and } \\
\text { Community } \\
\text { Involvement }\end{array}$} & Between Groups & .033 & 1 & .033 & .094 & .760 \\
\hline & Within Groups & 27.242 & 78 & .349 & & \\
\hline & Total & 27.275 & 79 & & & \\
\hline \multirow{3}{*}{$\begin{array}{l}\text { Organizational } \\
\text { Factors }\end{array}$} & Between Groups & .362 & 1 & .362 & .869 & .354 \\
\hline & Within Groups & 32.470 & 78 & .416 & & \\
\hline & Total & 32.832 & 79 & & & \\
\hline
\end{tabular}


VITA

Caleb N. Smith

Education: $\quad$ August 2015

May 2013

May 2009

Professional Experience:
October 2013 - August 2015

May 2013 - August 2013

January 2013 - May 2013
May 2011 - August 2011, May 2012 - August, 2012
Masters of Science

Agriculture and Extension

Education

West Virginia University

Morgantown, WV

Bachelors of Science

Agriculture and Extension

Education

West Virginia University

Morgantown, WV

Associates of Science in Agriculture Agriculture and Extension Education

Potomac State College of WVU

Keyser, WV

\section{Graduate Research Assistant \\ WVU Extension Service \\ West Virginia University \\ Morgantown, WV}

Summer Intern

Parkersburg Community Foundation Fellowship Program

Jackson County Extension Office

Cottageville, WV

Student Teaching

West Virginia University

Agriculture and Extension

Education

Ravenswood High School

Ravenswood, WV

Student Worker - Work Study

West Virginia University Jackson County Extension Office Cottageville, WV 